
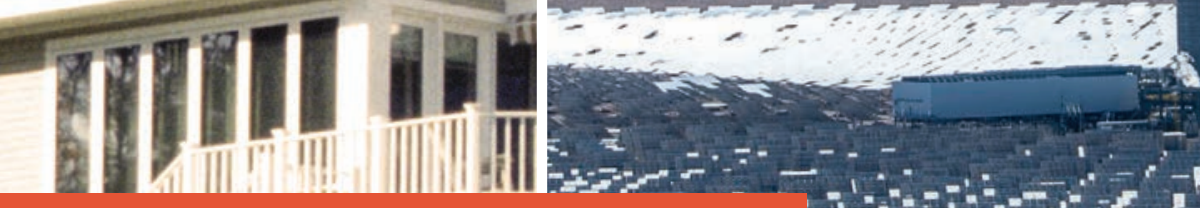

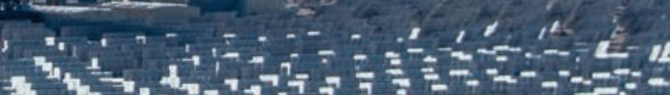

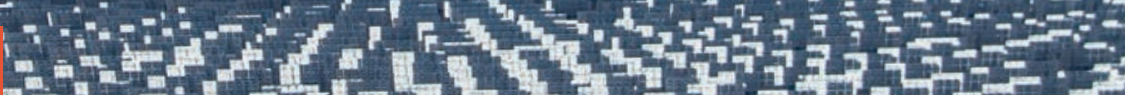
-

The Environmental and Public Health

Benefits of Achieving High Penetrations of Solar Energy in the United States

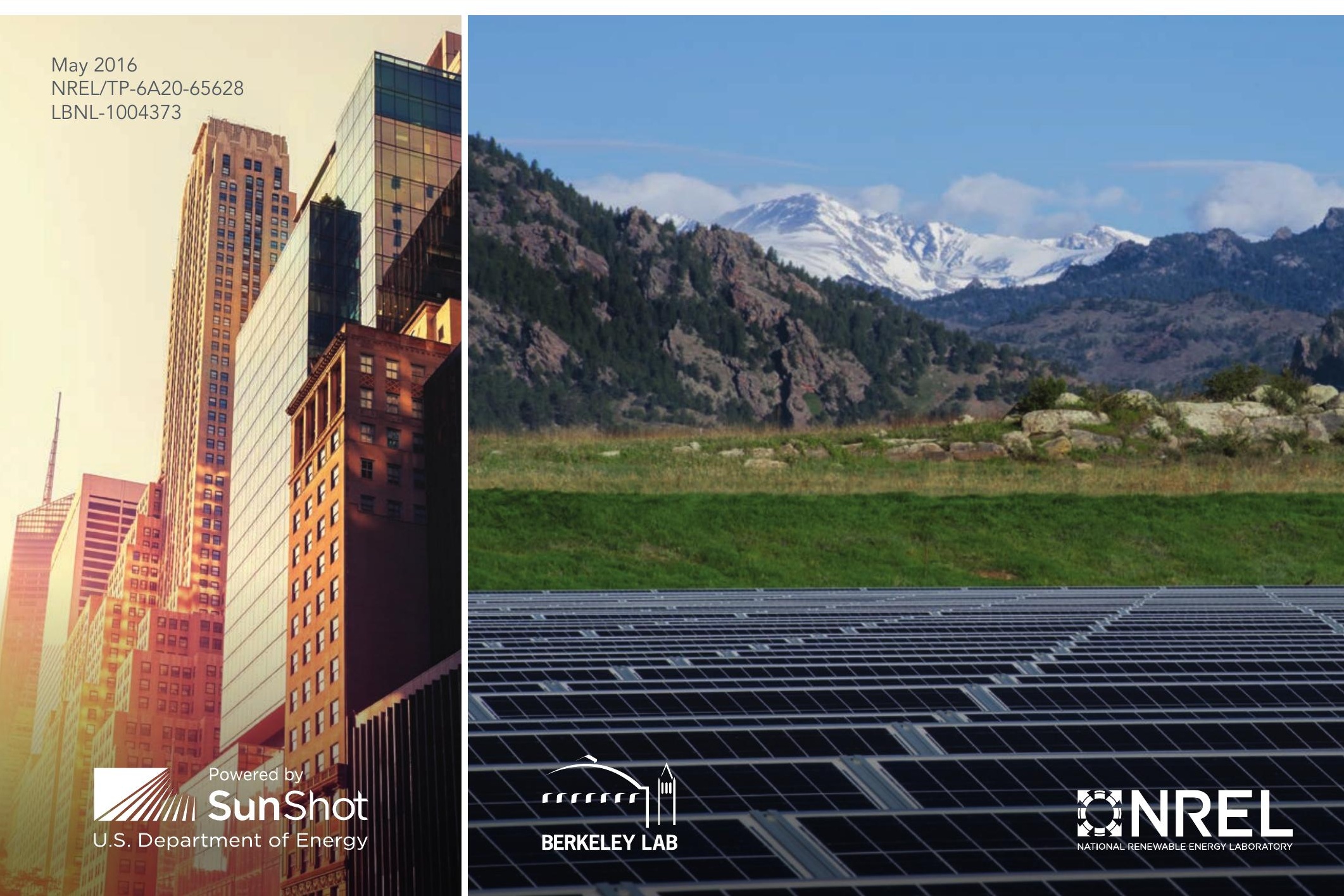




\section{On the Path to SunShot: The Environmental and Public Health Benefits of Achieving High Penetrations of Solar Energy in the United States}

Ryan Wiser ${ }^{1}$, Trieu Mai², Dev Millstein ${ }^{1}$, Jordan Macknick², Alberta Carpenter², Stuart Cohen², Wesley Cole², Bethany Frew², and Garvin Heath²

${ }^{1}$ Lawrence Berkeley National Laboratory

${ }^{2}$ National Renewable Energy Laboratory

Lawrence Berkeley National Laboratory is a Department of Energy Office of Science lab managed by University of California.

NREL is a national laboratory of the U.S. Department of Energy, Office of Energy Efficiency and Renewable Energy, operated by the Alliance for Sustainable Energy, LLC. 


\title{
NOTICE
}

This report was prepared as an account of work sponsored by an agency of the United States government. Neither the United States government nor any agency thereof, nor any of their employees, makes any warranty, express or implied, or assumes any legal liability or responsibility for the accuracy, completeness, or usefulness of any information, apparatus, product, or process disclosed, or represents that its use would not infringe privately owned rights. Reference herein to any specific commercial product, process, or service by trade name, trademark, manufacturer, or otherwise does not necessarily constitute or imply its endorsement, recommendation, or favoring by the United States government or any agency thereof. The views and opinions of authors expressed herein do not necessarily state or reflect those of the United States government or any agency thereof.

This report is available at no cost from the National Renewable Energy Laboratory (NREL) at www.nrel.gov/publications.

Available electronically at SciTech Connect http:/www.osti.gov/scitech Available for a processing fee to U.S. Department of Energy and its contractors, in paper, from:

\section{U.S. Department of Energy}

Office of Scientific and Technical Information

P.O. Box 62

Oak Ridge, TN 37831-0062

OSTI http://www.osti.gov

Phone: 865.576 .8401

Fax: 865.576.5728

Email: reports@osti.gov

Available for sale to the public, in paper, from:

\author{
U.S. Department of Commerce \\ National Technical Information Service \\ 5301 Shawnee Road \\ Alexandria, VA 22312 \\ NTIS http://www.ntis.gov \\ Phone: 800.553 .6847 or 703.605 .6000 \\ Fax: 703.605 .6900 \\ Email: orders@ntis.gov
}




\section{Preface}

The U.S. Department of Energy launched the SunShot Initiative in 2011 with the goal of making solar electricity cost-competitive with conventionally generated electricity by 2020 . At the time this meant reducing photovoltaic and concentrating solar power prices by approximately $75 \%$ relative to 2010 costs - across the residential, commercial, and utility-scale sectors. To examine the implications of this ambitious goal, the Department of Energy's Solar Energy Technologies Office (SETO) published the SunShot Vision Study in 2012. The study projected that achieving the SunShot price-reduction targets could result in solar meeting roughly $14 \%$ of U.S. electricity demand by 2030 and $27 \%$ by 2050 - while reducing fossil fuel use, cutting emissions of greenhouse gases and other pollutants, creating solar-related jobs, and lowering consumer electricity bills.

The SunShot Vision Study also acknowledged, however, that realizing the solar price and deployment targets would face a number of challenges. Both evolutionary and revolutionary technological changes would be required to hit the cost targets, as well as the capacity to manufacture these improved technologies at scale in the U.S. Additionally, operating the U.S. transmission and distribution grids with increasing quantities of solar energy would require advances in grid-integration technologies and techniques. Serious consideration would also have to be given to solar siting, regulation, and water use. Finally, substantial new financial resources and strategies would need to be directed toward solar deployment of this magnitude in a relatively short period of time. Still the study suggested that the resources required to overcome these challenges were well within the capabilities of the public and private sectors. SunShot-level price reductions, the study concluded, could accelerate the evolution toward a cleaner, more costeffective and more secure U.S. energy system.

That was the assessment in 2012. Today, at the halfway mark to the SunShot Initiative's 2020 target date, it is a good time to take stock: How much progress has been made? What have we learned? What barriers and opportunities must still be addressed to ensure that solar technologies achieve cost parity in 2020 and realize their full potential in the decades beyond?

To answer these questions, SETO launched the On the Path to SunShot series in early 2015 in collaboration with the National Renewable Energy Laboratory (NREL) and with contributions from Lawrence Berkeley National Laboratory (LBNL), Sandia National Laboratories (SNL), and Argonne National Laboratory (ANL). The series of technical reports focuses on the areas of grid integration, technology improvements, finance and policy evolution, and environment impacts and benefits. The resulting reports examine key topics that must be addressed to achieve the SunShot Initiative's price-reduction and deployment goals. The On the Path to SunShot series includes the following reports:

- Emerging Issues and Challenges with Integrating High Levels of Solar into the Electrical Generation and Transmission Systems (Denholm et al. 2016)

- Emerging Issues and Challenges with Integrating High Levels of Solar into the Distribution System (Palmintier et al. 2016)

- Emerging Opportunities and Challenges in Financing Solar (Feldman and Bolinger 2016) 
- On the Path to SunShot: Utility Regulatory and Business Model Reforms for Addressing the Financial Impacts of Distributed Solar on Utilities (Barbose et al. 2016)

- The Role of Advancements in Photovoltaic Efficiency, Reliability, and Costs (Woodhouse et al. 2016)

- Advancing Concentrating Solar Power Technology, Performance, and Dispatchability (Mehos et al. 2016)

- Emerging Opportunities and Challenges in U.S. Solar Manufacturing (Chung et al. 2016)

- The Environmental and Public Health Benefits of Achieving High Penetrations of Solar Energy in the United States (Wiser et al. 2016).

Solar technology, solar markets, and the solar industry have changed dramatically over the past five years. Cumulative U.S. solar deployment has increased more than tenfold, while solar's levelized cost of energy (LCOE) has dropped by as much as $65 \%$. New challenges and opportunities have emerged as solar has become much more affordable, and we have learned much as solar technologies have been deployed at increasing scale both in the U.S. and abroad. The reports included in this series, explore the remaining challenges to realizing widely available, cost-competitive solar in the United States. In conjunction with key stakeholders, SETO will use the results from the On the Path to SunShot series to aid the development of its solar price reduction and deployment strategies for the second half of the SunShot period and beyond. 


\section{Acknowledgments}

The authors thank the Solar Energy Technologies Office team for its support of this report and Robert Margolis of NREL for his management and oversight of the On the Path to SunShot report series. For providing overall guidance and comments, we thank our technical review committee: Ines Azevedo (Carnegie Mellon University), Justin Baca (Solar Energy Industries Association), Steve Clemmer (Union of Concerned Scientists), and Parikhit Sinha (First Solar). We also thank Naim Darghouth and Joachim Seel of LBNL for key input on the analysis related to greenhouse gas emissions. And, we thank Robin Newmark (NREL) for additional comments on a draft of the report. The authors also thank Jarett Zuboy (consultant) and Mike Meshek (NREL) for editorial assistance.

This work was funded by the Solar Energy Technologies Office of the U.S. Department of Energy (DOE) Office of Energy Efficiency and Renewable Energy (EERE). The contributions of the National Renewable Energy Laboratory (NREL) to this report were funded by the Solar Energy Technologies Office under Contract No. DE-AC36-08GO28308. The contributions of the Lawrence Berkeley National Laboratory (LBNL) to this report were funded by the Solar Energy Technologies Office under Contract No. DE-AC02-05CH11231.

John Frenzl of NREL designed the covers for the On the Path to SunShot report series. 


\section{List of Acronyms}

$\begin{array}{ll}\text { AEO } & \text { Annual Energy Outlook } \\ \text { AP2 } & \text { Air Pollution Emission Experiments and Policy analysis model } \\ \text { CC } & \text { combined cycle } \\ \mathrm{CO}_{2} & \text { carbon dioxide } \\ \mathrm{CO}_{2} \text { e } & \text { carbon dioxide equivalent } \\ \text { CPP } & \text { Clean Power Plan } \\ \text { CSAPR } & \text { Cross State Air Pollution Rule } \\ \text { CSP } & \text { concentrating solar power } \\ \text { CT } & \text { combustion turbine } \\ \text { DGPV } & \text { distributed-generation photovoltaics } \\ \text { DOE } & \text { U.S. Department of Energy } \\ \text { EPA } & \text { U.S. Environmental Protection Agency } \\ \text { GHG } & \text { greenhouse gas } \\ \text { IGCC } & \text { integrated gasification combined cycle } \\ \text { ITC } & \text { investment tax credit } \\ \text { IWG } & \text { U.S. Interagency Working Group on the Social Cost of Carbon } \\ \text { LCA } & \text { life-cycle assessment } \\ \text { MATS } & \text { Mercury Air Toxics Standard } \\ \text { NGCC } & \text { natural gas combined cycle } \\ \text { NNS } & \text { No New Solar [model scenario] } \\ \text { NO } & \text { nitrogen oxides } \\ \text { NREL } & \text { National Renewable Energy Laboratory } \\ \text { PM } 2.5 & \text { fine particulate matter } \\ \text { PV } & \text { photovoltaic(s) } \\ \text { ReEDS } & \text { Regional Energy Deployment System [model] } \\ \text { SCC } & \text { social cost of carbon } \\ \text { SO } 2 & \text { sulfur dioxide } \\ \text { UPV } & \text { utility photovoltaics } \\ \text { VSL } & \text { value of statistical life } \\ \text { WDC } & \text { watts direct current } \\ & \end{array}$




\section{Executive Summary}

The U.S. Department of Energy's SunShot Initiative (SunShot) seeks to motivate swift reductions in the cost of solar energy in order to strengthen the role of solar as a low-cost energy source. The SunShot Vision Study (DOE 2012) evaluated the profound implications of such cost reductions for the solar industry, the electricity sector as a whole, and end-use electricity consumers, finding that achieving the SunShot cost targets could result in overall solar electricity penetrations of $14 \%$ of annual U.S. electricity demand by 2030 and $27 \%$ by 2050 . Analyzed solar technologies included photovoltaics (PV) and concentrating solar power (CSP). That study, however, did not comprehensively quantify and value the potential environmental and health benefits associated with achieving these levels of solar penetration.

Our analysis fills that gap by thoroughly assessing three key potential environmental and health benefits of achieving the solar penetrations envisioned in the SunShot Vision Study: greenhousegas (GHG) emissions reductions, air-pollution health and environmental impacts, and water-use reductions. Specifically, we use a scenario-analysis approach in which the 14\%-by-2030 and 27\%-by-2050 "SunShot Vision" scenario is compared with a "No New Solar (NNS) baseline" scenario in which no new solar is deployed after 2014. This framework allows us to assess the potential benefits of all incremental solar deployment. We employ the National Renewable Energy Laboratory's Regional Energy Deployment System (ReEDS) electric sector capacityexpansion model to conduct our analysis, updating the analysis conducted in the SunShot Vision Study. For each of the three benefit categories, we take the modeled output from ReEDS and then apply additional tools - as necessary — to assess potential benefits in physical and, where feasible, monetary terms. We qualify the study results where appropriate, and highlight areas of uncertainty not otherwise explicitly addressed in our analysis.

The United States is already benefiting from an existing fleet of solar power projects. Evaluating the potential environmental and health benefits of that existing solar generation helps provide context for the future scenario analysis. To this end, we briefly assess the recent benefits of the 2014 U.S. solar fleet. In this case, we use the Environmental Protection Agency (EPA)'s Avoided Emissions and geneRation Tool (AVERT) to estimate the characteristics and location of fossil generation sources displaced by the 20 gigawatts (GW) of year-end 2014 solar capacity. As with the forward-looking analysis of the SunShot Vision scenario, we assess the potential benefits in physical and monetary terms using appropriate additional tools.

As summarized below and in Figures ES-1 (SunShot Vision), ES-2 (solar fleet at end of 2014), and ES-3 (regional results associated with solar fleet at end of 2014), our analysis finds that a future U.S. electricity system in which solar plays a major role would result in enduring environmental and health benefits; that the existing fleet of solar power plants is already offering a down-payment towards those benefits; and that there are sizable regional differences in the magnitude of the benefits. 


\section{Greenhouse Gas Emissions}

- SunShot Vision: Achieving the SunShot Vision scenario reduces life-cycle GHG emissions from the power sector by $13 \%$ in 2030 and $18 \%$ in 2050 , relative to the NNS baseline scenario. Cumulative GHG savings from 2015 to 2050 equal 10\% of life-cycle emissions from the power sector. ${ }^{i}$ These reductions produce global benefits of $\$ 259$ billion in the form of lower future climate change damages when applying a central value for the social cost of carbon (SCC), which is equivalent to a levelized benefit of solar of $2.2 \phi / \mathrm{kWh}$-solar. ${ }^{\mathrm{ii}}$ If, instead, solar is viewed as a way to meet future legal requirements to reduce carbon emissions - and therefore offsets the cost of complying with those regulations - then, under a medium trajectory for the cost of those future regulations, the SunShot Vision scenario yields $\$ 238$ billion in savings, which is equivalent to a levelized benefit of $2.0 \notin / \mathrm{kWh}$-solar. ${ }^{\mathrm{iii}}$

- Solar Fleet at End of 2014: These potential future benefits build on the 17 million metric tons of $\mathrm{CO}_{2}$ savings realized annually from the 2014 solar fleet, which is equivalent to an annual global benefit of $\$ 700$ million $(2.1 \phi / \mathrm{kWh}$-solar) when applying a central value for the social cost of carbon.

\section{Air-Pollution Emissions}

- SunShot Vision: Achieving the SunShot Vision scenario reduces emissions of sulfur dioxide $\left(\mathrm{SO}_{2}\right)$, nitrogen oxides $\left(\mathrm{NO}_{\mathrm{x}}\right)$, and fine particulate matter $\left(\mathrm{PM}_{2.5}\right)$ in the power sector by $14 \%$, $14 \%$, and $13 \%$ in 2030 and $15 \%, 18 \%$, and $13 \%$ in 2050, relative to the NNS baseline scenario. Cumulative emissions savings from 2015 to 2050 equal $9 \%, 11 \%$, and $8 \%$ of power-sector $\mathrm{SO}_{2}, \mathrm{NO}_{x}$, and $\mathrm{PM}_{2.5}$ emissions, respectively. These reductions produce benefits of $\$ 167$ billion in the form of lower future health and environmental damages based on central estimates which is equivalent to a levelized benefit of $1.4 \phi / \mathrm{kWh}$-solar. ${ }^{\text {iv }}{ }^{\text {The benefits }}$ derive, in large measure, from a reduction in premature mortality from sulfate particles from $\mathrm{SO}_{2}$ emissions - achieving the SunShot Vision scenario reduces premature mortalities by 25,000-59,000 based on methods developed by the U.S. Environmental Protection Agency.

- Solar Fleet at End of 2014: These potential future benefits build on annual reductions of $10,000,10,300$, and 1,200 metric tons of $\mathrm{SO}_{2}, \mathrm{NO}_{\mathrm{x}}$, and $\mathrm{PM}_{2.5}$, respectively, from the 2014 solar fleet, which provide annual domestic air quality benefits of $\$ 890$ million $(2.7 \notin / \mathrm{kWh}$ solar) based on central estimates.

\section{Water-Use Reductions}

- SunShot Vision: Achieving the SunShot Vision scenario reduces power-sector water withdrawals by $8 \%$ in 2030 and $5 \%$ in 2050, relative to the NNS baseline scenario, while power-sector water consumption is reduced by $10 \%$ in 2030 and $16 \%$ in $2050 .{ }^{\mathrm{v}}$ Cumulative water impacts from 2015 to 2050 equal 46 trillion gallons of avoided withdrawal (4\% of total power-sector withdrawals) and 5 trillion gallons of avoided water consumption ( $9 \%$ of total power-sector consumption). By 2050, water withdrawals in the continental United States are lower than the NNS baseline scenario in 35 of 48 states, and water consumption is lower in 36 of 48 states. Importantly, drought-prone and arid states are among those with the largest reductions in water use. These results assume dry cooling for CSP plants; greater use of wet or hybrid cooling reduces modestly the national water savings (e.g., water consumption savings drop from $16 \%$ in 2050 to $12 \%$ in 2050 ). 
- Solar Fleet at End of 2014: These potential future savings build on the water-use reductions from the 2014 solar fleet, including annual withdrawal and consumption savings of 294 billion gallons ( $0.8 \%$ of power sector total) and 7.6 billion gallons $(0.5 \%$ or power sector total), respectively, with much of those savings located in drought-impacted California.

The total monetary value of the GHG and criteria air pollution benefits of the SunShot Vision scenario exceed $\$ 400$ billion in present-value terms under our central estimates, which is equivalent to roughly $3.5 \phi / k W h$-solar. Focusing on the existing end-of-2014 fleet of solar power projects, recent annual benefits equal more than $\$ 1.5$ billion under our central estimates, which is equivalent to $4.8 \notin / \mathrm{kWh}$-solar. These are central estimates, with a sizable range of uncertainty. The figures exclude the value of reduced water use - for which monetary quantification was not feasible - as well as other non-quantified environmental considerations.

It is important to recognize that the environmental and health benefits of solar are strongly dependent on not only the amount of solar deployment but also the location of that deployment-solar that displaces higher-emitting coal generation has substantially larger benefits than solar that displaces lower-emitting gas-fired (or even wind) generation. Focusing on recent benefits from the end-of-2014 solar power fleet, Figure ES-3 illustrates the sizable regional variations in both the absolute magnitude of the GHG and air quality benefits and how those benefits translate on a normalized $\phi / \mathrm{kWh}$-solar basis. About two-thirds of total end-of2014 solar generation is delivered to California, and California accounts for roughly half of the recent total global GHG benefits. On a normalized $\phi / \mathrm{kWh}$-solar basis, recent GHG-reduction benefits range from 1.9 to $3.2 \mathrm{k} / \mathrm{kWh}$-solar depending on the region, when a central value for the social cost of carbon is applied. Normalized health-related air quality benefits are especially sensitive to regional attributes, with recent benefits ranging from 0.6 to $19 \not / \mathrm{kWh}$-solar, driven in significant measure by the degree to which higher-emitting coal-fired generation is displaced by solar.

Decision makers will naturally wish to compare these potential environmental and health benefits with, among other things, the potential costs and risks introduced by adding solar to the electric system as well as the potential impacts of solar on local ecosystems and communities. Although not addressed in this report, the SunShot Vision Study (DOE 2012) provides a thorough initial assessment of electric-system costs and impacts, while other papers in the On the Path to SunShot Study series help inform such comparisons. 


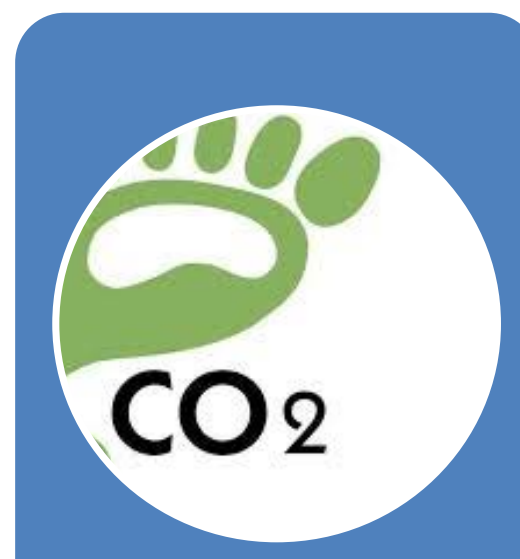

$10 \%$ reduction in powersector life-cycle greenhouse gas emissions: 2015-2050

\section{$\$ 259$ billion}

in present-value benefits of avoided global damages range: \$56-\$789 billion

\section{$\$ 238$ billion}

in present-value benefits of compliance cost offsets range: $\$ 60-\$ 347$ billion

Equivalent to: 2c/kWh-solar for central estimates

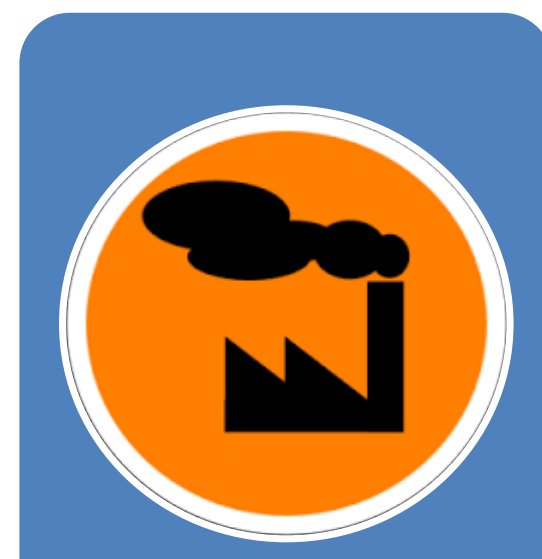

$9 \%\left(\mathrm{SO}_{2}\right), 11 \%\left(\mathrm{NO}_{\mathrm{x}}\right)$, and $8 \%$ $\left(\mathrm{PM}_{2.5}\right)$ reduction in powersector emissions: 2015-2050

\section{$\$ 167$ billion}

in present-value health and environmental benefits range: \$77-\$298 billion

Equivalent to:

$\sim 1.4 \mathrm{c} / \mathrm{kWh}$-solar for central estimates

\section{5,000-59,000}

avoided premature mortalities: 2015-2050

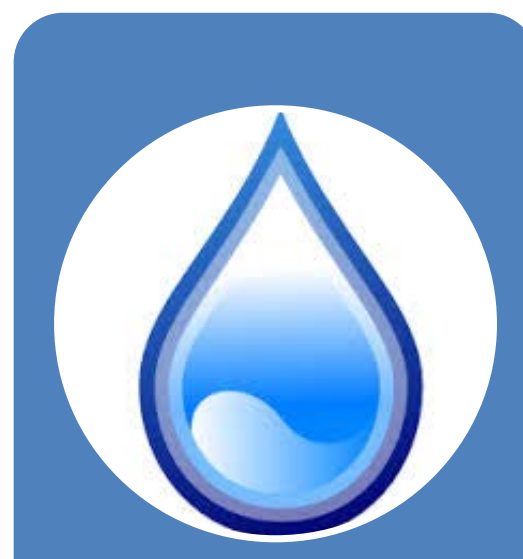

$4 \%$ reduction in powersector water withdrawals and $9 \%$ reduction in water consumption: 2015-2050

\section{Withdrawals fall in 35} states in 2050; consumption falls in 36 states; notably including many droughtprone and arid states

Consumption savings in 2050 = water demands of:

\section{3 million households}
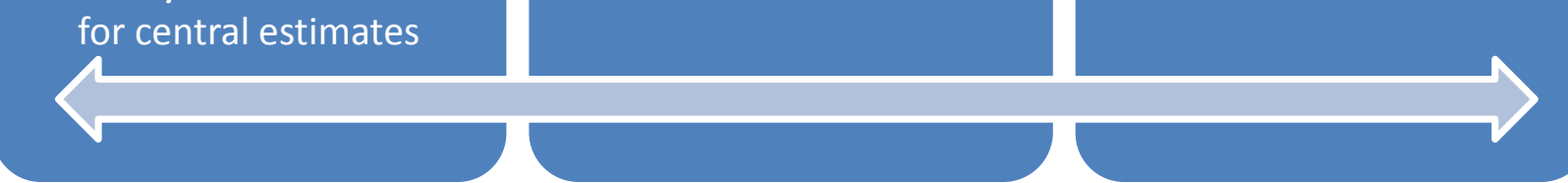

Figure ES-1. Environmental and health benefits of achieving the SunShot Vision Scenario (14\% of U.S. electricity demand by 2030 and $27 \%$ by 2050 ) 


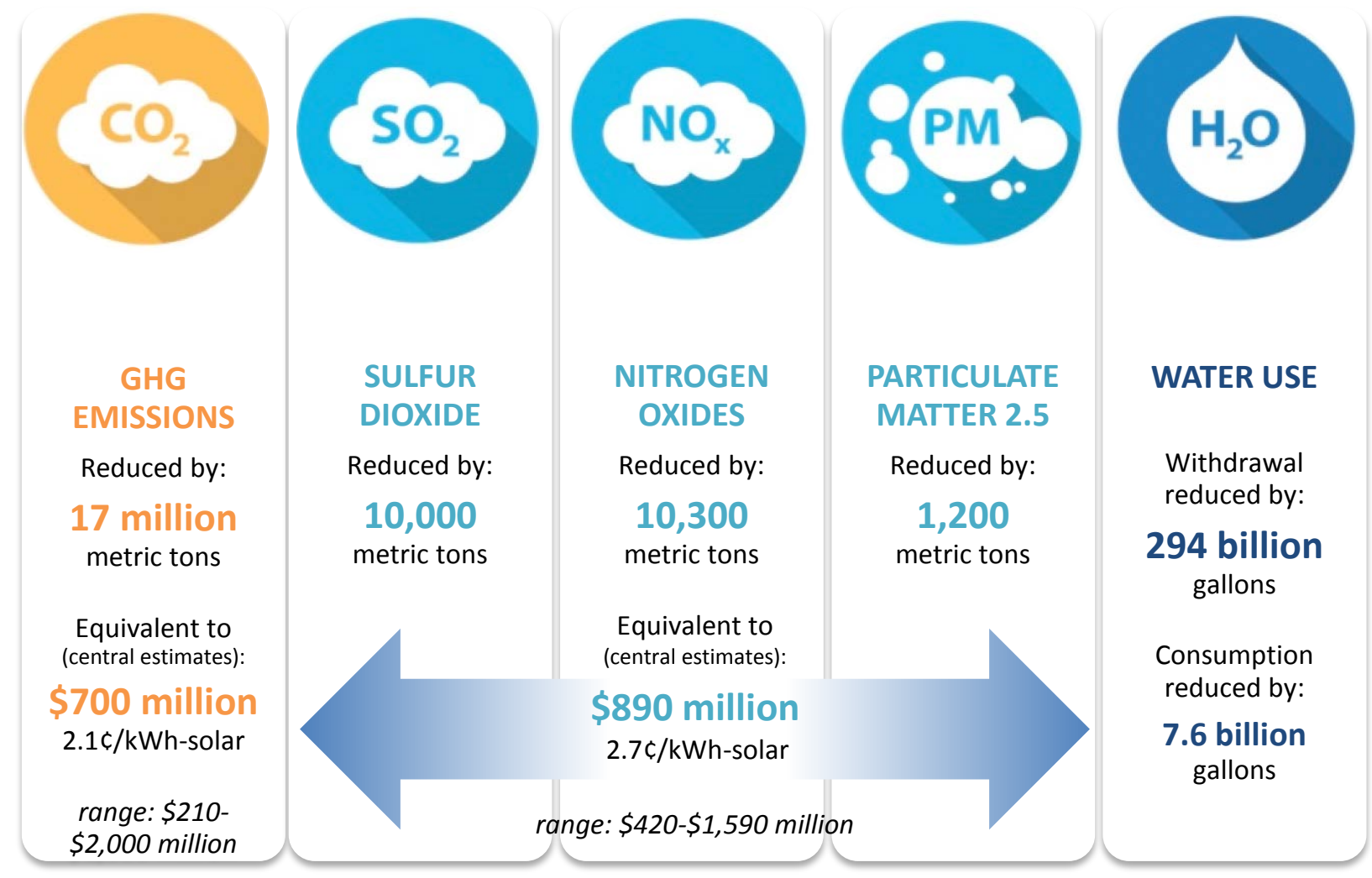

Figure ES-2. Annual environmental and health benefits of the $20 \mathrm{GW}$ of solar power installed by the end of 2014 
a) $\mathrm{CO} 2$ benefits by state (central value SCC; million \$2015)

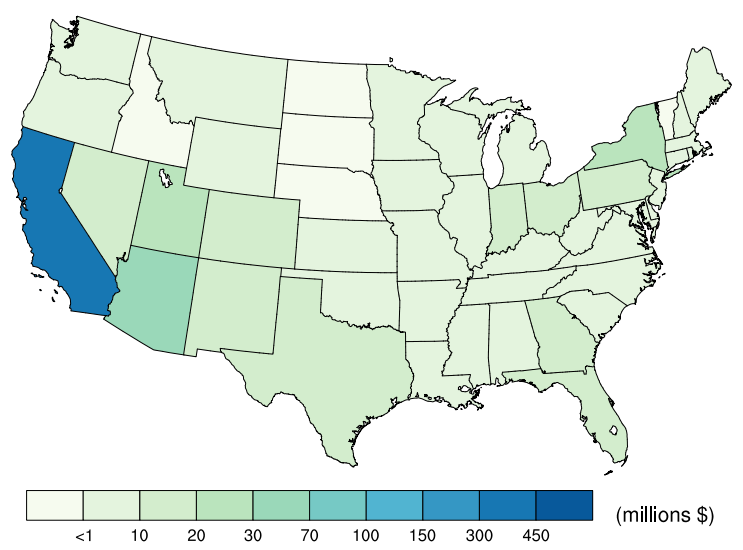

c) Air quality benefits by state (average COBRA; million \$2015)

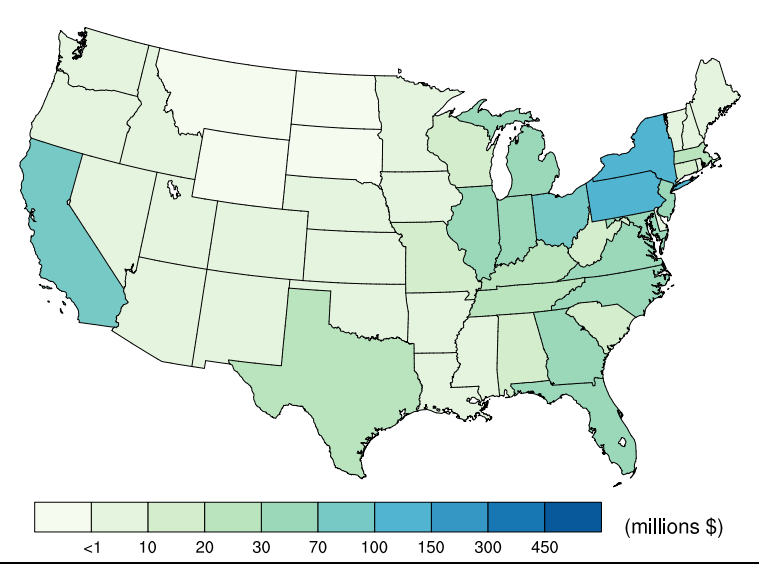

Figure ES-3. Annual GHG and air quality benefits of the $20 \mathrm{GW}$ of solar power installed by the end of 2014 by region or state b) Normalized $\mathrm{CO}_{2}$ benefits by AVERT electricity region (central value SCC; $\phi / k W h$ )

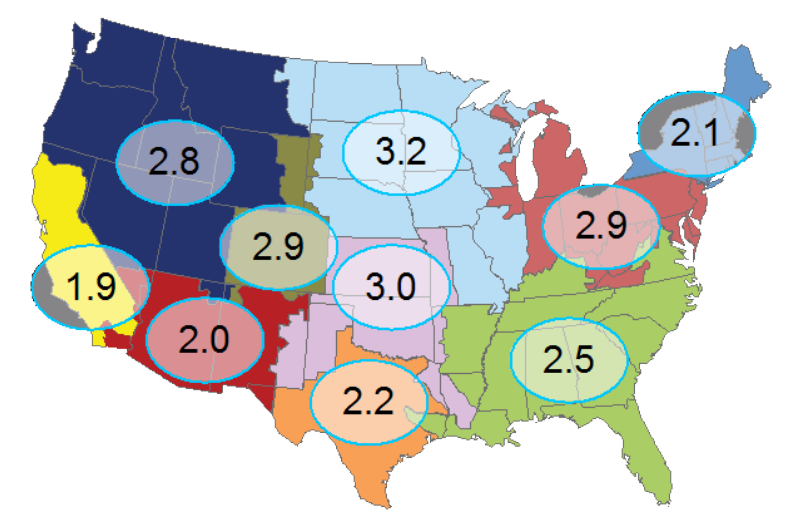

d) Normalized air quality benefits by AVERT electricity region (average COBRA; $\phi / k W h$ )

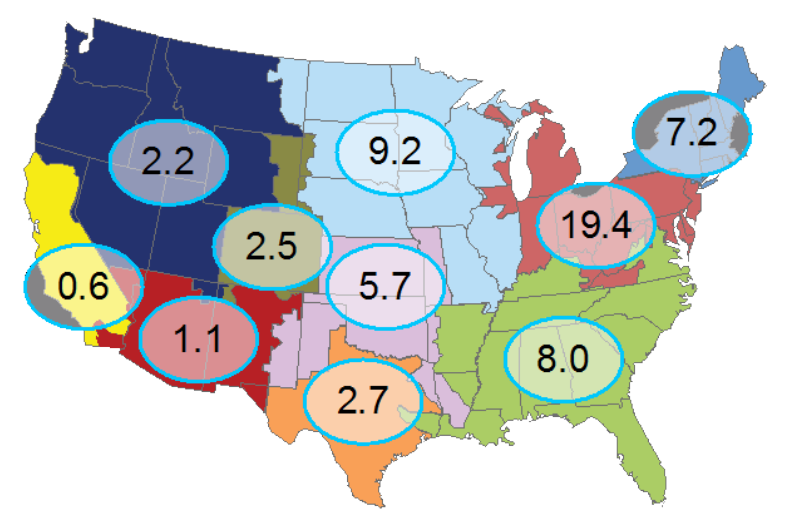

Finally, although the present work might inform policy decisions, it does not intend to suggest any specific type of policy. The costs and benefits of increased solar deployment will be impacted by the policy and market mechanisms used to effect that development; therefore, this analysis quantifies the general magnitude of environmental and health benefits only. Moreover, while the analysis presented in this report suggests a significant possible role for solar energy in delivering environmental and health benefits, previous research shows that achieving those benefits in the most cost-effective way might be best supported by a policy framework that directly addresses key market failures and unpriced externalities rather than solely using technology- or sector-specific incentives. 


\section{Table of Contents}

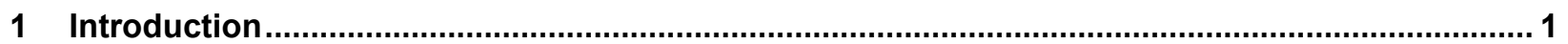

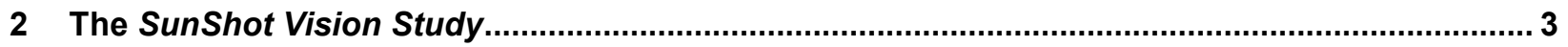

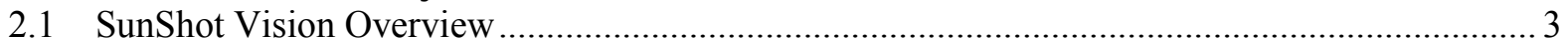

2.2 Limitations in the SunShot Vision Study's Benefits Assessment ............................................... 4

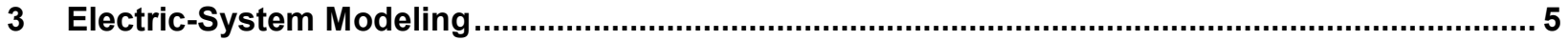

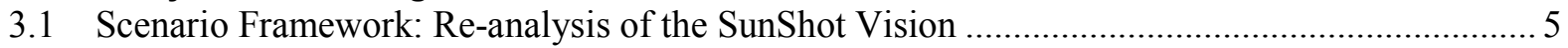

3.2 Regional Energy Deployment System (ReEDS) Model …..................................................... 5

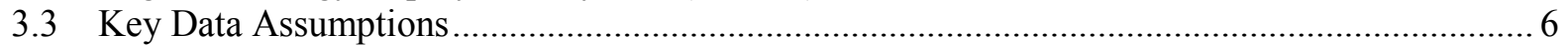

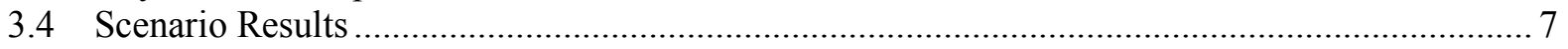

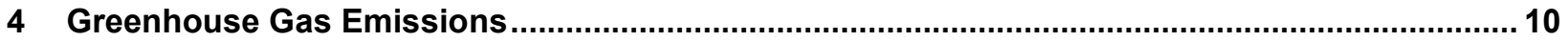

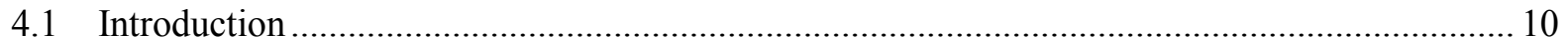

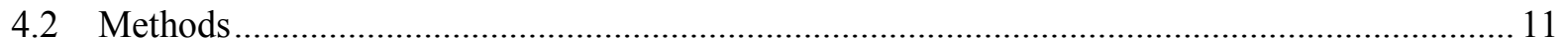

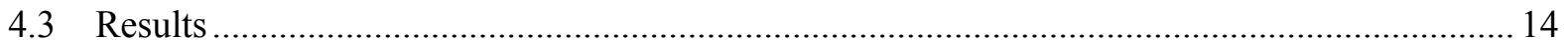

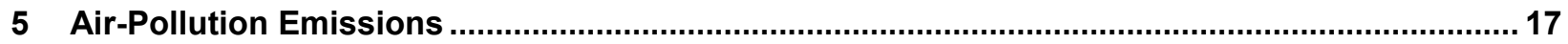

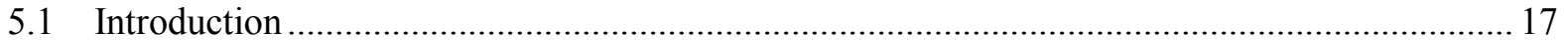

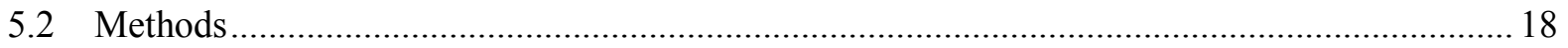

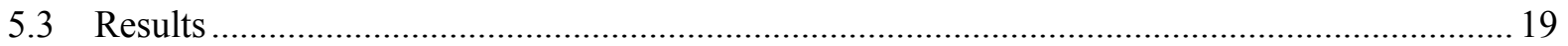

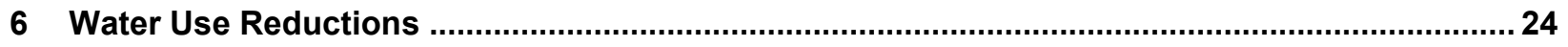

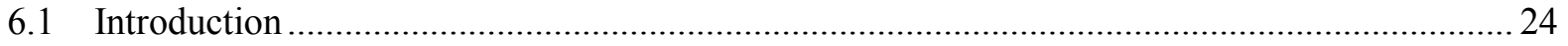

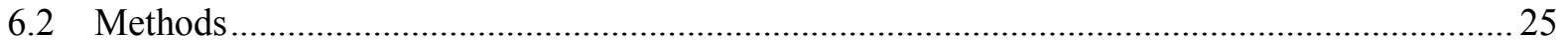

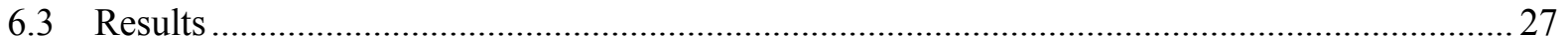

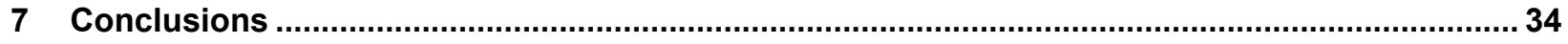

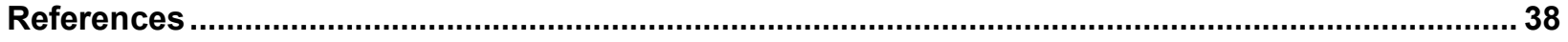

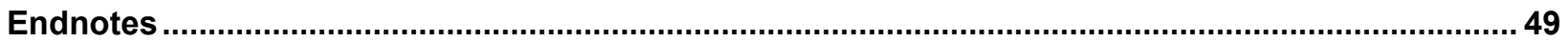




\section{List of Figures}

Figure ES-1. Environmental and health benefits of achieving the SunShot Vision Scenario (14\% of U.S. electricity demand by 2030 and $27 \%$ by 2050 )....

Figure ES-2. Annual environmental and health benefits of the $20 \mathrm{GW}$ of solar power installed by the end of 2014

Figure ES-3. Annual GHG and air quality benefits of the $20 \mathrm{GW}$ of solar power installed by the end of 2014 by region or state........................................................................................................

Figure 1. SunShot Vision Study (DOE 2012) estimates of the proportion of continental U.S. electricity demand met by solar if SunShot cost targets are achieved .................................................. 3

Figure 2. Solar installed capacity (left) and annual generation (right) under the SunShot Vision Scenario. 7 Figure 3. Geographic distribution of 2050 installed PV (top) and CSP (bottom) under the SunShot Vision Scenario.

Figure 4. Differences in installed capacity and annual generation between the NNS Baseline and SunShot Vision Scenarios for 2030 and 2050 .

Figure 5. Summary of life-cycle GHG emissions from electricity-generation technologies..................... 11

Figure 6. Overview of Methods: Greenhouse Gas Emissions .............................................................. 11

Figure 7. Estimates of the SCC (left) and carbon-reduction compliance costs (right) ............................. 13

Figure 8. Power-sector life-cycle GHG emissions impacts of SunShot Vision Scenario.......................... 14

Figure 9. Cumulative 2015-2050 absolute (top) and percent (bottom) combustion-related $\mathrm{CO}_{2}$ reductions of the SunShot Vision Scenario relative to the NNS Baseline Scenario................................. 15

Figure 10. Estimated value of SunShot Vision Scenario GHG-reduction benefits .................................. 16

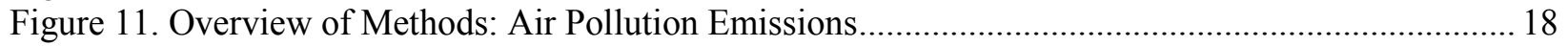

Figure 12. Power-sector SO2, NOx, and PM2.5 emissions impacts of SunShot Vision Scenario ............. 20

Figure 13. Cumulative 2015-2050 emissions reductions of $\mathrm{SO}_{2}$ (a), $\mathrm{NO}_{\mathrm{x}}$ (b), and $\mathrm{PM}_{2.5}$ (c) in the SunShot

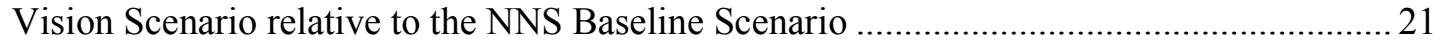

Figure 14. Estimated value of SunShot Vision Scenario $\mathrm{SO}_{2}, \mathrm{NO}_{\mathrm{x}}$, and $\mathrm{PM}_{2.5}$ benefits......................... 22

Figure 15. Overview of Methods: Water Use Reductions ................................................................... 25

Figure 16. Operational water withdrawal and consumption requirements by generation technology and

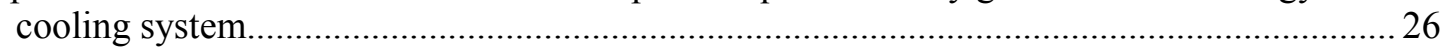

Figure 17. Power-sector water withdrawal impacts of SunShot Vision Scenario from 2015 to 2050 (left)

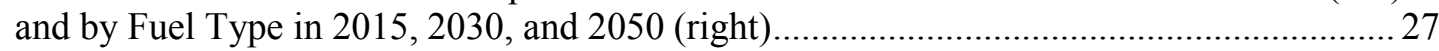

Figure 18. Power-sector water consumption impacts of the SunShot Vision Scenario from 2015 to 2050 (left) and by fuel type in 2015,2030 , and 2050 (right) .................................................. 28

Figure 19. Changes in water withdrawals (top) and water consumption (bottom) in the SunShot Vision Scenario Relative to the NNS Baseline Scenario................................................................... 29

Figure 20. Water consumption by state in 2015 and 2050 in the SunShot Vision (Dry-Cooled New CSP Only), NNS Baseline, and the SunShot Vision Sensitivity (Dry, Wet, and Hybrid Cooling) Scenarios........................................................................................... 30

Figure TB-1. Annual environmental and health benefits of solar power installed by the end of 2014 by

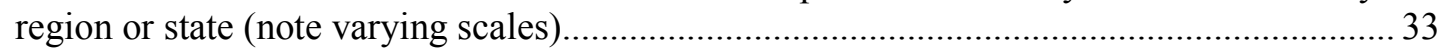

Figure 21. Environmental and health benefits of achieving the SunShot Vision Scenario (14\% of U.S.

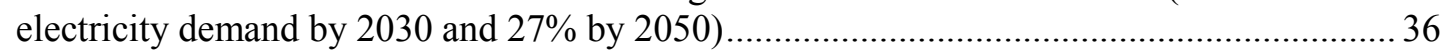

Figure 22. Annual environmental and health benefits of the $20 \mathrm{GW}$ of solar power installed by the end of 2014. 


\section{List of Tables}

Table 1. Emissions Reductions, Monetized Benefits, and Mortality and Morbidity Benefits over 20152050 for the SunShot Vision Scenario Relative to the NNS Baseline Scenario ..................... 23

Table TB-1. Total Annual Benefits of Solar Power Installed by the End of 2014: Central Estimates ........ 32 


\section{Introduction}

The contribution of solar energy to global (EPIA 2014) and U.S. (GTM/SEIA 2015) electricity supply is modest but is growing rapidly - a consequence of steep reductions in the cost of solar energy (Barbose et al. 2015; Bolinger and Seel 2015) and a wide array of policy measures (Sarzynski et al. 2012; Shrimali and Jenner 2013). The U.S. Department of Energy's SunShot Initiative seeks to further these cost reductions in order to strengthen the role of solar as a lowcost energy source and to motivate dramatically higher levels of solar electricity supply in the near, medium, and longer term. ${ }^{\mathrm{vi}}$

Achieving the cost reductions envisioned by the U.S. Department of Energy (DOE) would have profound implications for the solar industry, the electricity sector as a whole, end-use electricity consumers, and the environment. The SunShot Vision Study (DOE 2012) evaluated many of these implications for the United States, finding that achieving the SunShot cost targets could result in overall solar electricity penetrations - considering photovoltaics (PV) and concentrating solar power (CSP) — of 14\% of annual U.S. electricity demand by 2030 and $27 \%$ by 2050 . That study, however, did not comprehensively quantify the potential environmental and health benefits associated with achieving these levels of solar penetration.

Our analysis fills that gap by thoroughly assessing an important subset of the potential environmental and health benefits of achieving the solar penetrations envisioned by DOE (2012). Specifically, it covers greenhouse-gas (GHG) emissions reductions, air-pollution health and environmental impacts, and water-use reductions. Our research uses a scenario-analysis approach where the 14\%-by-2030 and 27\%-by-2050 "SunShot Vision" scenario is compared with a "No New Solar (NNS) baseline" scenario in which no new solar is deployed after 2014. This framework allows us to assess the potential benefits of all incremental solar deployment. We employ the National Renewable Energy Laboratory (NREL) Regional Energy Deployment System (ReEDS) electric sector capacity-expansion model to conduct our analysis, updating the analysis conducted in DOE (2012). For each of the three benefit categories, we take the modeled output from ReEDS and then apply additional tools - as necessary — to assess potential benefits in physical and, where feasible, monetary terms. We also briefly assess the recent environmental and health benefits of the 2014 U.S. solar fleet. In this case, we use the U.S. Environmental Protection Agency (EPA)'s Avoided Emissions and geneRation Tool (AVERT) to estimate the characteristics and location of fossil generation sources displaced by year-end 2014 solar capacity. We qualify the study results where appropriate, and we highlight areas of uncertainty not otherwise explicitly addressed in our analysis.

The focus of this analysis is narrow. We do not assess the full array of possible environmental and health benefits, instead choosing to emphasize what are - arguably - the three most notable benefits (Sinha et al. 2013). Moreover, decision makers will wish to compare these potential benefits with, among other things, the potential costs and risks introduced by adding solar to the electric system as well as the potential negative impacts of solar on local ecosystems and communities. Though we do not address electric-system costs or impacts in this analysis, DOE (2012) provides a thorough initial assessment of them. Moreover, other papers in the On the Path to SunShot Study series help inform such comparisons: Hartmann et al. (forthcoming) review experience with siting large-scale solar plants and identify best practices aimed at minimizing environmental and human impacts; Denholm et al. (2016) and Palmintier et al. (2016) assess 
electric-system integration challenges; and Chung et al. (2016) highlight the potential impacts of the solar industry on domestic manufacturing and jobs.

The remainder of the paper is organized as follows. Section 2 provides an overview of the SunShot Vision Study, on which the present analysis is based. Section 3 describes the analytical framework for the present analysis, highlights key features of the ReEDS model, and summarizes the assumptions and results of our re-analysis of the SunShot Vision highpenetration solar scenario. Sections 4 through 6 cover the methods and results of our analysis of the SunShot Vision scenario for each potential benefit category, in turn: GHGs, air pollution, and water use. Building on the methods applied in Sections 4 through 6, we summarize the potential benefits of the existing solar fleet in a text box between Sections 6 and 7. And, Section 7 summarizes the results and offers concluding remarks, highlighting both the key implications and limitations of the analysis in informing decisions. 


\section{The SunShot Vision Study}

\subsection{SunShot Vision Overview}

The U.S. Department of Energy launched the SunShot Initiative in 2011 with the aim of lowering the installed cost of solar by $75 \%$ between 2010 and 2020. As shown in other papers in the On the Path to SunShot Study series, substantial progress has already been made in meeting the SunShot cost goal, though additional effort is required to ensure success by 2020 . Achieving this goal was expected to make the unsubsidized cost of solar energy competitive with other electricity options, thereby potentially leading to widespread deployment of solar energy systems. Widespread solar deployment could, in turn, help realize the many benefits associated with solar. A natural question arises: assuming the SunShot price-reduction targets are achieved, how will this affect solar deployment in the continental United States over the next 20-40 years? Published in 2012, the SunShot Vision Study (DOE 2012) provided initial answers to this question and assessed some of the impacts associated with the projected solar deployment.

Using a scenario-analysis approach, the SunShot Vision Study assessed the potential impact of achieving the SunShot cost targets on solar deployment. Under that "SunShot Vision" scenario, solar was found to serve $14 \%$ of U.S. electricity demand in 2030, growing to $27 \%$ in 2050 . Figure 1 shows the overall solar penetration levels ("Solar Target") estimated in the SunShot Vision Study as well as the breakdown among different market segments: CSP, rooftop distributed generation from PV (DGPV), and ground-mounted utility PV (UPV). ${ }^{\text {vii }}$ To achieve these penetration levels, the SunShot Vision Study estimates that 329 GW of solar capacity would be needed by 2030 and $715 \mathrm{GW}$ by 2050 . The estimated geographic distribution of that solar capacity, the transmission infrastructure requirements, the displaced generation and capacity, and the electric-sector costs associated with that modeled scenario are also reported in the SunShot Vision report (DOE 2012). ${ }^{\text {viii }}$

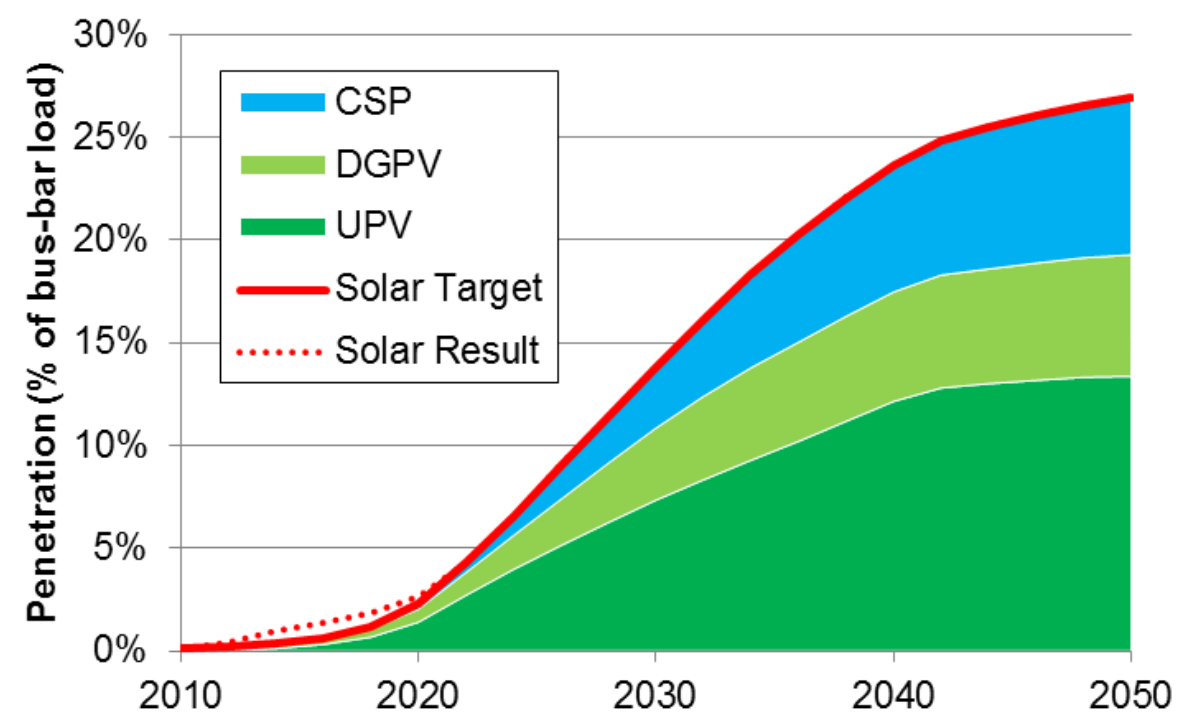

Figure 1. SunShot Vision Study (DOE 2012) estimates of the proportion of continental U.S. electricity demand met by solar if SunShot cost targets are achieved 


\subsection{Limitations in the SunShot Vision Study's Benefits Assessment}

In addition to the electric-sector scenario analysis, the SunShot Vision Study (DOE 2012) reports a select number of secondary impacts associated with high solar futures, including estimates of the avoided carbon dioxide $\left(\mathrm{CO}_{2}\right)$ emissions associated with the SunShot Vision scenario and discussions of other potential social, health, and environmental benefits. However, the study's analysis of benefits related to GHG reductions, reductions of other (non-GHG) air pollutants, and electric-sector water-use reductions is limited.

Specifically, the GHG analysis quantifies direct combustion-related $\mathrm{CO}_{2}$ emissions but lacks GHG accounting associated with a full life-cycle assessment (LCA), including emissions related to upstream equipment construction and fuel extraction and delivery, downstream plant decommissioning, and other non-combustion-related activities. In addition, although the SunShot Vision Study reports the SunShot Vision scenario's combustion-related emissions benefits in physical units (tons of $\mathrm{CO}_{2}$ ), it does not quantify these benefits in monetary terms. Similarly, it provides no quantitative assessments - in physical or monetary terms - of the non-GHG air pollution and water impacts. In some cases, these limitations were primarily due to a lack of credible tools or data available at the time. New tools and methods have subsequently been developed (DOE 2015) and are applied in the present analysis.

Developing an up-to-date assessment of SunShot Vision scenario benefits is also important because of the market changes that have occurred since the SunShot Vision analysis was conducted in 2010 and 2011. These changes include lower projected natural gas prices, greater expected coal-fired plant retirements, lower demand growth, new energy and environmental regulations, and advances in energy technologies. These changes could affect the conventional generation and capacity avoided due to increasing solar deployment and the resulting environmental and health benefits associated with the SunShot Vision scenario.

Finally, although the SunShot Vision Study includes a reference scenario with limited new solar deployment, that scenario does not offer the appropriate counterfactual for analyzing the environmental and health benefits associated with all new solar deployment. ${ }^{\text {ix }}$ Using the 2012 reference scenario would, instead, only capture the benefits associated with a subset of the new solar deployment estimated in the SunShot Vision scenario.

In our analysis, we address these limitations of the SunShot Vision Study. At the same time, we acknowledge the significant uncertainties and limitations of any analysis that spans multiple decades into the future as well as the limitations intrinsic to the tools and parameters applied. 


\section{Electric-System Modeling}

\subsection{Scenario Framework: Re-analysis of the SunShot Vision}

Our assessment of the potential environmental and health benefits of the SunShot Vision scenario begins with electric-sector modeling. Specifically, we build directly on the SunShot Vision Study (DOE 2012) by developing two scenarios of continental U.S. electricity systems out to 2050: (1) a SunShot Vision scenario that replicates the solar deployment trends of the SunShot Vision Study scenario (DOE 2012) and (2) a No-New-Solar (NNS) baseline scenario to serve as the relevant point of comparison.

With minor exceptions, our SunShot Vision scenario is consistent with the solar penetration levels in the SunShot Vision Study. We prescribe the same overall solar penetration levels (e.g., $14 \%$ by 2030 and $27 \%$ by 2050) and proportions of CSP and PV penetration (3\% CSP and $11 \%$ $\mathrm{PV}$ in $2030,8 \% \mathrm{CSP}$ and $19 \% \mathrm{PV}$ in 2050), as shown in Figure 1. Within the PV share, we update UPV deployment for the current assessment, but we rely on the same DGPV capacity deployment trajectory and locations as in the SunShot Vision Study: $121 \mathrm{GW}$ of combined commercial and residential rooftop PV systems by 2030 and $240 \mathrm{GW}$ by 2050 . We include updated recent (2010-2014) and anticipated modeled near-term solar deployment, which exceed the historical and near-term projections in the original SunShot Vision Study scenario. ${ }^{\mathrm{x}}$ As a result, pre-2022 solar penetration ("Solar Result" in Figure 1) slightly exceeds the "SunShot Target" and is captured in the new SunShot Vision scenario.

Although our solar penetration targets essentially mirror those in the SunShot Vision Study (DOE 2012), detailed deployment results associated with the capacity (MW), total generation (MWh), and geographic distribution of utility-scale solar are endogenous decisions - subject to the prescribed penetration levels - made by the model and somewhat differ from those in the original study. Similarly, results for non-solar technologies, and the associated emissions and water use, are also model decisions subject to the economics and constraints considered in the current analysis. ${ }^{\mathrm{xi}}$

The NNS baseline scenario serves as the counterfactual that allows us to estimate the full potential environmental and health benefits of the solar deployed in the SunShot Vision scenario. ${ }^{\text {xii }}$ In the NNS baseline scenario, installed solar capacity is artificially kept at year-end 2014 levels (19 GW) $)^{\text {xiii }}$ for all future years. Thus the SunShot Vision scenario benefits calculated in comparison with the NNS baseline scenario reflect the impacts of all new solar deployment over the study period (2015-2050). The NNS baseline and SunShot Vision scenarios are both designed for the benefits assessment reported herein, and neither reflects a forecast or prediction.

\subsection{Regional Energy Deployment System (ReEDS) Model}

As in the SunShot Vision Study (DOE 2012), the electric-sector analysis for the present assessment relies primarily on NREL's ReEDS model. ${ }^{\text {xiv }}$ ReEDS is an electric sector capacityexpansion model for the continental United States that relies on an optimization algorithm to estimate the type and location of new fossil, nuclear, renewable, and storage capacity and generation; transmission-expansion requirements; and fuel needed to satisfy regional demand requirements and maintain resource adequacy, all at least cost. ReEDS represents technological, physical, and policy constraints in its scenario development through 2050. It considers the 
characteristics of renewable energy technologies in estimating future electric-system investments by using high spatial resolution and statistical methods that account for the impacts of renewable variability, uncertainty, and resource distribution and quality. ReEDS endogenously estimates transmission-expansion needs, potential increases in ancillary-service requirements due to renewable energy forecast errors, renewable curtailments, and the changing capacity credit of renewable energy technologies, and it considers these estimates in its investment decisions.

ReEDS has been used in multiple recent analyses, including the original SunShot Vision Study (DOE 2012) and SunShot sensitivity analysis (Eurek et al. 2013), other renewable technology visions (DOE 2008; DOE 2015; Mai et al. 2014; NREL 2012), solar technology-specific assessments (Denholm et al. 2012; Sigrin et al. 2014; Cole et al. 2015), and policy analysis (Bird et al. 2011; Lantz et al. 2014; Logan et al. 2013; Mignone et al. 2012; Sullivan et al. 2014). Model documentation can be found in Short et al. (2011), although the model has been developed further since that documentation was published. ${ }^{\mathrm{xv}}$

\subsection{Key Data Assumptions}

The scenario modeling in the present analysis builds on the SunShot Vision Study (DOE 2012) and relies on input data assumptions recently developed and used for the NREL Standard Scenarios Annual Report (Sullivan et al. 2015) and the Wind Vision study (DOE 2015). These include cost and performance assumptions for non-solar renewable technologies. In particular, we model wind technologies using the "central" wind cost case from the Wind Vision study (DOE 2015). For non-renewable technology assumptions - including fossil and nuclear capital costs, operations and maintenance costs, and heat rates - we rely on data from the Energy Information Administration's Annual Energy Outlook (AEO) 2015 Reference scenario (EIA 2015a). AEO 2015 Reference scenario demand growth results and fuel-natural gas, coal, and uranium - costs are also used in the present analysis. ${ }^{\text {xvi }}$ Solar technology costs are closely aligned with those used in the SunShot Vision Study; new CSP is presumed to include thermal energy storage. ${ }^{\text {xii }}$ That said, because the modeled scenarios have prescribed solar-penetration levels, different solar technology assumptions will not yield significant differences in deployment.

The modeling includes existing (as of early 2015) policies and regulations only. In particular, state renewables portfolio standards, including those with solar-specific targets, and California's carbon cap are modeled in ReEDS. Although we recognize the ongoing uncertainties associated with federal air regulations, we include estimated retirement, retrofit, and dispatch impacts of the Cross State Air Pollution Rule (CSAPR) and the Mercury Air Toxics Standard (MATS) in our scenario modeling. Section 5 details the implications of this assumption on estimated airpollution benefits. Importantly, we do not explicitly model the U.S. Environmental Protection Agency (EPA) Clean Power Plan (CPP) regulation on power plant emissions; however, we do estimate the possible benefits of solar in meeting CPP compliance obligations in Section 4.

Lastly, we include the $30 \%$ solar investment tax credit (ITC) through 2016, as legislated as of early 2015; we assume no solar ITC exists after 2016 as consistent with the SunShot Vision Study and despite current legislation. ${ }^{\text {xviii }}$ Other technology tax incentives are modeled as currently legislated. 


\subsection{Scenario Results}

The SunShot Vision scenario demonstrates rapid and sustained increases in the deployment of all solar electricity technologies. Figure 2 shows that the estimated installed solar capacity reaches $319 \mathrm{GW}^{\mathrm{xix}}$ in 2030 and grows to $708 \mathrm{GW}^{\mathrm{xx}}$ in 2050 . This future solar capacity meets the $14 \%$ and 27\% penetration targets in 2030 and 2050, respectively, and requires 603 TWh of solar energy be produced in 2030 and 1,327 TWh in 2050. Utility-scale PV is the largest contributor to this solar energy supply, with significant but lower levels of DGPV and CSP. ${ }^{\mathrm{xx}}$
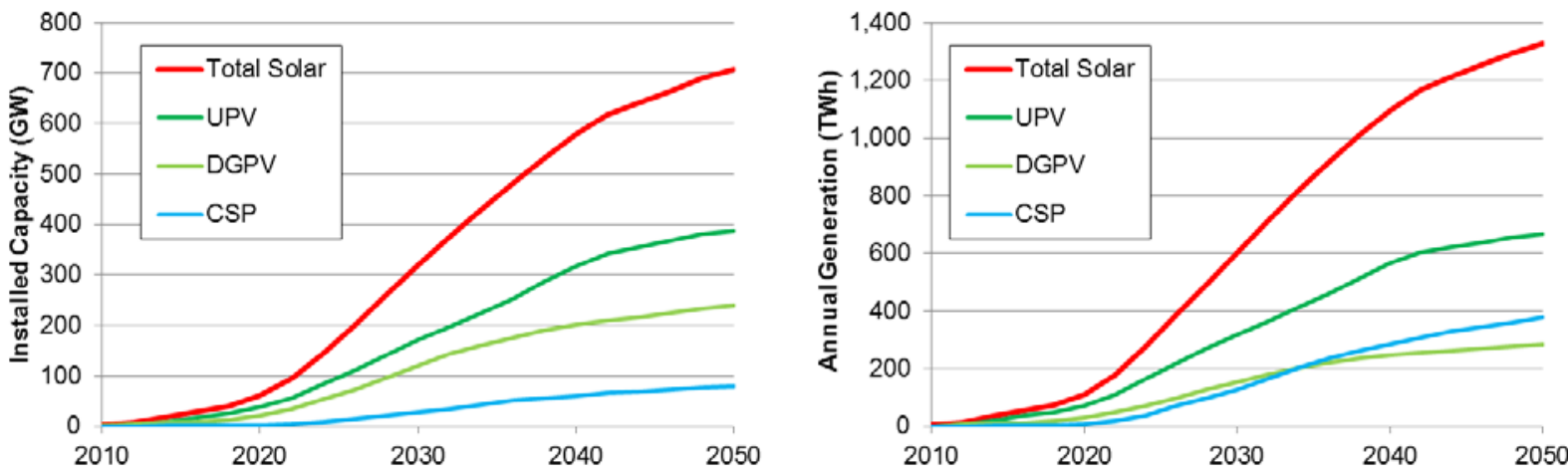

Figure 2. Solar installed capacity (left) and annual generation (right) under the SunShot Vision Scenario

The geographic distribution of solar capacity influences estimated benefits, including avoided emissions and water use. Figure 3 shows the 2050 state distribution of combined DGPV and UPV (top) and CSP (bottom) capacity under the SunShot Vision scenario. PV capacity is widely distributed across all 48 states modeled, although the amount of PV is higher in states with a combination of high resource quality, high electricity demand, and concentrated population densities. In contrast, CSP is restricted to eight states primarily located in the Southwest because of CSP's solar-resource requirements. ${ }^{\text {xii }}$ Nevertheless, generation from both CSP and PV meets electricity demands throughout the entire continental United States. 

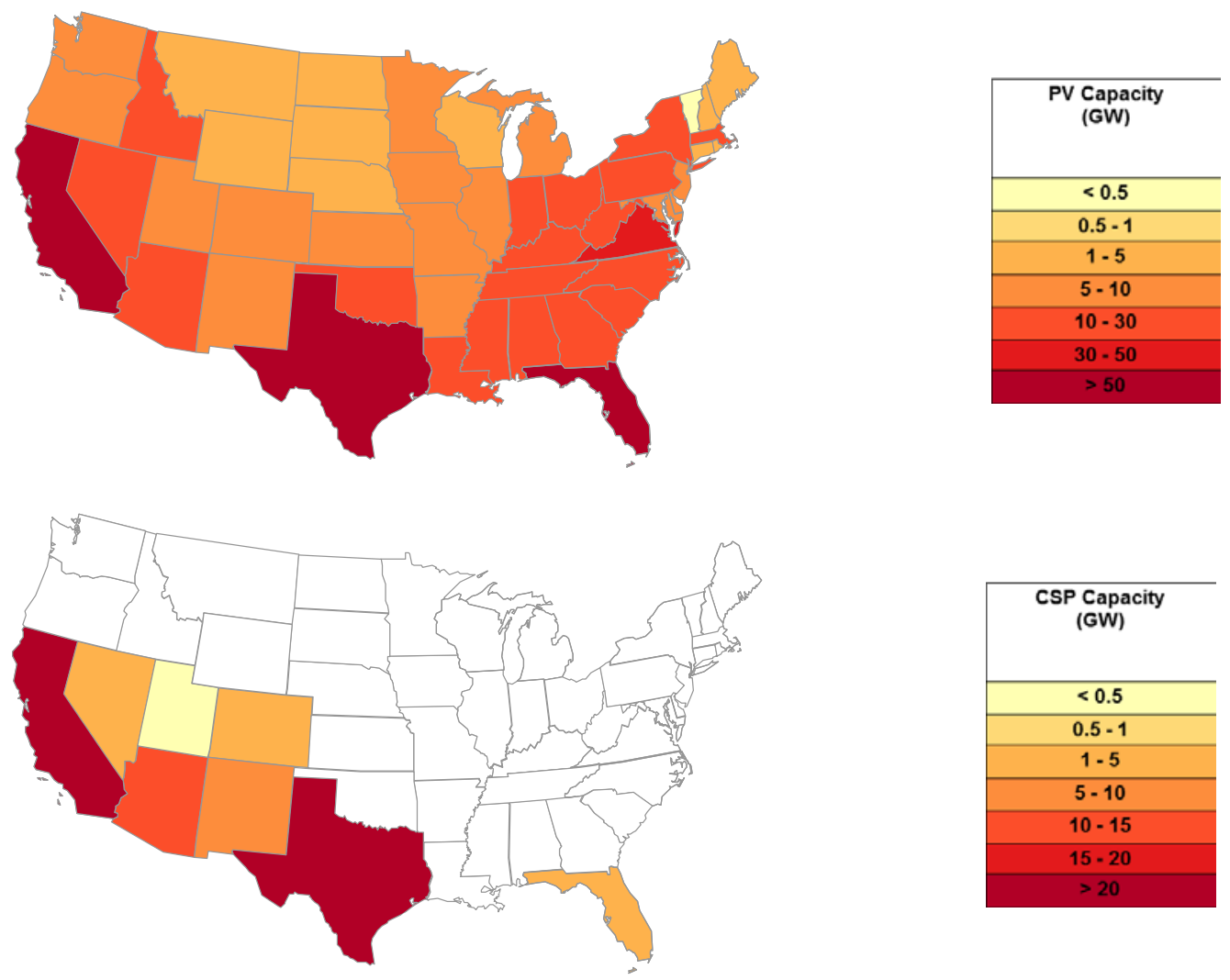

Figure 3. Geographic distribution of 2050 installed PV (top) and CSP (bottom) under the SunShot Vision Scenario

The relative nationwide shares of CSP and PV are determined entirely by the prescriptive scenario design that replicates the penetration levels in the SunShot Vision Study (DOE 2012). Deviations from these shares would yield different results in terms of location and amount of solar capacity deployed and associated environmental and health impacts. ${ }^{\text {xxii }}$

Avoided capacity and generation are particularly important for assessing the potential environmental and health benefits associated with new solar deployment. In the scenario construct used here, avoided values refer to differences between the NNS baseline and SunShot Vision scenarios. Figure 4 shows avoided capacity and generation results for 2030 and 2050 over the entire continental U.S. footprint. In 2030, new solar in the SunShot Vision scenario is estimated to avoid $87 \mathrm{GW}$ of total capacity, of which natural gas-fired capacity constitutes the majority (54 GW). Avoided 2030 generation also mostly comprises fossil sources (75\% fossil), nearly evenly split between coal-based and natural-gas-based generation. The remaining smaller shares of 2030 avoided capacity and generation are predominantly from wind power technologies. 
As also shown in Figure 4, the amount of avoided fossil capacity and generation grows between 2030 and 2050; however, avoided values from non-fossil - predominantly wind - sources grow at an especially rapid pace. As a result, of the $277 \mathrm{GW}$ of avoided capacity in $2050,159 \mathrm{GW}$ comes from wind and $102 \mathrm{GW}$ from natural gas. Similarly, wind constitutes $50 \%$ of 2050 avoided generation compared with $46 \%$ from fossil sources and the small remainder from nuclear and non-wind renewables. This increase in avoided wind stems directly from the modeled robust growth in wind energy, especially after 2030, and the fact that increased solar deployment places downward pressure on that growth. This result also impacts our subsequent analysis, lowering the estimated environmental and health benefits of solar in comparison to a scenario is which solar is presumed to displace more fossil generation and less wind power generation.

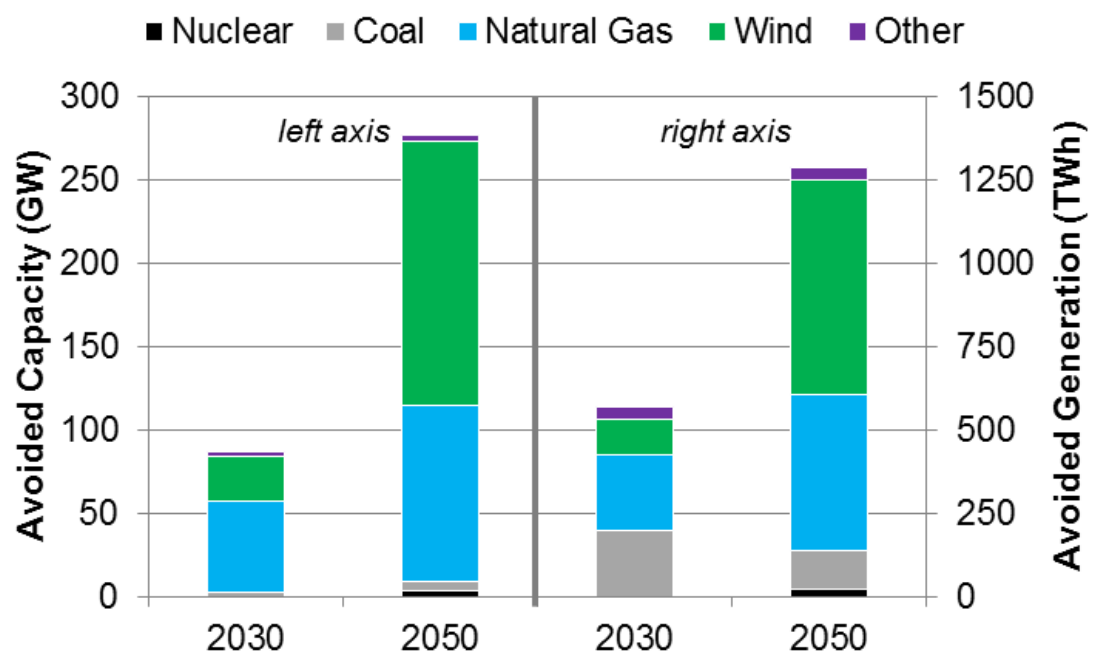

Figure 4. Differences in installed capacity and annual generation between the NNS Baseline and SunShot Vision Scenarios for 2030 and 2050

Significant uncertainties exist around the future amount and nature of avoided capacity, generation, and emissions driven by SunShot-level solar penetration. Nonetheless, the present analysis applies an electric-sector modeling approach to generate these estimates selfconsistently using the assumptions noted. Any differences in avoided values would yield potential benefits different from those presented in the following sections. Finally, it deserves note that our analysis extends through 2050: as such, any GHG and air pollutant emissions reductions or water use savings that accrue after 2050 are not assessed in the present analysis. 


\section{Greenhouse Gas Emissions}

Summary: Achieving the SunShot Vision scenario reduces life-cycle GHG emissions from the power sector by $13 \%$ in 2030 and $18 \%$ in 2050 , relative to the NNS baseline scenario. Cumulative GHG savings from 2015 to 2050 equal 8 billion metric tons of $\mathrm{CO}_{2}$ equivalent $\left(\mathrm{CO}_{2} \mathrm{e}\right)$, which is more than $10 \%$ of total life-cycle emissions from the power sector. These reductions could produce $\$ 259$ billion of global benefits in the form of lower future climate change damages when applying a "central value" for the social cost of carbon (SCC), which is equivalent to a levelized benefit of solar of $2.2 \mathrm{c} / \mathrm{kWh}$-solar. Across a range of SCC estimates, total benefits span from $\$ 56$ billion $(0.5 \phi / \mathrm{kWh}$-solar) to $\$ 789$ billion ( $6.8 \notin / \mathrm{kWh}$-solar). If, alternatively, solar is viewed as a way to meet future carbon-reduction requirements, for example under EPA's Clean Power Plan and any subsequent legal obligations, then the benefits of achieving the SunShot Vision scenario range from $\$ 60$ billion $(0.5 \notin / \mathrm{kWh}$-solar) to $\$ 347$ billion (3.0غ/kWh-solar).

\subsection{Introduction}

Scientists predict significant changes to Earth's climate due to past and future GHG emissions, including higher average temperatures, increased frequency and intensity of some types of extreme weather, rising sea levels, and ocean acidification (IPCC 2013; IPCC 2014a). As highlighted in Melillo et al. (2014), these changes are expected to impose a wide range of damages globally and in the United States: threatening human health and wellbeing through more-extreme weather and wildfires as well as decreased air quality; putting infrastructure at risk; jeopardizing water quality and supply; disrupting agricultural production; and negatively affecting ecosystems and biodiversity.

EPA (2015a) finds that efforts to limit climate change damages through reductions in GHGs can offer many benefits, and there is growing recognition of the desirability of near-term actions to limit emissions (IPCC 2014b; Luderer et al. 2013; Nordhaus 2013). Responding to this challenge, EPA has established GHG emission limits for - among other things - existing and new power plants (EPA 2015b; EPA 2015c).

Solar energy technologies - both PV and CSP — have low GHG emissions in comparison to fossil energy sources even when considering all life-cycle stages from upstream materials requirements to operations and decommissioning (see Figure 5, which summarizes an NREL systematic review of the available life-cycle literature; see also www.nrel.gov/harmonization). Achieving the SunShot Vision scenario, therefore, promises to reduce GHG emissions. In this section, we estimate those potential GHG reductions and then quantify their monetary value in (1) mitigating the severity of climate-related damages and (2) meeting future legal requirements to reduce GHG emissions. 


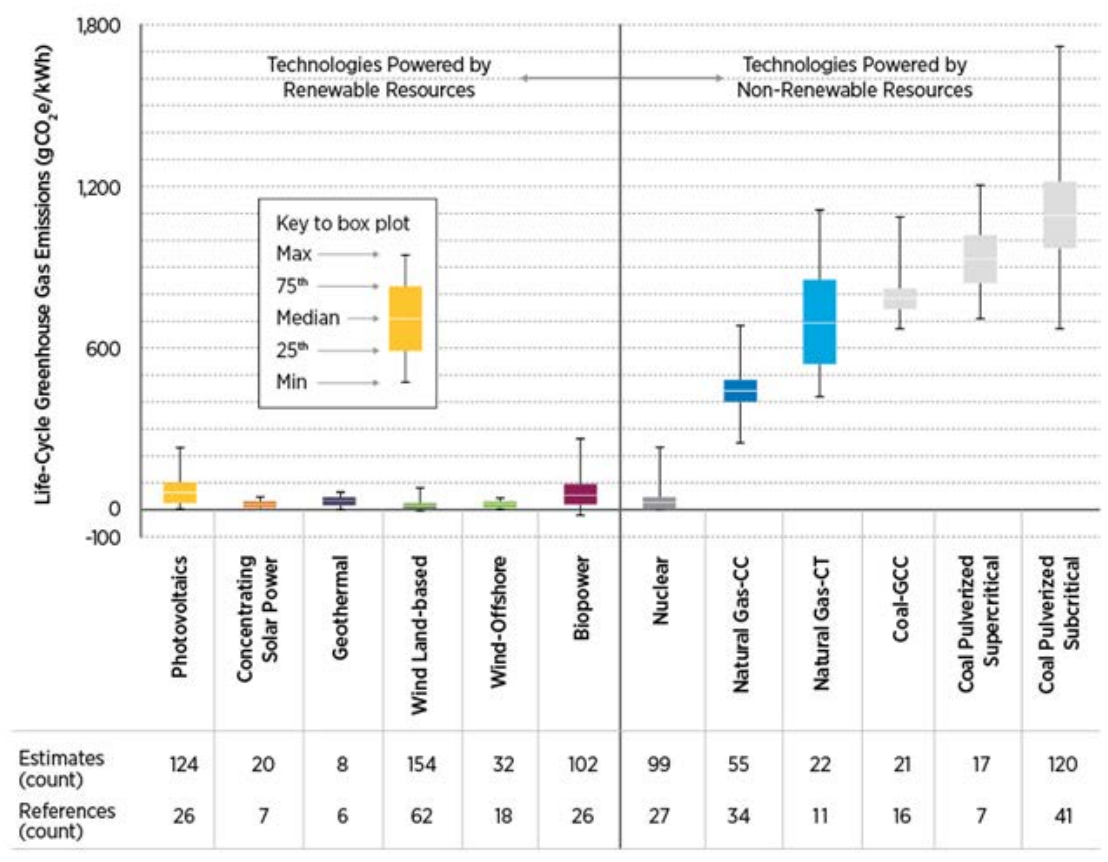

Note: Acronyms used in this figure: Natural Gas-CC $=$ Natural gas combined cycle; Natural Gas-CT = Natural gas combustion turbine; Coal $-16 C C=$ Coal integrated gasification combined cycle

Figure 5. Summary of life-cycle GHG emissions from electricity-generation technologies DOE 2015

\subsection{Methods}

To value the potential GHG benefits of achieving the SunShot Vision scenario, we estimate the life-cycle GHG reductions from solar from 2015 to 2050 in the SunShot Vision scenario relative to the NNS baseline scenario and then quantify the monetary value of those reductions based on both a range of social cost of carbon (SCC) estimates and a range of carbonreduction compliance-cost estimates (Figure 6). These methods are broadly similar to those used in the recent Wind Vision report (DOE 2015) as well as those used by U.S. regulatory agencies (GAO 2014) and academic researchers (Buonocore et al. 2015; Callaway et al. 2015; Cullen 2013; Graff Zivin et al. 2014; Johnson et al. 2013; Kaffine et al. 2013; McCubbin and Sovacool 2013; Novan 2014; Siler-

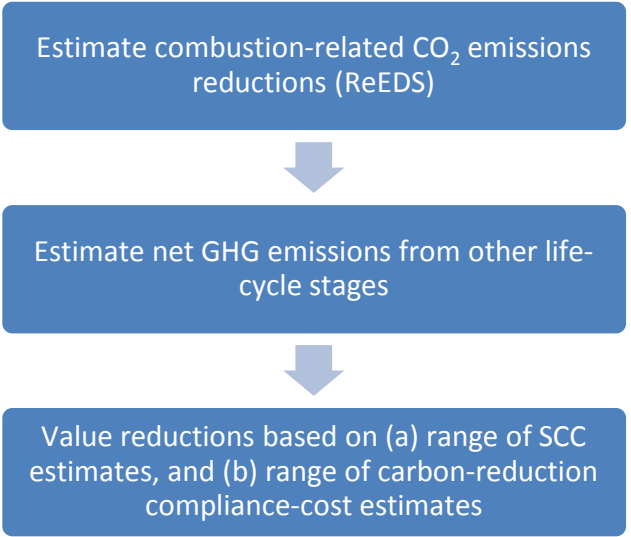

Figure 6. Overview of Methods: Greenhouse Gas Emissions Evans et al. 2013; Shindell 2015).

We start with ReEDS-estimated, power-sector combustion-related $\mathrm{CO}_{2}$ emissions in the SunShot Vision and NNS baseline scenarios. ${ }^{\text {xxiv }}$ We adjust these figures to account for life-cycle impacts by combining ReEDS combustion-related emissions with life-cycle, non-combustion emission values for each generation technology based on results developed in NREL's LCA 
Harmonization study (www.nrel.gov/harmonization). The additional life-cycle stages that we consider include: (1) ongoing fuel-cycle emissions from the production and transport of fuels and from other aspects of power plant operations (e.g., operation of maintenance vehicles, auxiliary heating, etc.); (2) construction-related emissions (e.g., from materials, equipment, and construction); and (3) emissions from end-of-life decommissioning (e.g., from removal of equipment). ${ }^{\mathrm{xx}}$ By applying these life-cycle adjustments, we capture avoided fuel-cycle, construction, and decommissioning emissions from displaced fossil generation and capacity, while also accounting for increased fuel-cycle, construction, and decommissioning emissions from the solar generation and capacity.

We then estimate the monetary benefits of these GHG reductions in the form of reduced climatechange damages using SCC estimates. ${ }^{\text {xxvi }}$ The SCC reflects, among other elements, monetary damages from the impacts of climate change on agricultural productivity, human health, property damages, and ecosystem services (IWG 2010; IWG 2015). U.S. government regulatory bodies regularly use the SCC when formulating policy (GAO 2014; Kopp and Mignone 2012), supported by estimates provided by the U.S. Interagency Working Group on the Social Cost of Carbon, or IWG (IWG 2010; IWG 2015). The IWG SCC estimates represent global future damages from $\mathrm{CO} 2$ emitted in a particular year. Reflecting the uncertainties involved, the IWG (2015) provides four SCC trajectories: a "low" case, a "central value" case, a "high" case, and a "higher-than-expected" case intended to account for a much less likely outcome with a moreextreme impact (Figure 7). For our purpose and as recommended by the IWG, the monetary value of achieving the SunShot Vision scenario is estimated based on all four IWG trajectories.

As an alternative to valuing GHG reductions based on the SCC, we also value those reductions based on the possible cost of complying with legal requirements to reduce GHG emissions. Some U.S. states and regions have already enacted carbon-reduction policies, the U.S. Congress has considered such policies in the past, and EPA has established regulations that may limit emissions from existing and new power plants through the Clean Power Plan (EPA 2015b; EPA 2015c; Luckow et al. 2015). ${ }^{\text {xxvii }}$ Especially when binding cap-and-trade programs are used to limit GHG emissions, as envisioned - in part- by the Clean Power Plan (CPP), the climatechange benefits of solar energy might best be valued based on the cost of complying with legal requirements to reduce carbon emissions (Cullen 2013; Siler-Evans et al. 2013). ${ }^{\text {xxviii }}$ In this case, the GHG co-benefits of solar energy come in the form of solar helping to meet the carbonreduction target and thereby offsetting some of the "marginal" costs of complying with the policy.

More specifically, we value the GHG reductions based on two sets of estimates for this compliance cost. First, we use EPA estimates of the average national cost of complying with the CPP under both mass-based and rate-base application (EPA 2015b). ${ }^{\mathrm{xxix}}$ Those estimates are provided by EPA for 2020, 2025, and 2030: we interpolate between these years to estimate costs in intervening periods. We also assume that the 2030 compliance cost estimates remain constant through 2050. Second, we use Synapse estimates of carbon costs under "low," "medium," and "high" trajectories (Luckow et al. 2015). Synapse considers the possibility of more-stringent long-term carbon-reduction goals than envisioned by the CPP and so estimates higher costs than those from EPA (2015b). Figure 7 summarizes both sets of resulting carbon costs. 

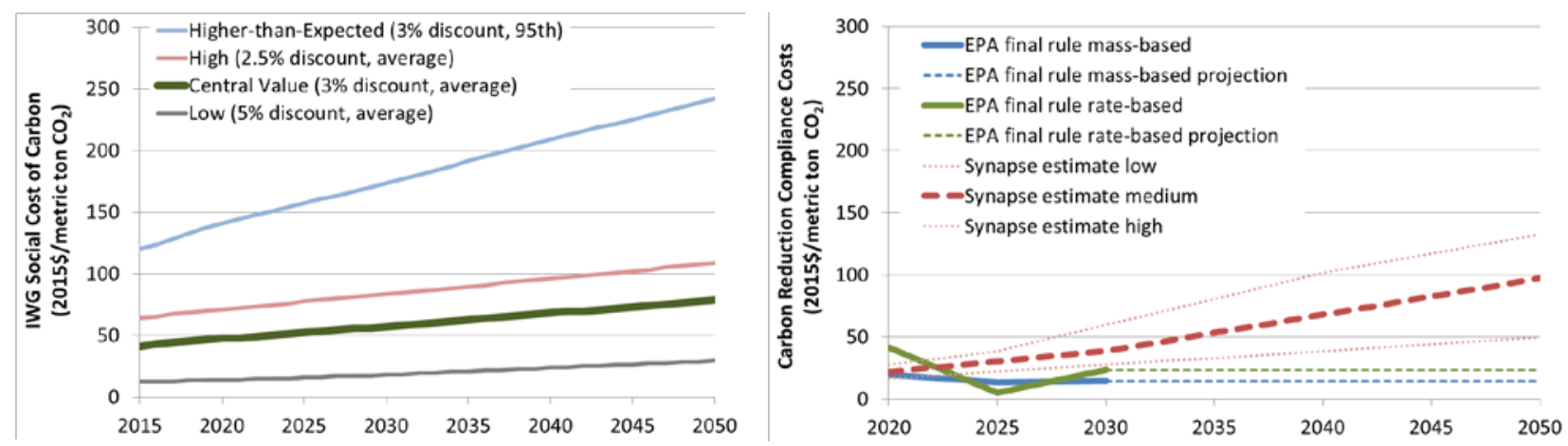

Figure 7. Estimates of the SCC (left) and carbon-reduction compliance costs (right)

Several additional aspects of the methodology, and possible related limitations, deserve note:

- Our GHG emissions-reduction estimates are inherently uncertain, in part owing to the impact of uncertain policy and market factors on those reductions. Moreover, life-cycle emissions adjustments are based on median (and static, not affected by future decarbonization trends) literature estimates.

- We do not consider the possible erosion of the GHG benefits due to the increased cycling, ramping, and part loading required of fossil generators in electric systems with higher penetrations of variable renewable generation. This omission, however, will not meaningfully bias our results, because the available literature clearly demonstrates that this impact is small. ${ }^{\mathrm{xxx}}$

- Although IWG SCC estimates span a large range, an even wider range exists in the literature. Also, as recommended by the IWG and others (IWG 2015; Pizer et al. 2014), we rely on global SCC estimates: this means that the results are reflective of future global benefits (discounted to the present), only a portion of which would directly benefit the United States and the majority of which would accrue in years after the GHG emissions reductions occur.

- Estimates of the cost of complying with uncertain future carbon-reduction policies are similarly uncertain (Luckow et al. 2015), and a wide range of estimates is therefore applied.

- We apply the IWG SCC estimates to the estimated life-cycle GHG emissions savings (in $\mathrm{CO}_{2} \mathrm{e}$ ), whereas we apply compliance cost estimates only to combustion-related power-sector emissions (only $\mathrm{CO}_{2}$ ). ${ }^{\mathrm{xxxi}}$ 


\subsection{Results}

Achieving the SunShot Vision scenario reduces life-cycle GHG emissions from the power sector by $13 \%$ in 2030 and $18 \%$ in 2050, relative to the NNS baseline scenario (Figure 8 ). Cumulative GHG savings from 2015 to 2050 equal 8 billion metric tons of $\mathrm{CO}_{2}$ e, which is more than $10 \%$ of total life-cycle emissions from the power sector over that same time period. In total, this represents a sizable contribution to EPA's recently released CPP power-sector emissions targets.

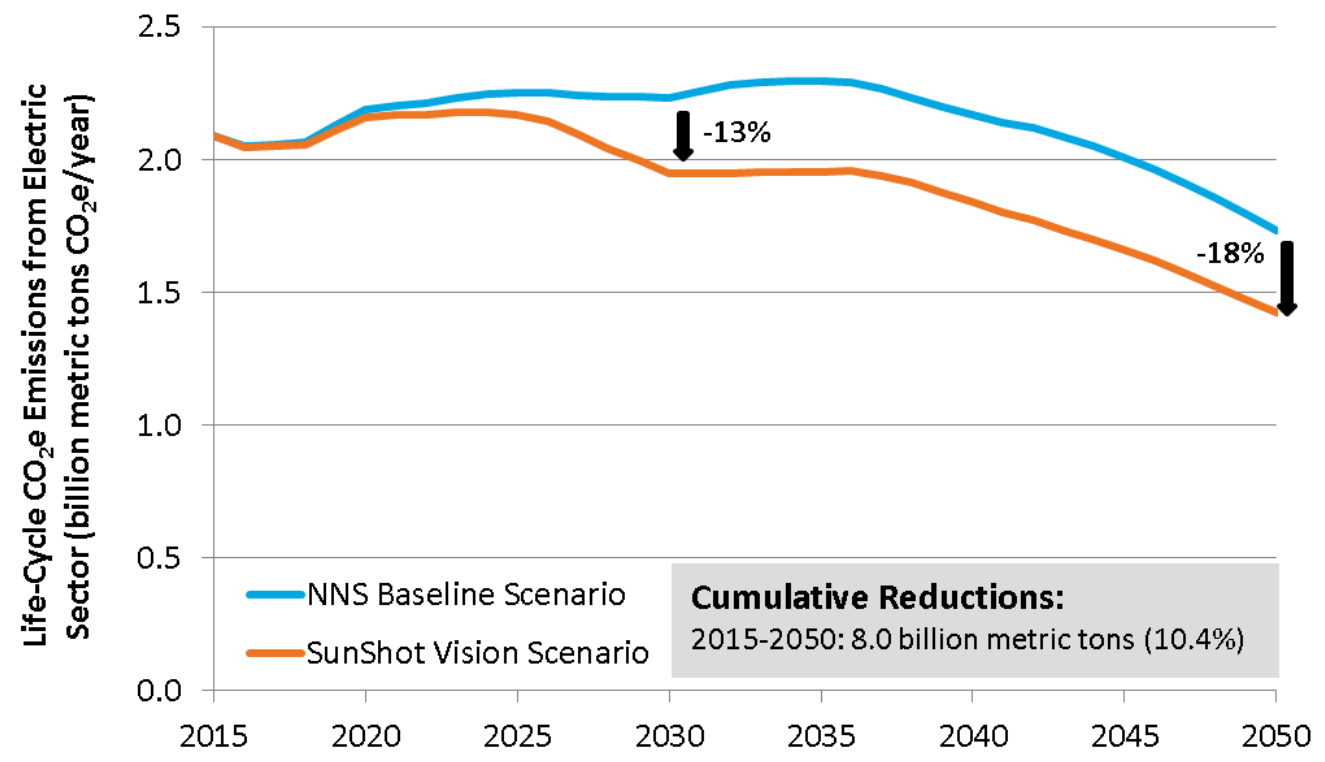

Figure 8. Power-sector life-cycle GHG emissions impacts of SunShot Vision Scenario

Emissions reductions from avoided fossil-fuel combustion are estimated with ReEDS at 8.3 billion metric tons of $\mathrm{CO}_{2}$. As shown in Figure 9 (top), these combustion-related $\mathrm{CO}_{2}$ savings are somewhat concentrated in California, Texas, and the Southeast, driven both by the amount of solar deployment in these regions (see Section 3) and by the degree to which high-carbonemitting coal plants (and, to a lesser extent, natural gas-fired generation) are displaced. On a percentage basis (Figure 9, bottom), relative to total statewide power-sector emissions, reductions are spread somewhat more broadly, but with some concentration in the Southwest, South, and Southeast as well as some states in the Northeast. ${ }^{\text {xxxii }}$

Factoring in the full life cycle, total emissions reductions are somewhat lower $(8.0$ billion metric tons) than when only considering combustion ( 8.3 billion metric tons). This is largely because the sizable solar capacity additions under the SunShot Vision scenario result in higher construction-related emissions than under the NNS baseline. The non-combustion, life-cycle impacts are not assigned to regions (and so are not included in Figure 9) because of the challenges of estimating the location of upstream and downstream emissions. 

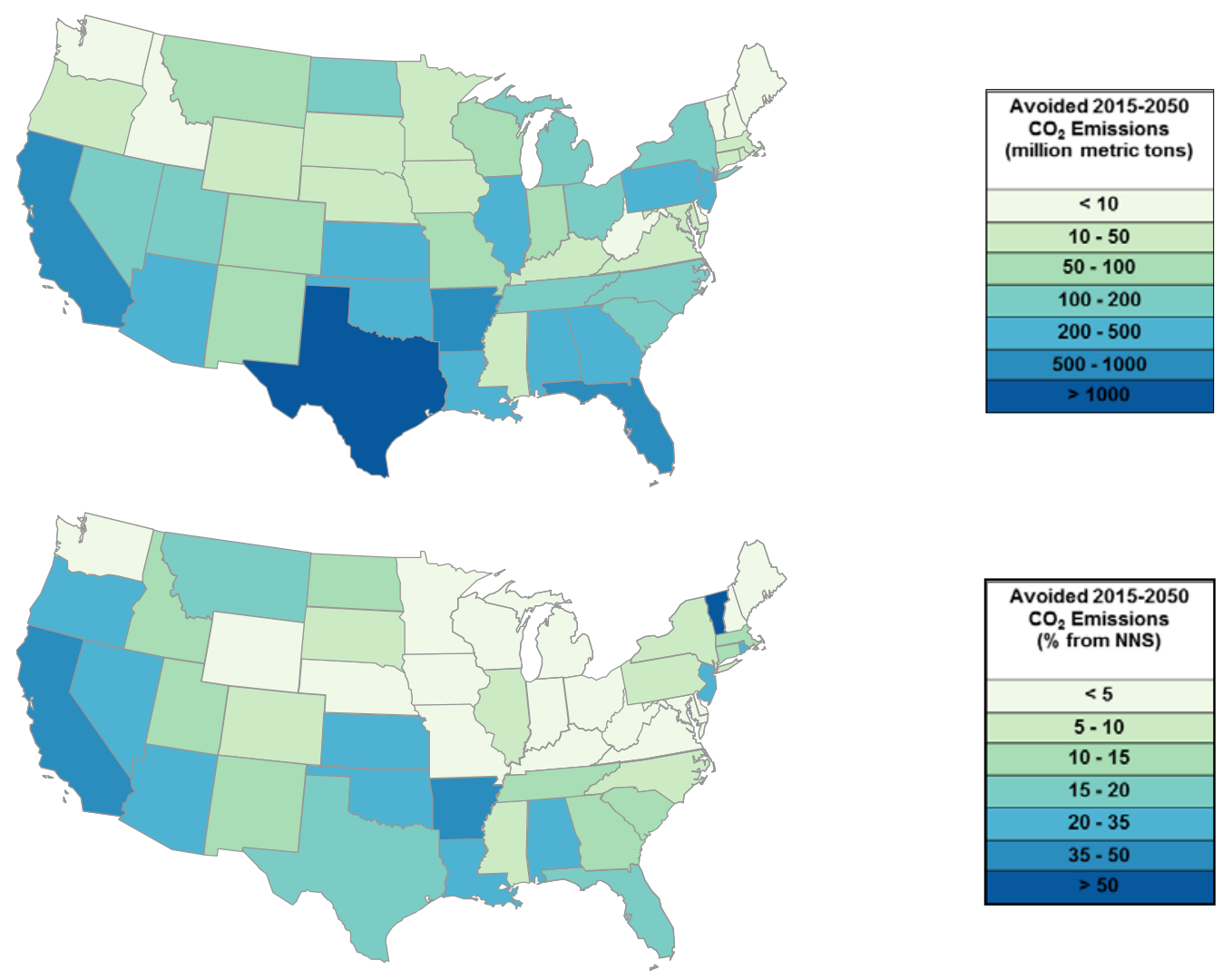

Figure 9. Cumulative 2015-2050 absolute (top) and percent (bottom) combustion-related $\mathrm{CO}_{2}$ reductions of the SunShot Vision Scenario relative to the NNS Baseline Scenario

Estimates of the monetary value of these GHG emissions reductions are sizable but span a large range (Figure 10). Using the IWG's "central" trajectory for the SCC, discounted, present-value global climate damage reductions from the SunShot Vision scenario equal \$259 billion. This is equivalent to a levelized benefit of solar of $2.2 \phi / \mathrm{kWh}$-solar. Across the full range of SCC estimates, total benefits span $\$ 56$ billion $(0.5 \notin / \mathrm{kWh}$-solar) to $\$ 789$ billion $(6.8 \notin / \mathrm{kWh}$-solar), a sizable range but significant even in the lower case. If, alternatively, solar is viewed as a way to meet future carbon-reduction requirements, then the present-value benefits of achieving the SunShot Vision scenario range from $\$ 60$ billion to $\$ 92$ billion $(0.5-0.8 \phi / \mathrm{kWh}$-solar) when only considering EPA CPP estimates, and from $\$ 142$ billion to $\$ 347$ billion (1.2-3.0ф/kWh-solar) when considering longer-term carbon-reduction policy possibilities. Under Synapse's "medium" trajectory for the cost of carbon, the SunShot Vision scenario yields $\$ 238$ billion in savings, which is equivalent to a levelized benefit of solar of $2.0 \notin / \mathrm{kWh}$-solar. In all cases, valuation estimates are based on emissions reductions that occur from 2015 through 2050: any emissions reductions after 2050 are not considered in our analysis. 


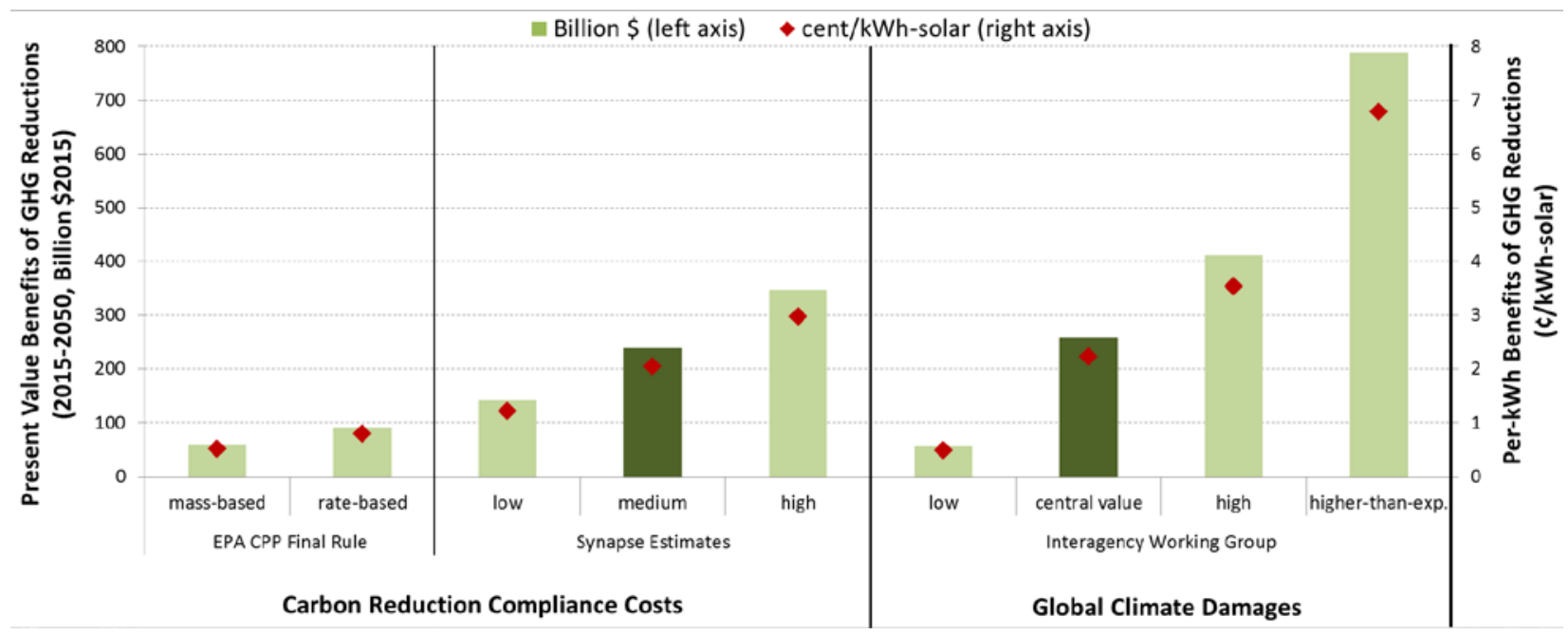

Figure 10. Estimated value of SunShot Vision Scenario GHG-reduction benefits 


\section{Air-Pollution Emissions}

Summary: Achieving the SunShot Vision scenario reduces emissions of sulfur dioxide $\left(\mathrm{SO}_{2}\right)$, nitrogen oxides $\left(\mathrm{NO}_{\mathrm{x}}\right)$, and fine particulate matter $\left(\mathrm{PM}_{2.5}\right)$ in the power sector by $14 \%, 14 \%$, and $13 \%$ in 2030 and $15 \%, 18 \%$, and $13 \%$ in 2050 , relative to the NNS baseline scenario. Cumulative emissions savings from 2015 to 2050 equal $9 \%, 11 \%$, and $8 \%$ of total power-sector $\mathrm{SO}_{2}, \mathrm{NO}_{x}$, and $\mathrm{PM}_{2.5}$ emissions, respectively. These reductions could produce $\$ 167$ billion of benefits to the United States in the form of lower future health and environmental damages based on central estimates, which is equivalent to a levelized benefit of solar of $1.4 \phi / \mathrm{kWh}$-solar. Across the full set of methods considered, total monetary benefits span $\$ 77$ billion ( $0.7 \varnothing / \mathrm{kWh}$-solar) to $\$ 298$ billion $(2.6 \phi / \mathrm{kWh}$-solar). These benefits derive, in large measure, from a reduction in premature mortality from sulfate particles from $\mathrm{SO}_{2}$ emissions - achieving the SunShot Vision scenario reduces premature mortalities by 25,000-59,000 based on methods developed at EPA.

\subsection{Introduction}

Combusting fuels to generate electricity produces air pollutants that harm human health and cause environmental damage (NRC 2010). Epidemiological studies have shown a causal association between increased mortality and morbidity and chronic exposure to air pollution, specifically exposure to $\mathrm{PM}_{2.5}$ (for examples of the association with mortality, see Dockery et al. 1993, Krewski et al. 2009, and Lepeule et al. 2012). Chronic exposure to elevated ozone levels is also associated with increased mortality and morbidity (for examples of the association with mortality, see Bell et al. 2004 and Levy et al. 2005). Combustion-based electricity generation can contribute to elevated $\mathrm{PM}_{2.5}$ levels through two pathways: through direct emissions of $\mathrm{PM}_{2.5}$ and through emissions of gases that undergo chemical reactions in the atmosphere and transform to $\mathrm{PM}_{2.5}$, including $\mathrm{SO}_{2}$ and $\mathrm{NO}_{\mathrm{x}} . \mathrm{SO}_{2}$ is transformed to sulfate particles in the atmosphere and NOx can undergo transformation to particulate nitrate under certain conditions. Power plants also contribute to ground-level ozone through emissions of $\mathrm{NO}_{\mathrm{x}}$, which, in combination with volatile organic compounds (VOC), can contribute to ozone formation.

Outdoor air pollution has a large impact both globally and in the United States. Lim et al. (2012), for example, report that more than 3 million premature deaths occur globally, each year, from outdoor particulate air pollution, and that outdoor particulate air pollution is the 14th leading modifiable risk factor for deaths in North America. In the United States, recent studies have evaluated the potential air-quality and public-health benefits of reducing combustion-based electricity generation. For example, Driscoll et al. (2015) found that policies aimed at reducing power-sector $\mathrm{CO}_{2}$ emissions would also reduce $\mathrm{PM}_{2.5}$ and ozone, preventing as many as 3,500 premature mortalities in 2020. Siler-Evans et al. (2013) value the health and environmental benefits of displaced conventional generation from new solar and wind power at $1 \phi / \mathrm{kWh}$ to $10 \notin / \mathrm{kWh}$, with the range largely reflecting locational differences; Buonocore et al. (2015) build on this work by further exploring how benefits vary by location and technology. EPA has estimated that its CPP would provide \$14-\$34 billion of monetized health co-benefits in 2030, mostly based on reducing premature mortality (EPA 2015d). 
Although all energy sources have environmental impacts, most renewable energy sourcesincluding PV and CSP - have no direct and also low life-cycle air-pollution emissions (IPCC 2011; Ricci 2010; Turconi et al. 2013). Achieving the SunShot Vision scenario, therefore, promises to reduce air-pollution emissions. In this section, we calculate those potential emissions reductions and present the associated public health and environmental benefits both in the form of health indicators and in monetary terms.

\subsection{Methods}

To value the potential air-quality benefits of achieving the SunShot Vision scenario, we estimate the reductions in emissions of $\mathrm{SO}_{2}, \mathrm{NO}_{\mathrm{x}}$, and $\mathrm{PM}_{2.5}$ from 2015 to 2050 in the SunShot Vision scenario relative to the NNS baseline scenario. We then quantify the public-health and environmental benefits of those changes in emissions in the form of reduced mortality and morbidity, and we translate them into monetary terms (Figure 11). Given uncertainty in pollutant transport, transformation, and exposure as well as uncertainty in the human response to ambient $\mathrm{PM}_{2.5}$ and ozone, we use multiple established methods to quantify the health and environmental outcomes and monetary benefits of the emissions changes. Our overall approach is similar to that used in the Wind Vision report (DOE 2015), and it is broadly consistent with methods used in Buonocore et al. (2015), Cullen (2013), Driscoll et al. (2015), EPA (2015d), Fann et al. (2012), Johnson et al. (2013), Novan (2014), NRC (2010), McCubbin and Sovacool (2013), and Siler-Evans et al. (2013).

We start with ReEDS-estimated, power-sector combustion-related $\mathrm{SO}_{2}$ and $\mathrm{NO}_{x}$ emissions in the SunShot Vision and NNS baseline scenarios. We then estimate power-sector $\mathrm{PM}_{2.5}$ emissions as a function of ReEDS generation by power plant type and location. xxxiii Incorporated in these estimates are assumptions about power-sector regulations that apply to emissions of $\mathrm{SO}_{2}$, $\mathrm{NO}_{\mathrm{x}}$ and/or $\mathrm{PM}_{2.5}$, such as MATS and CSAPR. ${ }^{\mathrm{xx} x \mathrm{v}}$

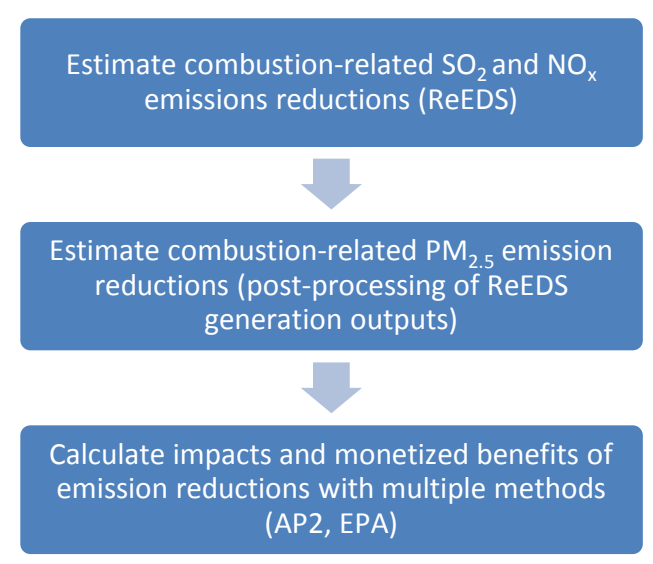

Figure 11. Overview of Methods: Air Pollution Emissions

We then calculate a range of health and environmental benefits (including reduced morbidity and mortality outcomes and total monetary value) from these emissions changes based on two different peer-reviewed approaches. Each approach accounts for pollutant transport and chemical transformation as well as population exposure and response: (1) the Air Pollution Emission Experiments and Policy analysis model (AP2, formerly APEEP; created by and described in Muller et al. 2011) and (2) EPA's benefit-per-ton methodology developed for the CPP (EPA 2015b; EPA 2015d). ${ }^{\mathrm{xxv}}$ The EPA CPP approach includes two estimates of the health impacts in order to span the uncertainty in the underlying epidemiological studies. ${ }^{\text {xxxvi }}$ Henceforth we refer to the two outputs from the EPA CPP approach as "EPA Low" and "EPA High." The "high" and "low" classification corresponds to differences only between the underlying health impact functions employed by EPA, and EPA does not favor either of its estimates over the other. We take the simple average of all three benefit estimates as the "central" value. One important assumption across all methods used is the monetary value of preventing a premature mortality 
(or the Value of Statistical Life, VSL). Consistent with the broader literature, all use a VSL of approximately $\$ 6$ million (in 2000\$). ${ }^{\text {xxxvii }}$

Several additional aspects of the methodology, and possible related limitations, deserve note:

- Our focus is on a subset of air emissions impacts: $\mathrm{SO}_{2}, \mathrm{NO}_{\mathrm{x}}$, and $\mathrm{PM}_{2.5}$. Environmental impacts that we do not evaluate include heavy metal releases, radiological releases, waste products, and land-use impacts associated with power and upstream fuel production as well as noise, aesthetics, and others. We only consider emissions from power plant operations, and so do not assess upstream and downstream life-cycle impacts.

- Our air emissions reduction estimates are inherently uncertain, in part owing to the impact of uncertain policy and market factors on those reductions.

- We do not consider the possible erosion of the air-quality benefits due to the increased cycling, ramping, and part loading required of fossil generators in electric systems with higher penetrations of variable renewable generation. Literature suggests that this omission will not alter dramatically the basic results reported here. ${ }^{\text {xxxviii }}$

- Our methodology presumes that MATS is maintained or replaced with a similar regulation such that $\mathrm{SO}_{2}$ and $\mathrm{NO}_{x}$ cap-and-trade programs, such as CSAPR, are essentially non-binding over time: otherwise, the benefits of achieving the SunShot Vision scenario should arguably be valued at allowance prices to reflect savings in the cost of complying with the cap (SilerEvans et al. 2013). ${ }^{\text {xxxix }}$

- Estimates of the health and environmental benefits associated with emissions reductions are inherently uncertain. We reflect some — but not all —of those uncertainties by calculating benefits using two approaches (AP2, EPA) leading to three different estimates (AP2, EPA Low and High).

\subsection{Results}

The Achieving the SunShot Vision scenario reduces national power sector emissions of $\mathrm{SO}_{2}$, $\mathrm{NO}_{\mathrm{x}}$, and $\mathrm{PM}_{2.5}$ by $14 \%, 14 \%$, and $13 \%$ in 2030 and by $15 \%, 18 \%$, and $13 \%$ in 2050 , relative to the NNS baseline scenario (Figure 12). Cumulative emission savings from 2015 to 2050 equal $3.8,5.1$, and 0.6 million metric tons, or $9 \%, 11 \%$, and $8 \%$ of total power-sector emissions for $\mathrm{SO}_{2}, \mathrm{NO}_{\mathrm{x}}$, and $\mathrm{PM}_{2.5}$, respectively.

As shown in Figure 13, the emissions savings are spread widely across the United States but with some concentration in Texas, Oklahoma, Louisiana, Arkansas, and the broader Southeastern region. These results are driven both by the amount of solar deployment in each states (see Section 3) and by the regions in which high-emitting coal generation is displaced. 

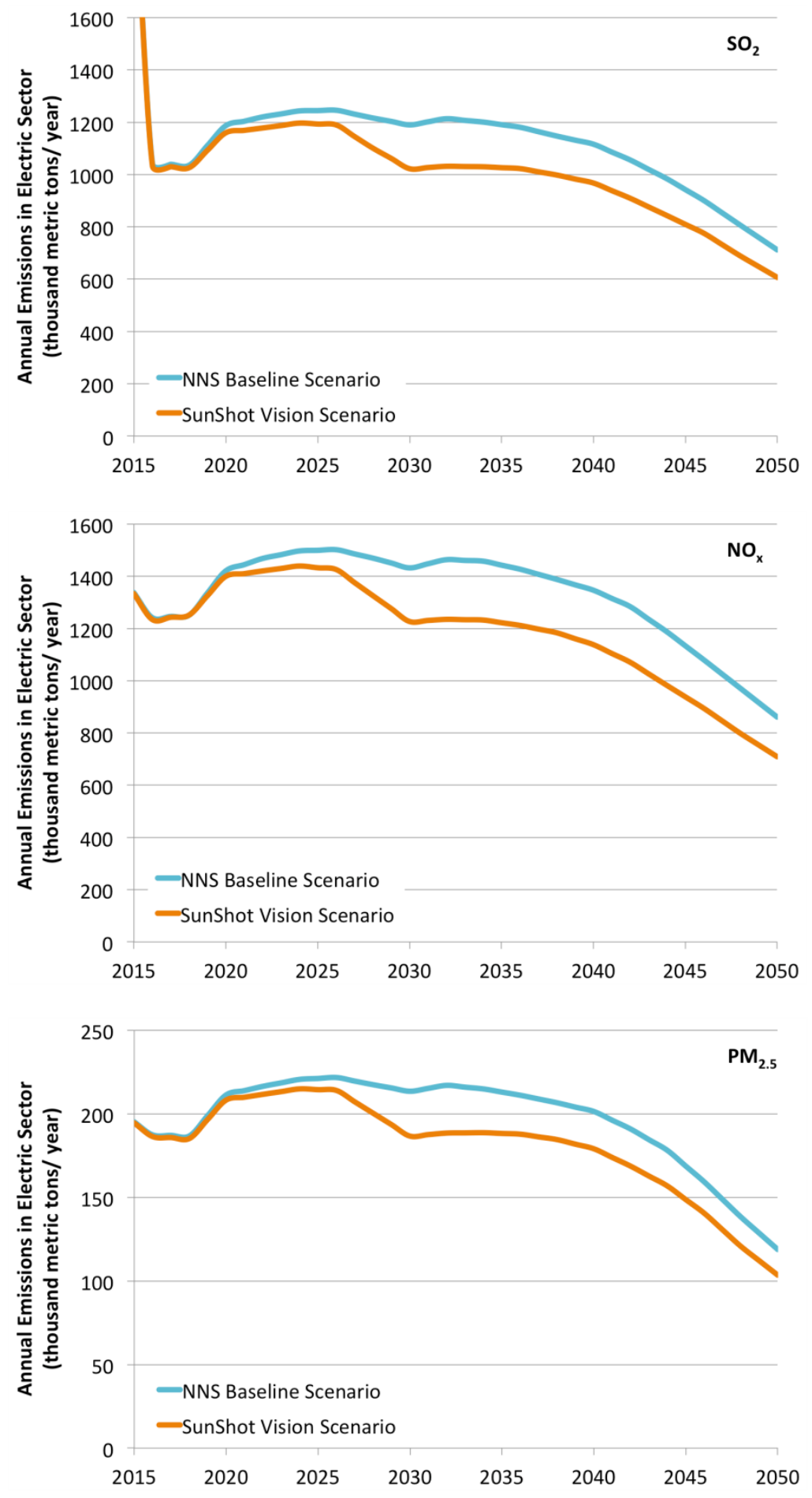

Figure 12. Power-sector SO2, NOx, and PM2.5 emissions impacts of SunShot Vision Scenario 
(a) $\mathrm{SO}_{2}$ reductions $(3,800,000$ metric tons total $)$
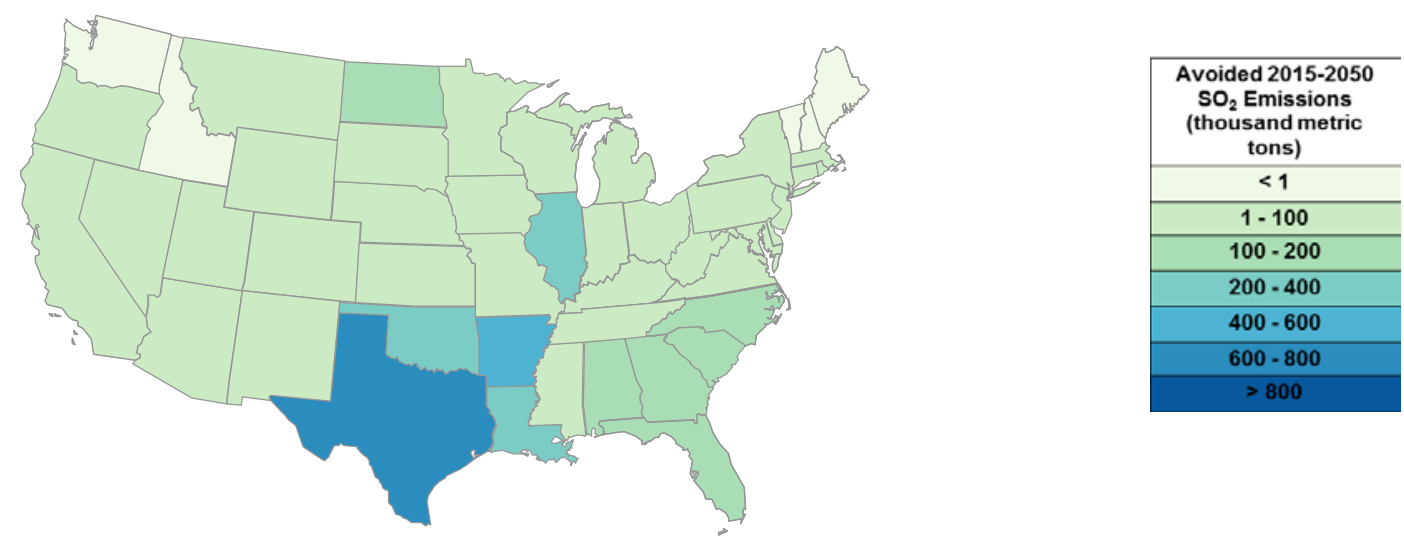

(b) $\mathrm{NO}_{x}$ reductions $(5,100,000$ metric tons total $)$
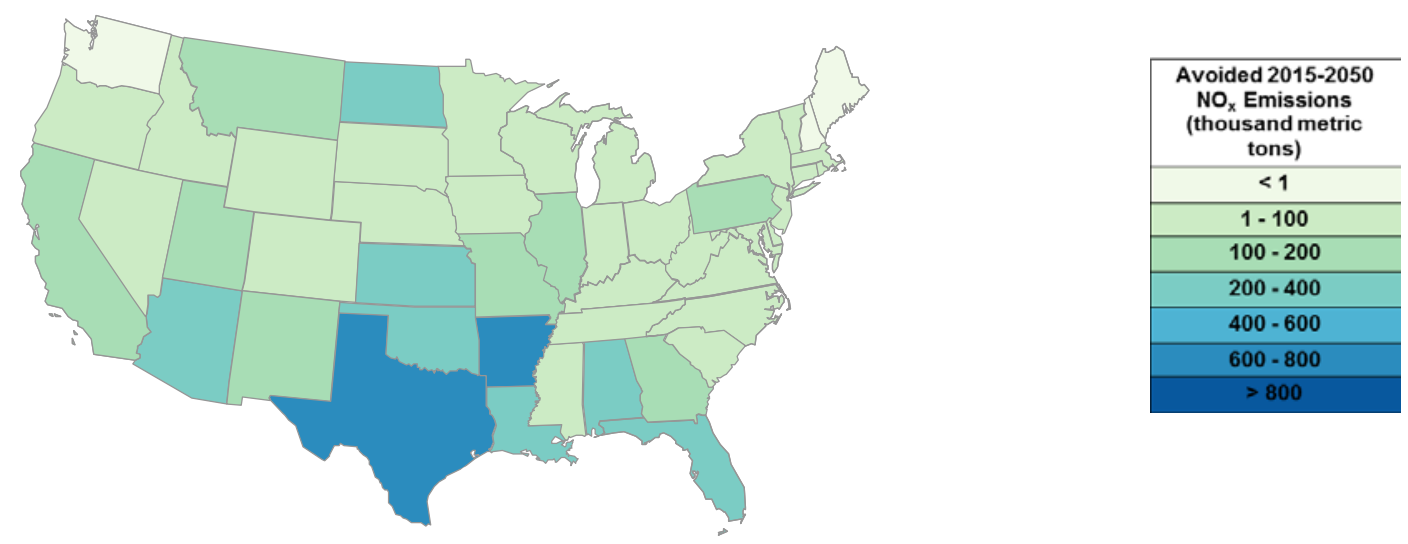

(c) $\mathrm{PM}_{2.5}$ reductions $(600,000$ metric tons total)
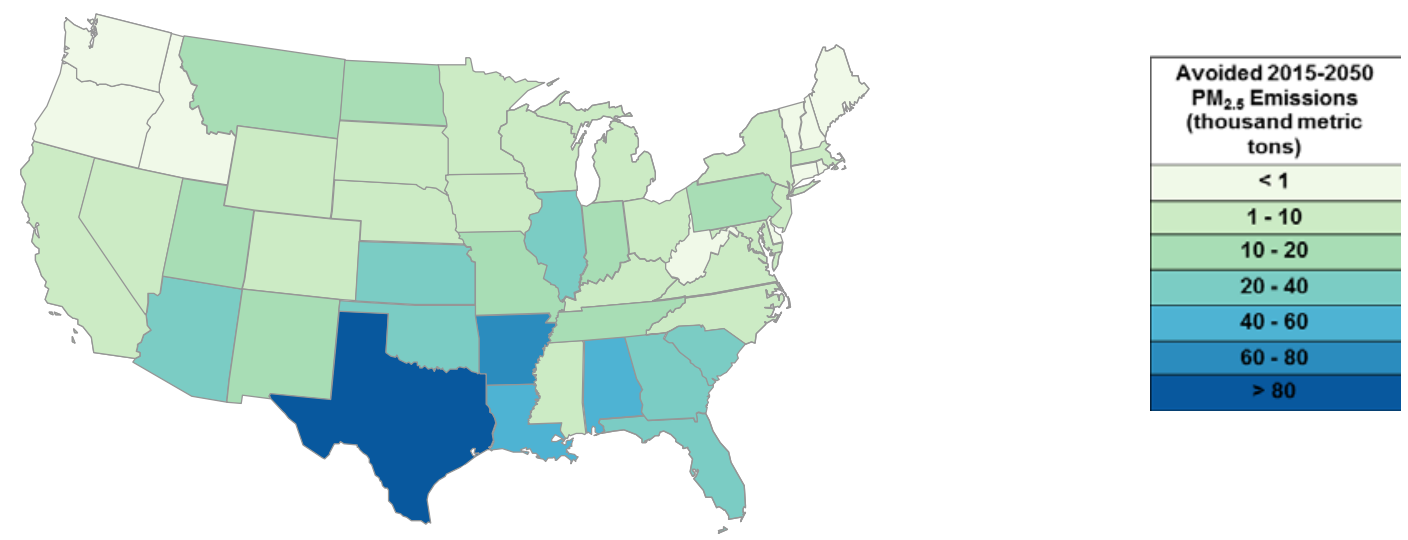

Figure 13. Cumulative 2015-2050 emissions reductions of $\mathrm{SO}_{2}(\mathrm{a}), \mathrm{NO}_{\mathrm{x}}(\mathrm{b})$, and $\mathrm{PM}_{2.5}(\mathrm{c})$ in the SunShot Vision Scenario relative to the NNS Baseline Scenario

All units in thousands of metric tons; note smaller scale for $\mathrm{PM}_{2.5 .}$ 
These emissions reductions lead to improved air quality and health outcomes across the continental United States. Specifically, total U.S. health and environmental benefits from the SunShot Vision scenario fall in the range of \$77-\$298 billion on a discounted, present-value basis, depending on the method used to quantify those benefits. The average "central" estimate is $\$ 167$ billion, which is equivalent to a levelized benefit of solar of $1.4 \mathrm{k} / \mathrm{kWh}$-solar; the total range is $0.7-2.6 \notin / \mathrm{kWh}$-solar (Figure 14). The range of benefits estimates reflects uncertainties in how to value emissions reductions, but the benefits are sizable even under the lowest AP2 estimate. All of the valuation estimates are based on emissions reductions that occur from 2015 through 2050: any emissions reductions after 2050 are not considered in our analysis.

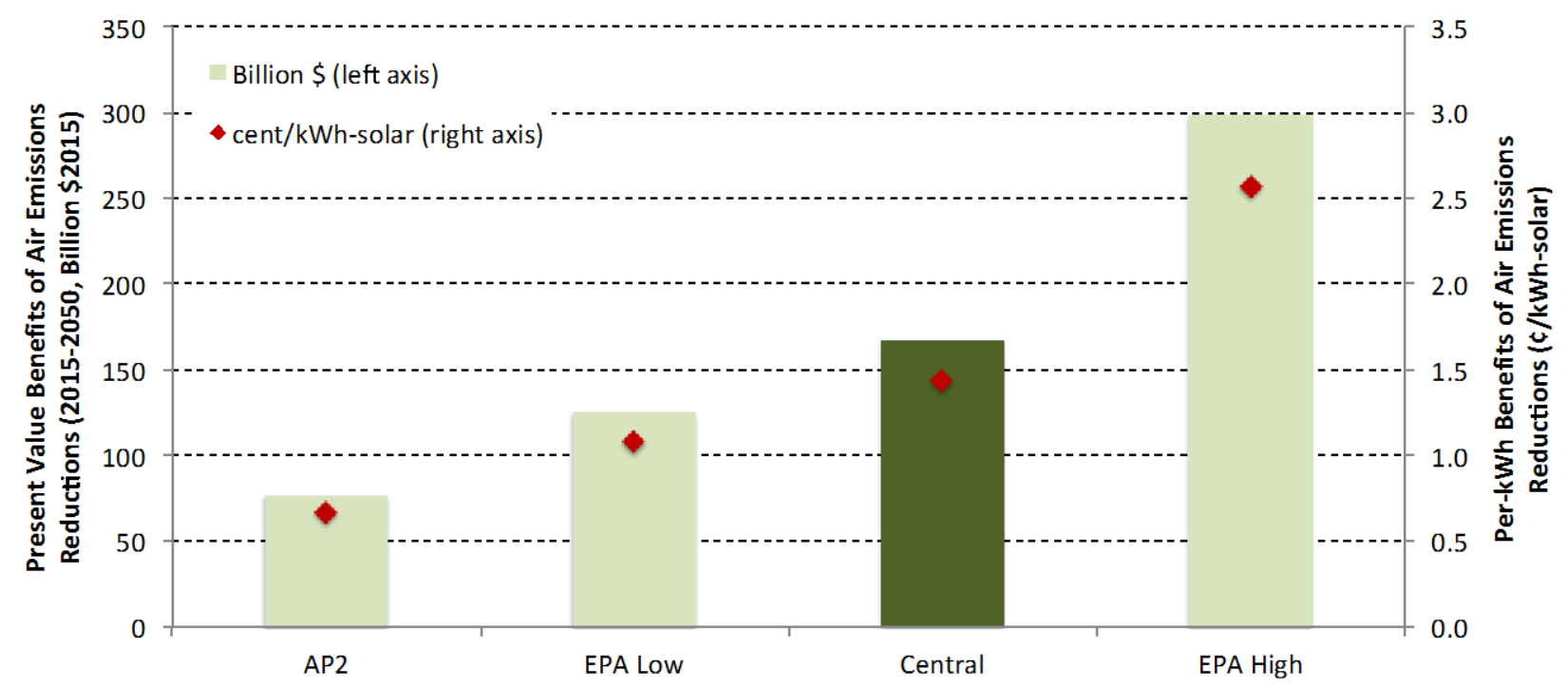

Figure 14. Estimated value of SunShot Vision Scenario $\mathrm{SO}_{2}, \mathrm{NO}_{\mathrm{x}}$, and $\mathrm{PM}_{2.5}$ benefits

Reduction of $\mathrm{SO}_{2}$ and the subsequent reduction of particulate sulfate concentrations account for most of the monetized benefits. For example, reduced $\mathrm{SO}_{2}$ emissions accounted for $61 \%, 73 \%$, and $68 \%$ of the AP2, EPA Low, and EPA High benefit estimates, respectively. The benefits of reduced tropospheric ozone (due to reduced $\mathrm{NO}_{\mathrm{x}}$ emissions) were relatively small, accounting for $7 \%$ and $14 \%$ of the EPA Low and High benefit estimates, respectively. ${ }^{\mathrm{xl}}$ Clearly, exposure to particulates (directly or indirectly from emissions of $\mathrm{SO}_{2}, \mathrm{NO}_{\mathrm{x}}$ and $\mathrm{PM}_{2.5}$ ) is the primary driver of health outcomes.

Most of the health benefits come from avoided premature mortality, again primarily associated with reduced chronic exposure to ambient $\mathrm{PM}_{2.5}$ (largely derived from the transformation of $\mathrm{SO}_{2}$ to sulfate and $\mathrm{NO}_{\mathrm{x}}$ to nitrate particles). Based on the EPA approach, achieving the SunShot Vision scenario prevents 25,000-59,000 premature mortalities in total from 2015 to 2050. Achieving the SunShot Vision scenario also would result in numerous forms of avoided morbidity outcomes (Table 1), including 30,800 hospital admissions for respiratory and cardiovascular symptoms, 2.5 million lost work days, and 2.5 million missed school days. 
Table 1. Emissions Reductions, Monetized Benefits, and Mortality and Morbidity Benefits over 2015-2050 for the SunShot Vision Scenario Relative to the NNS Baseline Scenario

\begin{tabular}{|c|c|c|c|c|}
\hline Impacts & $\mathrm{SO}_{2}$ & $\mathbf{N O}_{\mathrm{x}}$ & $\mathbf{P M}_{2.5}$ & Total \\
\hline \multicolumn{5}{|l|}{ Emissions Reductions: 2015-2050 } \\
\hline $\begin{array}{l}\text { SunShot Vision scenario air-pollution reductions } \\
\text { (millions metric tons) }\end{array}$ & 3.8 & 5.1 & 0.6 & --- \\
\hline \multicolumn{5}{|c|}{ Total Monetized Benefits (Present Value, 2015-2050) } \\
\hline EPA Low benefits (billions $2015 \$$ ) & 92 & 21 & 13 & 125 \\
\hline EPA High benefits (billions $2015 \$$ ) & 202 & 67 & 28 & 298 \\
\hline AP2 benefits (billions $2015 \$$ ) & 47 & 20 & 10 & 77 \\
\hline \multicolumn{5}{|l|}{ EPA Total Mortality Reductions: 2015-2050 } \\
\hline EPA Low mortality reductions (count) & 18,000 & 4,000 & 3,000 & 25,000 \\
\hline EPA High mortality reductions (count) & 41,000 & 12,000 & 6,000 & 59,000 \\
\hline
\end{tabular}

EPA Morbidity Reductions from Primary and Secondary PM 2.5 Impacts: 2015-2050

Emergency department visits for asthma (all ages)

4,200

Acute bronchitis (age 8-12)

Lower respiratory symptoms (age 7-14)

Upper respiratory symptoms (asthmatics age 9-11)

Minor restricted-activity days (age 18-65)

Lost work days (age 18-65)

Asthma exacerbation (age 6-18)

Hospital admissions-respiratory (all ages)

Hospital admissions-cardiovascular (age $>18$ )

Non-fatal heart attacks (Peters et al. 2001)

Non-fatal heart attacks (Pooled estimates, 4 studies)

5,600

7,300

2,400
EPA Morbidity Reductions from $\mathrm{NO}_{\mathrm{x}}$--> Ozone Impacts

Hospital admissions, respiratory (ages $>65$ )

Hospital admissions, respiratory (ages $<2$ )

Emergency room visits, respiratory (all ages)

Acute respiratory symptoms (ages 18-65)

School loss days
24,400

312,800

486,700

$11,995,300$

$1,959,600$

$1,083,800$

21,600

600

3,400

42,200

61,200

$1,593,800$

257,300

153,400

700

900

2,800

300

10,500

4,000

---

---

10,500

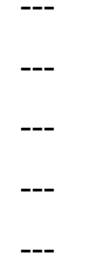

800

3,500

44,400

63,800

$1,657,700$

272,000

151,800

800

1,000

3,100

300
5,600

31,300

399,400

611,700

$15,246,800$

$2,488,900$

$1,389,000$

7,100

9,200

27,500

3,000

Monetized benefits are discounted at 3\% (real), but emissions reductions and mortality and morbidity values are simply summed over the 2015-2050 period. EPA benefits derive from mortality and morbidity estimates based on population exposure to direct emissions of $\mathrm{PM}_{2.5}$ and secondary $\mathrm{PM}_{2.5}$ (from $\mathrm{SO}_{2}$ and $\mathrm{NO}$ x emissions) as well as ozone exposure from NOx emissions during the ozone season (May-September). AP2 benefits are derived from mortality and morbidity estimates based on population exposure to direct emissions of $\mathrm{PM}_{2.5}, \mathrm{SO}_{2}$, and $\mathrm{NO} x$ and secondary $\mathrm{PM}_{2.5}$ (from $\mathrm{SO}_{2}$ and $\mathrm{NO}$ emissions) as well as ozone exposure from $\mathrm{NO}$ emissions during the ozone season (May-September). AP2 benefits also include consequences from decreased timber and agriculture yields, reduced visibility, accelerated degradation of materials, and reductions in recreation services. 


\section{Water Use Reductions}

Summary: Achieving the SunShot Vision scenario reduces power-sector water withdrawals by $8 \%$ in 2030 and $5 \%$ in 2050, relative to the NNS baseline scenario; water consumption is reduced by $10 \%$ in 2030 and $16 \%$ in 2050 . Water consumption savings in 2050 alone could supply the annual water demands of more than 1.3 million U.S. households. Cumulative water impacts from 2015 to 2050 equal 46 trillion gallons of avoided withdrawals (4\% of total power-sector withdrawals) and 5 trillion gallons of avoided consumption ( $9 \%$ of total power-sector consumption). By 2050 , water withdrawals in the continental United States are lower than the NNS baseline scenario in 35 of 48 states, and water consumption is lower in 36 of 48 states. Importantly, drought-prone and arid states are among those with the largest reductions in water use. These results assume dry cooling for CSP plants. Even under SunShot Vision scenarios in which wet-cooled and hybridcooled CSP systems are deployed, however, 2050 national water withdrawal and consumption reductions equal $5 \%$ and $12 \%$, respectively, relative to the NNS baseline scenario. State-level water impacts vary when including wet- and hybrid-cooled CSP systems.

\subsection{Introduction}

The electric sector relies on readily available supplies of water for reliable operations. Most water requirements are for thermal plant cooling, but all life-cycle stages of energy production require water. Although energy supply can also affect water resources through changes in water quality and temperature, water use is typically categorized into two metrics: withdrawal and consumption. Withdrawals are defined as the amount of water removed or diverted from a water source for use, while consumption is the amount of water evaporated, transpired, incorporated into products or crops, or otherwise removed from the immediate water environment (Kenny et al. 2009). The U.S. power sector is the largest withdrawer of water in the nation, at $38 \%$ of total withdrawals (Maupin et al. 2014). Its share of consumption is much lower, around 3\% nationally, but can be regionally important (Solley et al. 1998). Water availability can impact the electric system in multiple ways, including influencing new capacity decisions (Averyt et al. 2011; Macknick et al. 2015) and power plant operations and reliability (DOE 2013; Rogers et al. 2013). In turn, water availability and quality for other competing uses are impacted by the power sector. Moreover, future uncertainties around water availability and temperature, including those associated with climate change may exacerbate vulnerabilities and water-related costs in the power sector (Cohen et al. 2014; DOE 2013; Melillo et al. 2014).

Prior studies have evaluated the impact of a range of U.S. electric sector futures on water demands (Arent et al. 2014; Chandel et al. 2011; Clemmer et al. 2013; DOE 2015; Macknick et al. 2012b; Roy et al. 2012; Tidwell et al. 2013; van Vliet et al. 2012). Many renewable energy technologies have low operational (see Methods discussion below) and life-cycle (see Macknick et al. 2012a; Meldrum et al. 2013) water use compared to fossil and nuclear technologies. As a result, prior work generally finds that future scenarios designed to meet carbon-reduction goals also result in water savings, particularly when renewable-based pathways are envisioned (Clemmer et al. 2013; Macknick et al. 2012b). 
Given the relatively low water-use intensity of PV and dry-cooled CSP technologies, achieving the SunShot Vision scenario promises to reduce power-sector water use, potentially providing economic and environmental benefits. Some states have already proposed measures to reduce the water intensity of the electricity produced in their states, and EPA has invoked the Clean Water Act to propose various measures to limit the impacts of thermal power plant cooling on aquatic habitats (EPA 2011). To the extent that solar deployment can reduce power-sector water demands, it might also reduce the cost of meeting future policies intended to manage water use. In this section, we calculate the potential water withdrawal and consumption impacts of achieving the SunShot Vision scenario, both nationally and regionally, and discuss the possible benefits of the resulting reduced water demands.

\subsection{Methods}

This section evaluates the potential operational water withdrawal and consumption impacts associated with achieving the SunShot Vision scenario compared to the NNS baseline scenario (Figure 15). Results are presented on a national and state basis - regional impacts are essential because water resources are managed locally, and water is not easily transferred across basins. Consistent with the SunShot Vision Study (DOE 2012), we assume new capacity builds of CSP technologies use dry cooling under the core SunShot Vision scenario; however, we present an alternative scenario that includes wet and hybrid cooling as well. Finally, the benefits of water use reductions are described qualitatively, given limitations to monetary quantification.

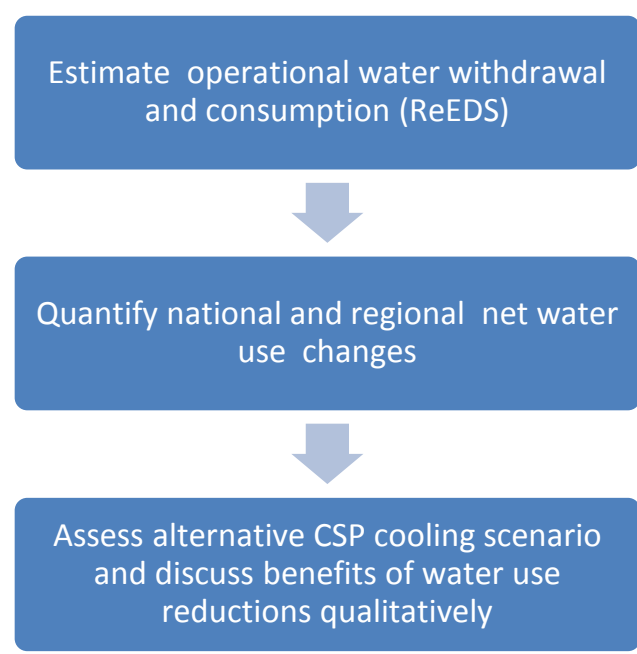

Figure 15. Overview of Methods: Water Use Reductions

ReEDS was used to compute power-sector water withdrawal and consumption in the SunShot Vision and NNS baseline scenarios. ReEDS incorporates the cost, performance, and water-use characteristics of different generation technology and cooling-system combinations, and it considers water availability as a limiting condition for new power plant construction (Macknick et al. 2015). Cooling systems for thermal power plants implemented in ReEDS fall into four categories: once-through, pond, recirculating, and dry cooling. ${ }^{x l i}$ Consistent with prior studies and proposed EPA regulations, our analysis does not allow new power plants in ReEDS to employ once-through cooling technologies (Macknick et al. 2012b; Tidwell et al. 2013). The basic approach used here has been applied in multiple studies evaluating the national and regional water impacts of the U.S. electricity sector (Clemmer et al. 2013; DOE 2015; Macknick et al. 2012b; Macknick et al. 2015; Rogers et al. 2013).

Our analysis focuses exclusively on operational water-use requirements. These requirements can vary greatly depending on fuel type, power plant type, and cooling system, and many renewable energy technologies have relatively low operational water withdrawal and consumption intensities (Figure 16). Thermal power plants using once-through cooling withdraw far more water for every megawatt-hour of electricity generated than do plants using recirculating cooling systems. For water consumption, however, once-through cooling has lower demands than 
recirculating systems. Dry cooling can be used to reduce both water withdrawal and consumption for thermal plants, but at a cost and efficiency penalty (EPA 2009). Non-thermal renewable energy technologies, such as PV and wind, do not require water for cooling and thus have very low operational water-use intensities. Some PV facilities use a relatively small amount of water for washing panels, but not every PV facility washes panels. CSP facilities can use dry-cooling systems to minimize water use; wet and hybrid cooling impose greater water demands.

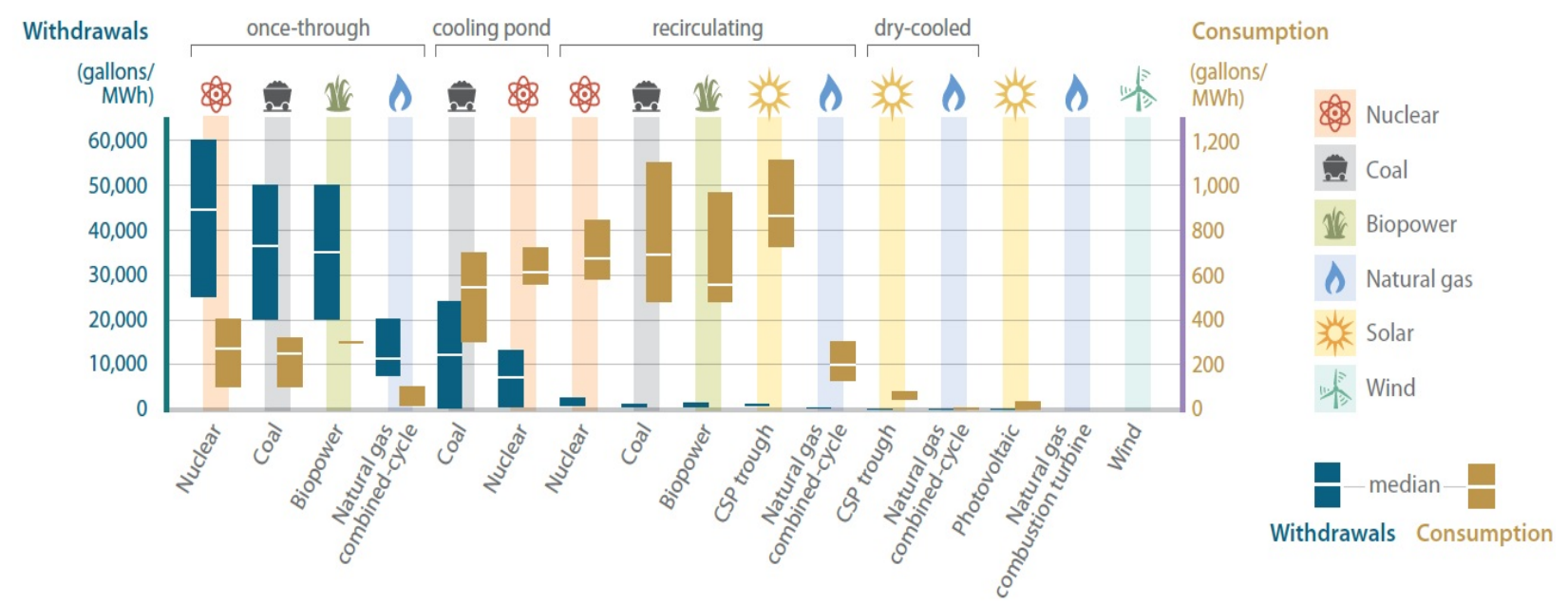

Figure 16. Operational water withdrawal and consumption requirements by generation technology and cooling system

Averyt et al. 2011

Although the core SunShot Vision scenario assumes all new CSP capacity uses dry cooling, we performed a sensitivity analysis to analyze variations in water use resulting from different CSP cooling systems. ${ }^{\text {xlii }}$ In this sensitivity analysis, new CSP capacity is built assuming an equal distribution (one third each) of dry cooling, wet cooling using a recirculating cooling system, and hybrid wet-dry-cooling. Wet-cooled CSP systems can withdraw and consume water at 10 times the rate of dry cooling, with hybrid-cooled CSP systems falling in between (Turchi et al. 2010; Macknick et al. 2012b). Wet- and hybrid-cooled CSP systems generally have lower costs and higher efficiencies than dry-cooled CSP systems; these benefits and tradeoffs are not included in the sensitivity analysis, because we focus exclusively on environmental outcomes.

Several additional aspects of the methodology, and possible related limitations, deserve note.

- This analysis does not estimate full life-cycle water uses, including upstream processes such as construction, manufacturing, and fuel supply. Including these requirements would likely increase the water savings from the SunShot Vision scenario, but associating upstream water uses to regions is challenging. Moreover, although life-cycle water demands for solar technologies can sometimes impose challenges (e.g., construction-related water requirements in arid regions), prior work has demonstrated that thermoelectric water withdrawals and consumption during plant operations are orders of magnitude greater than the demands from other life-cycle stages (Meldrum et al. 2013). 
- Power-sector water use will be impacted by various possible changes in the electric sector, such as coal-plant retirements, new combined-cycle natural gas plant construction, and the increased use of dry cooling. These changes, in turn, may be driven in part by future, uncertain water policies, and they could affect the estimated water savings under the SunShot Vision scenario.

- Although water resource impacts are described regionally at the state level, there can be considerable variation in water resource availability and impacts within a given state; evaluating water impacts on a smaller watershed level could partially address this limitation.

The benefits of water-use reductions are not quantified in monetary terms owing to challenges associated with quantifying the value of water resource services (DOE 2015).

\subsection{Results}

Achieving the SunShot Vision scenario reduces national power-sector water withdrawal and consumption, both compared with recent use and compared with the NNS baseline scenario.

Figure 17 shows the decline in annual power-sector water withdrawals for the SunShot Vision and NNS baseline scenarios, in total and by fuel type. On a national level, withdrawals decline substantially over time under both scenarios, largely owing to the retirement and reduced operations of once-through-cooled thermal facilities and the assumed replacement of those plants with newer, less water-intensive generation and cooling technologies. In the NNS baseline scenario, once-through-cooled plants are largely replaced by new thermal plants using recirculating cooling and wind power capacity. In the SunShot Vision scenario, water-intensive plants are also replaced by solar energy. As a result, national power-sector withdrawals are $8 \%$ lower in 2030 (3.0 trillion gallons) and 5\% lower in 2050 (0.7 trillion gallons) in the SunShot Vision scenario than in the NNS baseline scenario. Cumulative water withdrawal savings from 2015 to 2050 total 46 trillion gallons, or $4 \%$ of total power-sector withdrawals over that time period. In comparison to 2015 values, SunShot Vision scenario water withdrawals are $68 \%$ lower in 2050 .

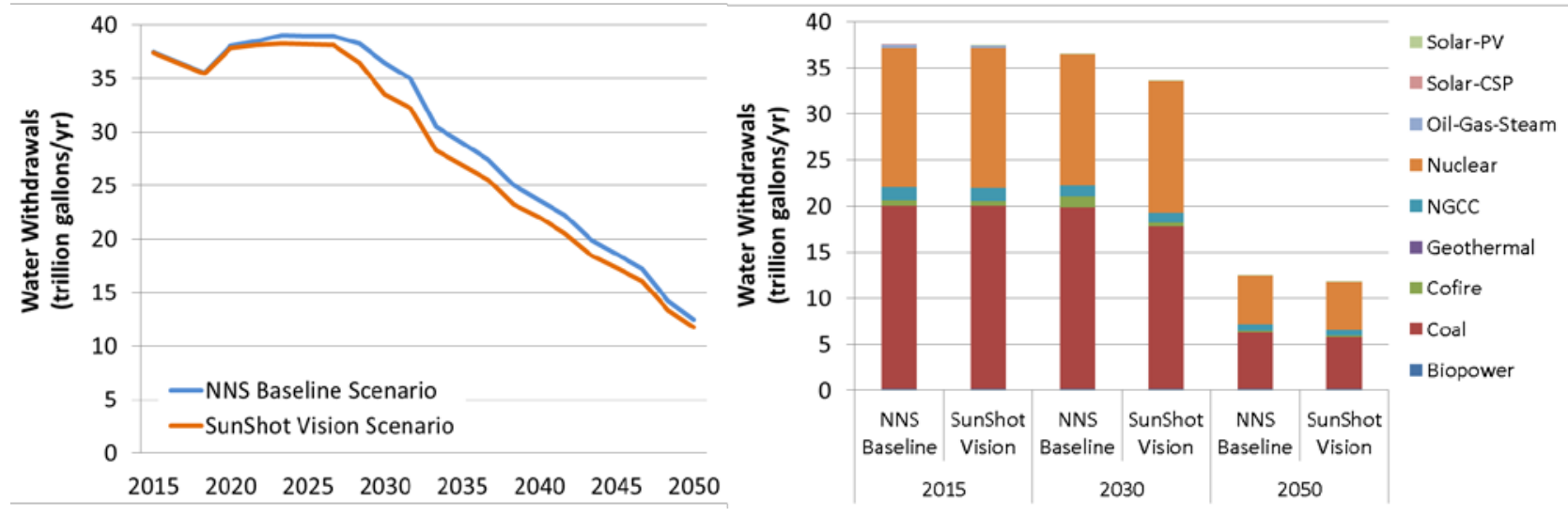

NGCC = natural-gas combined cycle; Cofire: biomass-fossil cofiring

Figure 17. Power-sector water withdrawal impacts of SunShot Vision Scenario from 2015 to 2050 (left) and by Fuel Type in 2015, 2030, and 2050 (right) 
Figure 18 shows the change in annual power-sector water consumption for the SunShot Vision and NNS baseline scenarios, in total and by fuel type. National power-sector water consumption declines over time in both scenarios, but to a lesser extent than water withdrawals. Consumption decreases sooner and more significantly in the SunShot Vision scenario. The delayed decrease in water consumption in the NNS baseline scenario is caused by the assumed replacement of oncethrough-cooled plants with those using recirculating cooling systems (because recirculating cooling has higher water consumption). Such cooling-system changes also occur in the SunShot Vision scenario, but the greater penetration of solar energy reduces water consumption for the sector as a whole. Overall, national power-sector consumption is 10\% lower in 2030 (160 billion gallons) and 16\% lower in 2050 (200 billion gallons) in the SunShot Vision scenario than in the NNS baseline scenario. The estimated 2050 water consumption savings roughly equate to the annual water use of approximately 1.3 million U.S. households. Cumulative water consumption savings from 2015 to 2050 total 5 trillion gallons, or $9 \%$ of total power-sector consumption over that time period. In comparison to 2015 values, SunShot Vision scenario consumption is $28 \%$ lower in 2050.
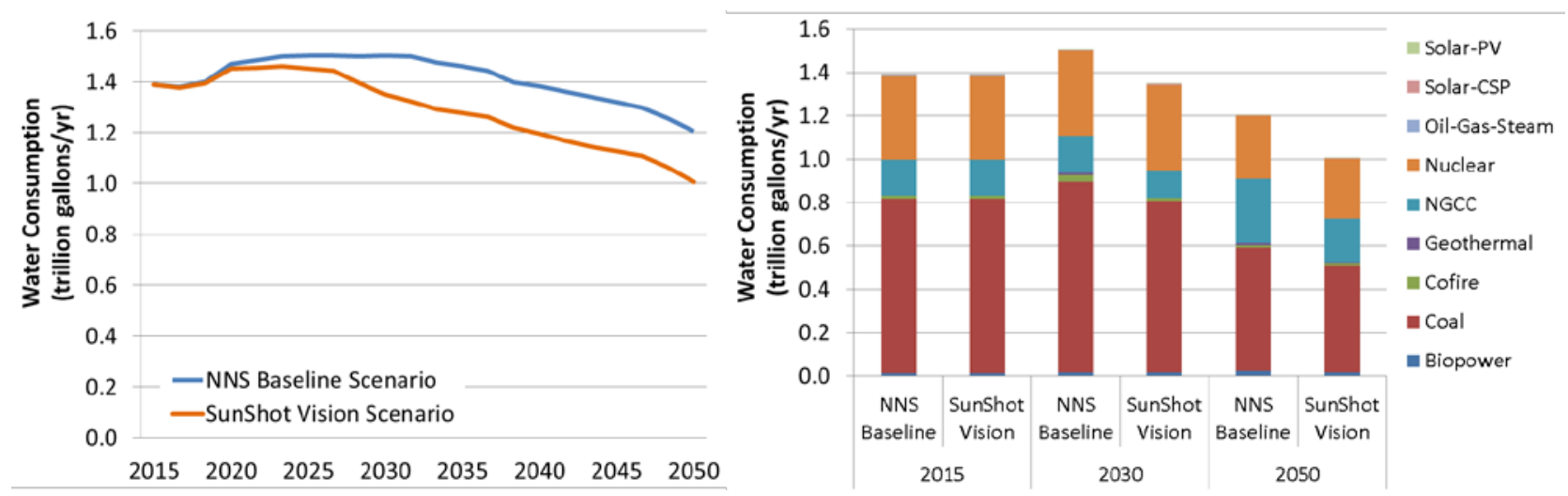

NGCC = natural-gas combined cycle; Cofire: biomass-fossil cofiring

Figure 18. Power-sector water consumption impacts of the SunShot Vision Scenario from 2015 to 2050 (left) and by fuel type in 2015, 2030, and 2050 (right)

Water withdrawal and consumption impacts under the SunShot Vision scenario are not uniform throughout the continental United States (Figure 19). Focusing first on withdrawal, by 2050, 35 of 48 states have lower withdrawals in the SunShot Vision scenario than in the NNS baseline scenario, a reflection of where solar capacity is deployed and where the most water-intensive thermal plants are offset. The largest water withdrawal reductions are seen in Texas, Louisiana, Florida, and California, with substantial reductions seen in the Southwest, Southeast, Central, and Mid-Atlantic regions. For water consumption, by 2050, 36 of 48 states have lower consumption in the SunShot Vision scenario than in the NNS baseline scenario. States with the largest consumption savings include California, Texas, Arkansas, and Florida, with substantial reductions seen in the Southwest, Southeast, and Mid-Atlantic regions. Many states with increases in water withdrawals also see slight increases in consumption. ${ }^{\text {xliii }}$ 
(a) 2050 Avoided Water Withdrawal ( 700 billion gallons)
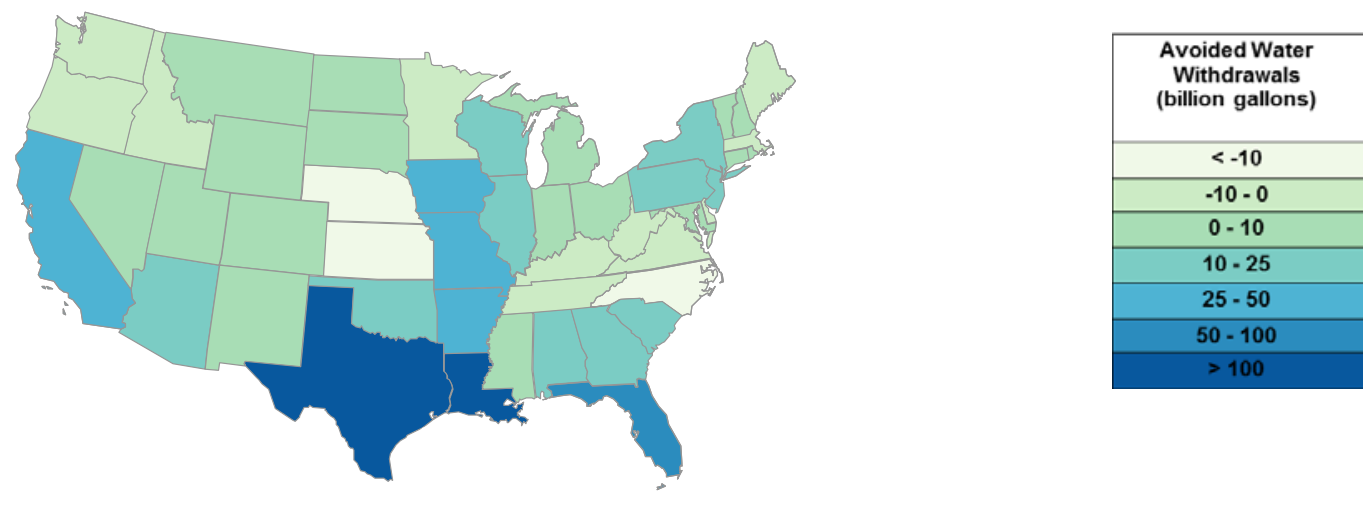

(b) 2050 Avoided Water Consumption ( 200 billion gallons)
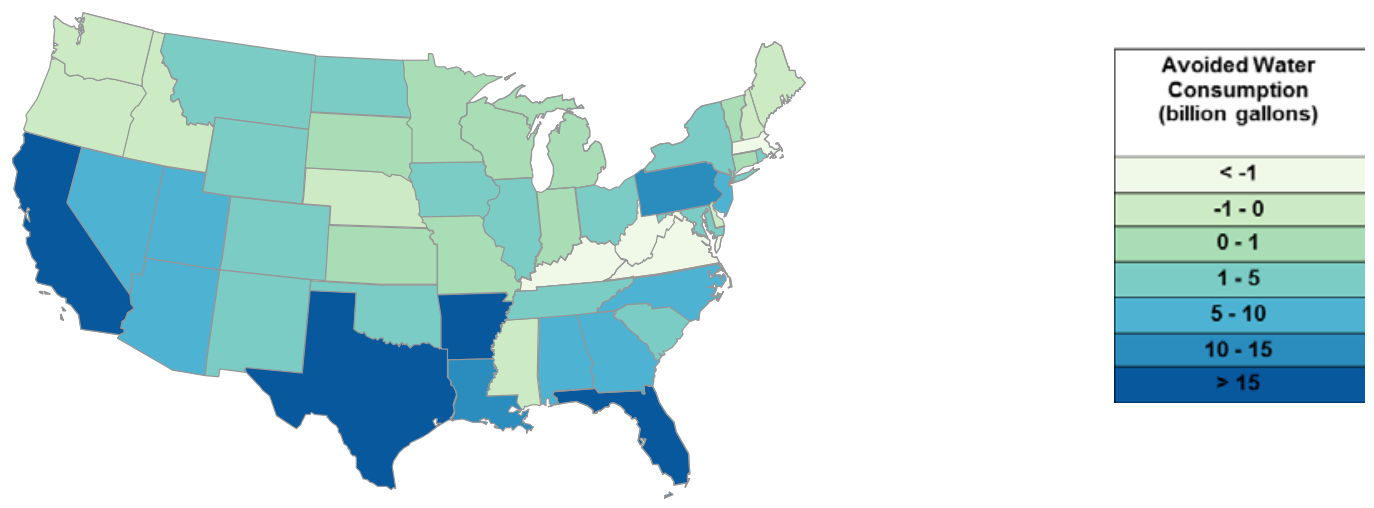

Figure 19. Changes in water withdrawals (top) and water consumption (bottom) in the SunShot Vision Scenario Relative to the NNS Baseline Scenario

The water consumption and withdrawal savings described above assume that all new CSP plants are deployed with dry-cooling technologies. To evaluate the robustness of these impacts to different assumptions about CSP cooling, we considered a scenario in which new CSP capacity is built with equal shares of dry cooling, wet cooling, and hybrid wet-dry cooling systems. Because wet-cooled CSP systems are assumed to use recirculating cooling, whether wet, dry, or hybrid cooling is used has a larger impact on consumption than on withdrawals; we therefore focus on consumption impacts. As shown in Figure 20, of the eight states with CSP deployment, six still show lower levels of water consumption in 2050 under the SunShot cooling-sensitivity scenario than under the NNS baseline scenario-California and New Mexico are the exceptions, although New Mexico's water consumption under the sensitivity scenario is still lower than its consumption in 2015. California's increased consumption is largely due to its relatively low levels of consumption in 2015 and the transition of once-through-cooled thermal generators on the coast to inland-based generation using freshwater. ${ }^{\text {xliv }}$ Relatively high levels of modeled CSP deployment in California indicate that CSP cooling system decisions can affect state-level power-sector water use. That said, on a national basis, 2050 water withdrawals remain 5\% lower in the SunShot cooling-sensitivity scenario than in the NNS baseline scenario, and 2050 water 
consumption is $12 \%$ lower, demonstrating that significant national water-use reductions are anticipated even if dry cooling is not deployed in all cases.

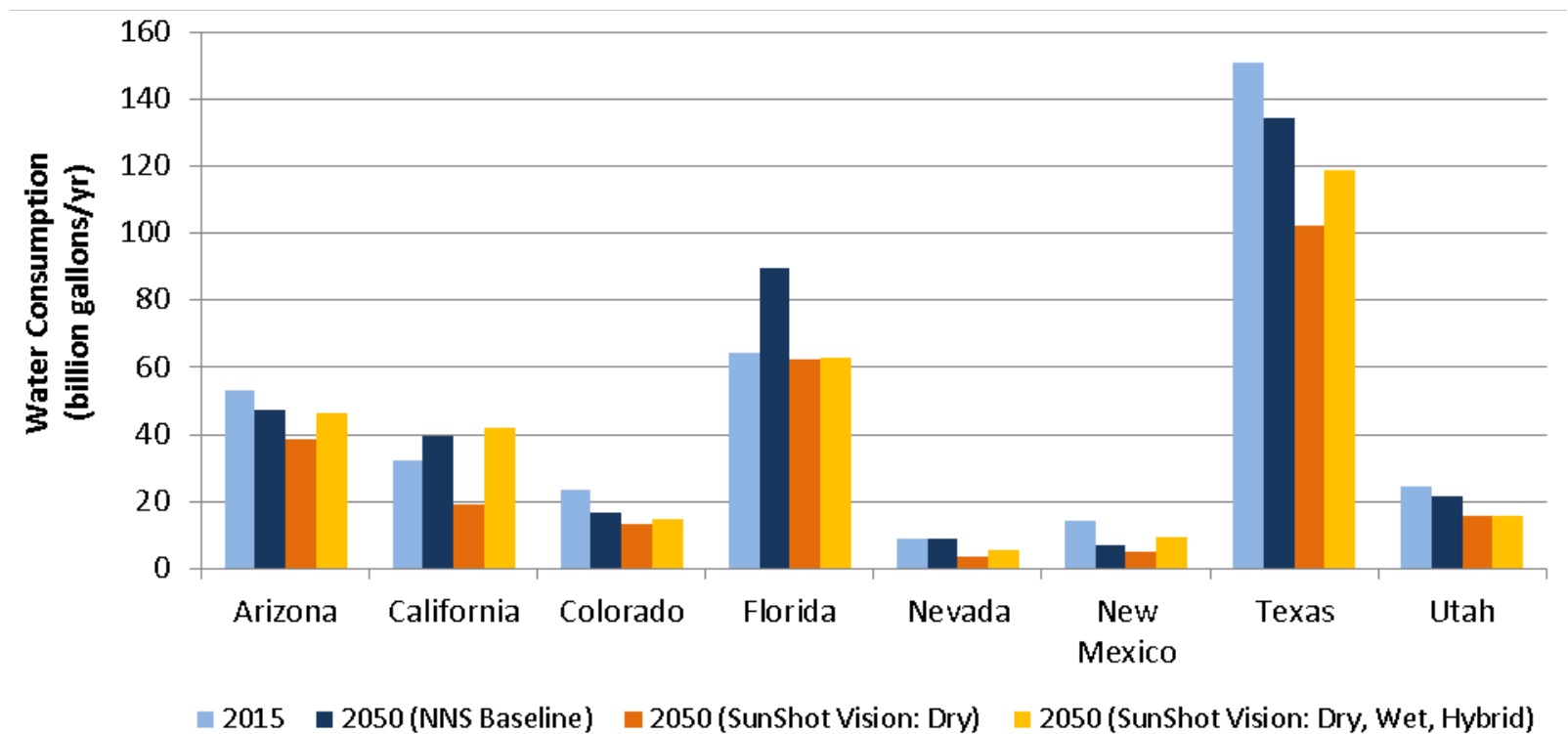

Figure 20. Water consumption by state in 2015 and 2050 in the SunShot Vision (Dry-Cooled New CSP Only), NNS Baseline, and the SunShot Vision Sensitivity (Dry, Wet, and Hybrid Cooling) Scenarios

The ability of solar energy to reduce water withdrawals and consumption offers economic and environmental benefits, especially in regions where water is scarce. By reducing electric-sector water use, solar energy reduces the vulnerability of electricity supply to the availability or temperature of water, potentially avoiding electric-sector reliability events and/or the effects of reduced thermal plant efficiencies - concerns that might otherwise grow as the climate changes (DOE 2013). Additionally, increased solar deployment can free up water for other productive purposes (e.g., agricultural, industrial, or municipal use) or to strengthen local ecosystems (e.g., benefiting wildlife owing to greater water availability, lack of temperature change, etc.). The lower life-cycle water requirements of solar energy technologies, meanwhile, can help alleviate other energy-sector impacts on water resource quality and quantity that occur during upstream fuel production for other technologies (Averyt et al. 2011). Finally, solar deployment might help reduce the cost of future national or state policies intended to limit electric-sector water use.

Quantifying in monetary terms the societal value of these water-use reductions is difficult, however, because no standardized methodology for doing this exists in the literature. One potential approach is to consider solar deployment as avoiding the possible need to otherwise employ thermal power plants with lower water use or to site power plants where water is available and less costly. ReEDS already includes the cost and performance characteristics of different cooling technologies as well as the availability and cost of water supply in its optimization; these costs and considerations are embedded in the ReEDS decision-making and resultant deployment impacts presented in Section 3. However, if water becomes scarcer in the future and/or if water policy becomes stricter, then additional costs might be incurred. In such an instance, a possible upper limit of the incremental cost of water-use reductions associated with 
conventional thermal generation can be estimated by comparing the cost of traditional wet cooling with the cost of dry cooling. Dry cooling adds capital expense to thermal plants and reduces plant efficiencies. The total cost increase of dry cooling for coal generation has been estimated at $0.32-0.64 \phi / \mathrm{kWh}$ (Zhai and Rubin 2010). For natural gas combined cycle plants, Maulbetsch and DiFilippo (2006) estimate an "effective cost" of saved water at \$3.8-\$6.8 per 1,000 gallons, corresponding to approximately $0.06-0.17 \notin / \mathrm{kWh}$ (DOE 2015). These estimated incremental costs for dry cooling are relatively small, and they likely set an upper limit on the water-related cost-savings of solar energy or any other power technology intended, in part, to reduce water use. ${ }^{\text {xlv }}$ 


\section{Environmental and Health Benefits of the 2014 Existing Solar Fleet}

At the end of 2014, there were 8.6 and $9.7 \mathrm{GW}_{\mathrm{dc}}$ of distributed and utility PV capacity, respectively, and an additional $1.7 \mathrm{GW}_{\text {ac }}$ of CSP capacity in the United States. ${ }^{\text {xlvi }}$ EPA's AVERT model ${ }^{\text {xlvii }}$, EPA's COBRA model $^{\text {xlviii }}$, and other analysis methods described in this report were used to estimate the GHG, air pollution, and water use impacts of the existing solar fleet over the course of a full year.

Table TB-1. Total Annual Benefits of Solar Power Installed by the End of 2014: Central Estimates

\begin{tabular}{|c|c|c|}
\hline Greenhouse Gas Emissions & Air Pollution Emissions & Water Use Reduction \\
\hline $\begin{array}{l}\$ 700 \text { million } \\
(2.1 \phi / \mathrm{kWh} \text {-solar })\end{array}$ & $\begin{array}{l}\$ 890 \text { million } \\
(2.7 \phi / k W h-\text { solar })\end{array}$ & $\begin{array}{l}294 \text { billion (withdrawal) } \\
7.6 \text { billion (consumption) }\end{array}$ \\
\hline
\end{tabular}

Greenhouse gas emissions: The 2014 solar fleet is estimated to reduce power-sector $\mathrm{CO}_{2}$ emissions by 17 million metric tons per year. ${ }^{\text {xlix }}$ This reduction produces $\$ 700$ million of annual global benefits in the form of lower future climate change damages when applying a central value for the SCC. Annual benefit estimates span $\$ 210$ million to $\$ 2,000$ million across the full range of SCC values considered here. These global benefits are equivalent to $2.1 \phi / \mathrm{kWh}$-solar in the central value case, and 0.6 to $6.2 \phi / \mathrm{kWh}$-solar across the full range. About two-thirds of total solar generation is delivered to California, and California accounts for roughly half of the total global GHG benefits (see Figure TB-1a). On a normalized $\phi / \mathrm{kWh}-$ solar basis, the GHG-reduction benefits of solar are greater in regions in which solar displaces more coal (and less gas) fired generation, with benefits ranging from 1.9 to $3.2 \phi / \mathrm{kWh}$-solar depending on the region, when applying a central value for the SCC (see Figure TB-1b). ${ }^{1}$

Air pollution emissions: The 2014 solar fleet is estimated to reduce power-sector emissions of $\mathrm{SO}_{2}, \mathrm{NO}_{\mathrm{x}}$, and $\mathrm{PM}_{2.5}$ by $10,000,10,300$ and 1,200 metric tons per year, respectively. ${ }^{\mathrm{li}}$ These reductions produce $\$ 890$ million of annual benefits across the United States in the form of reduced health and environmental damages based on central (i.e., averaged across the various methods) estimates. Across the full set of methods considered, annual benefits span $\$ 420$ million to $\$ 1,590$ million. These benefits are equivalent to $2.7 \notin / \mathrm{kWh}$-solar in the central value case, and 1.3 to $4.8 \phi / \mathrm{kWh}$-solar across the full range of valuation approaches. The benefits derive, in large measure, from a reduction to premature mortality associated with reduced ambient particulate matter concentrations, primarily from reductions in $\mathrm{SO}_{2}$. The benefits accrue across the country, driven by where solar has been deployed, where high-emitting fossil plants are located, and the degree of human exposure to pollution emissions: the 10 states realizing the greatest benefits were found to be New York, Pennsylvania, Ohio, California, New Jersey, Virginia, Michigan, Maryland, North Carolina, and Illinois (based on average COBRA valuations focusing only on fine particular exposure; see Figure TB-1c). ${ }^{\text {lii }}$ On a normalized $\phi / \mathrm{kWh}$-solar basis, the air-pollution-reduction benefits are highly dependent on the location of displacement. In particular, in regions with higher population densities and greater power-sector emissions, the normalized ( $\phi / \mathrm{kWh}$-solar) value of solar generation can be especially high: solar generated in the Great-Lakes-Mid-Atlantic (EMW) region, for example, provided $19 \notin / \mathrm{kWh}$-solar of air quality benefits to that and downwind regions, based on average COBRA valuations for exposure to particulates (see Figure TB-1d). In contrast, solar generated in California provided $0.6 \notin / \mathrm{kWh}$-solar of benefits, due largely to the low air pollution emissions rates of fossil units in the state. .iii

Water use reductions: The 2014 solar fleet is estimated to reduce power-sector net water withdrawals and consumption by 294 billion $(0.8 \%$ of power sector total) and 7.6 billion $(0.5 \%)$ gallons per year, respectively. ${ }^{\text {liv }}$ These annual reductions are concentrated in drought-impacted California, with withdrawal savings of 192 billion gallons and consumption savings of 3.4 billion gallons (FiguresTB-1e,f). 
a) $\mathrm{CO}_{2}$ benefits by state (central value SCC; million $\$ 2015$ )

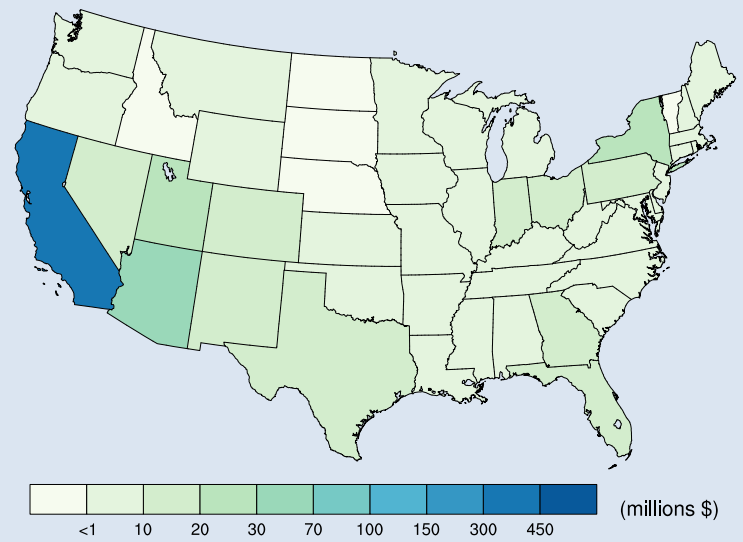

c) Air quality benefits by state (average COBRA; million \$2015)

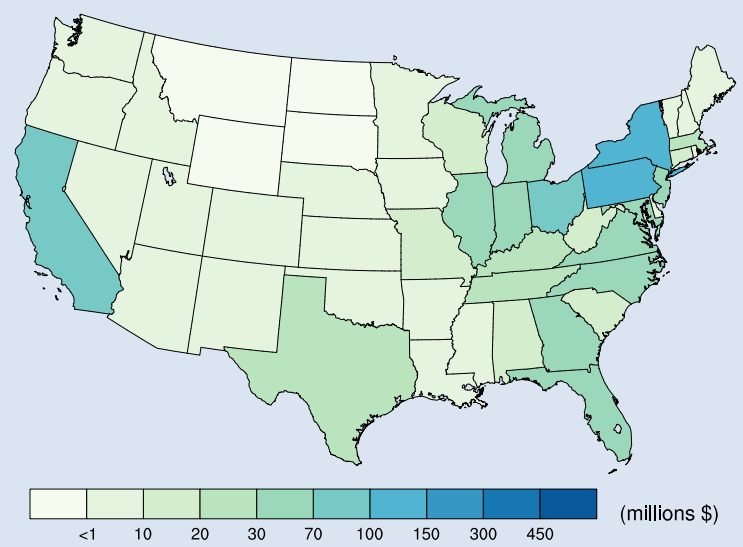

e) Avoided water withdrawals by state (million gallons)

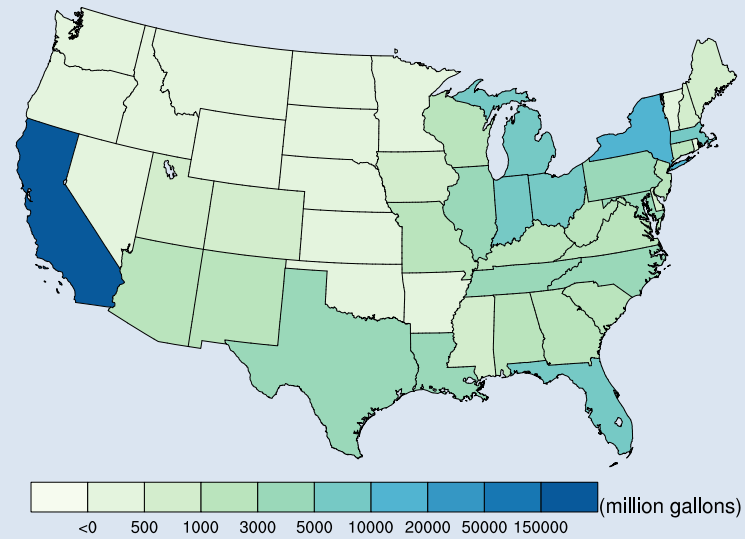

b) Normalized $\mathrm{CO}_{2}$ benefits by AVERT electricity region (central value SCC; $\phi / \mathrm{kWh}$ )

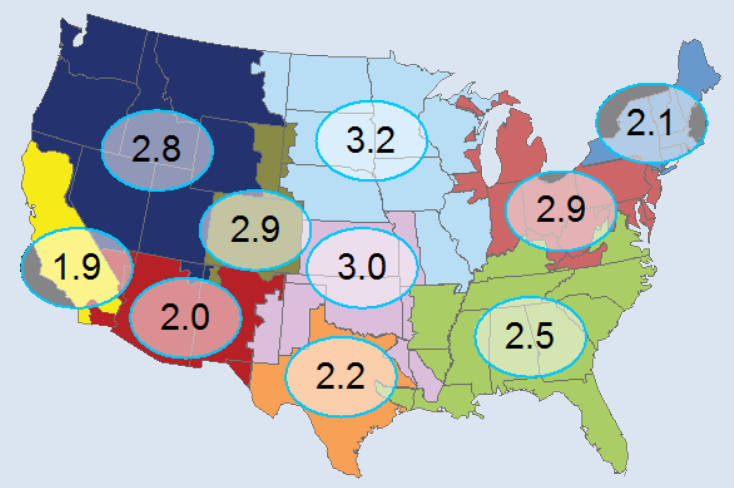

d) Normalized air quality benefits by AVERT electricity region (average COBRA; $\phi / k W h$ )

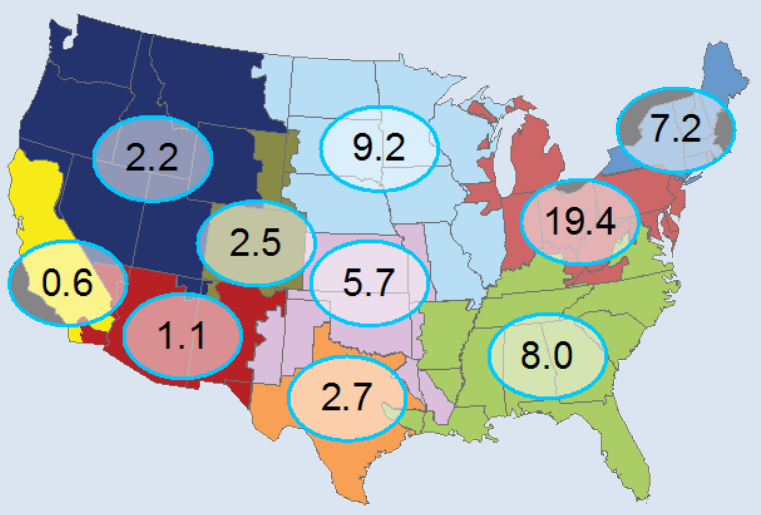

f) Avoided water consumption by state (million gallons)

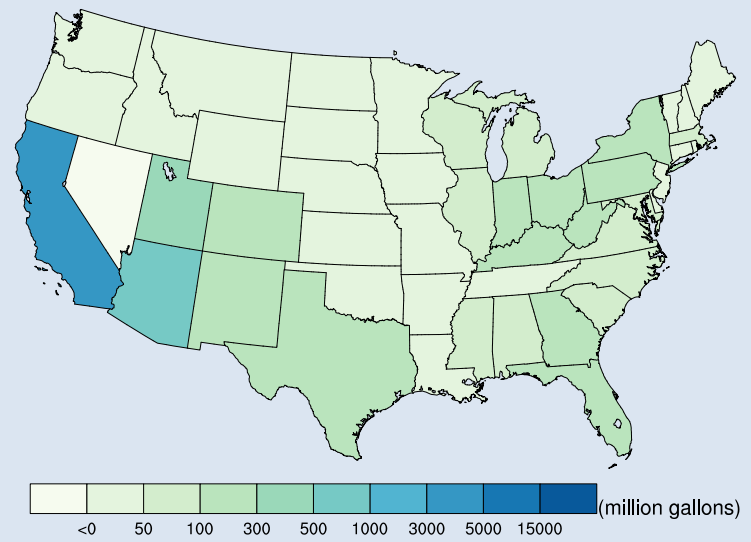

Figure TB-1. Annual environmental and health benefits of solar power installed by the end of 2014 by region or state (note varying scales) 


\section{Conclusions}

The U.S. Department of Energy's SunShot Initiative seeks to motivate swift reductions in the cost of solar energy in order to strengthen the role of solar as a low-cost energy source. The SunShot Vision Study (DOE 2012) evaluated the profound implications of such cost reductions for the solar industry, the electricity sector as a whole, and end-use electricity consumers, finding that achieving the SunShot cost targets could result in solar electricity penetrations of $14 \%$ of U.S. electricity demand by 2030 and $27 \%$ by 2050 . That study, however, did not comprehensively quantify and value the potential environmental and health benefits associated with achieving these levels of solar penetration.

Our analysis fills that gap by assessing three key potential environmental and health benefits of achieving the solar penetrations envisioned by DOE (2012). Specifically, we use a scenarioanalysis approach in which the 14\%-by-2030 and 27\%-by-2050 "SunShot Vision" scenario is compared with a "NNS baseline" scenario (which deploys no new solar after 2014) over the 2015-2050 period. We also evaluate today's benefits based on cumulative U.S. solar capacity installed by the end of 2014. As summarized below and in Figures 21 and 22, our analysis shows that the United States is already gaining environmental and health benefits from solar and that a future U.S. electricity system in which solar plays a major role would result in enduring environmental and health benefits globally, nationally, and locally.

- Greenhouse Gas Emissions: We find potential global, present-value GHG benefits of \$259 billion in the form of lower future climate change damages when applying a "central value" for the social cost of carbon, which is equivalent to a levelized benefit of solar of $2.2 \mathrm{c} / \mathrm{kWh}$ solar. Across a range of social cost of carbon estimates, total benefits span $\$ 56$ billion $(0.5 \notin / \mathrm{kWh}$-solar) to $\$ 789$ billion $(6.8 \notin / \mathrm{kWh}$-solar $)$. If, alternatively, solar is viewed as a way to meet future carbon-reduction requirements - and therefore offsets the cost of complying with those regulations - the benefits of achieving the SunShot Vision scenario range from $\$ 60$ billion to $\$ 92$ billion $(0.5-0.8 \notin / \mathrm{kWh}$-solar) when only considering EPA Clean Power Plan estimates and from $\$ 142$ billion to $\$ 347$ billion (1.2-3.0 $\phi / \mathrm{kWh}$-solar) when considering longer-term carbon-reduction policy possibilities. Under a "medium" trajectory for the cost of future regulations, the SunShot Vision scenario yields \$238 billion in savings, which is equivalent to a levelized benefit of solar of $2.0 \mathrm{\phi} / \mathrm{kWh}$-solar. These potential future benefits build on the 17 million metric tons of $\mathrm{CO}_{2}$ savings realized annually from the 2014 solar fleet, which is equivalent to an annual global benefit of $\$ 700$ million (2.1 $\$ / k W h$-solar) when a central value for the social cost of carbon is applied; across a range of social cost of carbon estimates, annual benefits of the existing solar fleet span $\$ 210$ million $(0.6 \mathrm{k} / \mathrm{kWh}$ solar) to $\$ 2,000$ million $(6.2 \mathrm{c} / \mathrm{kWh}$-solar).

- Air-Pollution Emissions: We find potential present-value air-pollution benefits of \$167 billion in the form of lower future health and environmental damages based on central estimates, which is equivalent to a levelized benefit of solar of $1.4 \phi / \mathrm{kWh}$-solar. Across the full set of methods considered, total monetary benefits span $\$ 77$ billion $(0.7 \phi / \mathrm{kWh}$-solar) to $\$ 298$ billion (2.6 $/ \mathrm{kWh}$-solar). These benefits derive, in large measure, from a reduction in premature mortality from sulfate particles from $\mathrm{SO}_{2}$ emissions-achieving the SunShot Vision scenario reduces premature mortalities by 25,000-59,000 based on methods developed at EPA. These potential future benefits build on annual reductions of 10,000, 
10,300, and 1,200 metric tons of $\mathrm{SO}_{2}, \mathrm{NO}_{x}$, and $\mathrm{PM}_{2.5}$, respectively, from the 2014 solar fleet, which provide annual domestic air quality benefits of $\$ 890$ million $(2.7 \mathrm{k} / \mathrm{kWh}$-solar) based on central estimates; across the full set of methods considered, annual benefits of the existing solar fleet span $\$ 420$ million (1.3ф/kWh-solar) to $\$ 1,590$ million $(4.8 \phi / k W h$-solar).

- Water-Use Reductions: We find potential power-sector water-use savings from 2015 to 2050 of 46 trillion gallons of avoided withdrawal (4\% of total power-sector withdrawals) and 5 trillion gallons of avoided water consumption ( $9 \%$ of total power-sector consumption). By 2050, water withdrawals in the continental United States are lower than the NNS baseline scenario in 35 of 48 states, and water consumption is lower in 36 of 48 states. Importantly, drought-prone and arid states are among those with the largest reductions in water use. National water consumption savings in 2050 alone could supply the annual water demands of more than 1.3 million U.S. households. These results assume dry cooling for CSP plants; greater use of wet or hybrid cooling reduces modestly the national water savings (e.g., water consumption savings drop from $16 \%$ in 2050 to $12 \%$ in 2050). These potential future savings build on the water-use reductions from the 2014 solar fleet, including annual withdrawal and consumption savings of 294 billion gallons ( $0.8 \%$ of power sector total) and 7.6 billion gallons ( $0.5 \%$ of power sector total), respectively, with much of those savings located in drought-impacted California.

The total monetary value of the GHG and criteria air pollution benefits of the SunShot Vision scenario exceed $\$ 400$ billion in present-value terms under our central estimates, which is equivalent to roughly $3.5 \mathrm{k} / \mathrm{kWh}$-solar. Focusing on just the existing end-of-2014 fleet of solar power projects, recent annual benefits equal more than $\$ 1.5$ billion under our central estimates, which is equivalent to $4.8 \mathrm{c} / \mathrm{kWh}$-solar. These are central estimates, with a sizable range of uncertainty. The figures exclude the value of reduced water use - for which monetary quantification was not feasible - as well as other non-quantified environmental considerations. Additionally, it is important to recognize that the environmental and health benefits of solar are strongly dependent on not only the amount of solar deployment but also the location of that deployment — solar that displaces higher-emitting coal generation has substantially larger benefits than solar that displaces lower-emitting gas-fired (or even wind) generation. Moreover, decision makers will naturally wish to compare these potential environmental and health benefits with, among other things, the potential costs and risks introduced by adding solar to the electric system as well as the potential impacts of solar on local ecosystems and communities. Though we do not address electric-system costs or impacts in this analysis, DOE (2012) provides a thorough initial assessment of them, while other papers in the On the Path to SunShot Study series help inform such comparisons.

Finally, although the present work might inform policy decisions, it is not intended to suggest any specific type of policy. The costs and benefits of increased solar deployment will be impacted by the policy and market mechanisms used to effect that deployment - this analysis quantifies the general magnitude of potential environmental and health benefits only. Moreover, economic research has found that policies directly targeting the internalization of external costs and correction of market failures are likely to be more cost effective than technology- or sectorspecific policy incentives, in part due to possible economy-wide rebound and spillover effects and also because such policies directly target the achievement of public benefits (Borenstein 2012; Edenhofer et al. 2013; Fischer and Newell 2008; Fell and Linn 2013; IPCC 2011; IPCC 
2014b; Kalkuhl et al. 2013; McKibbin et al. 2014; Novan 2014; Rausch and Karplus 2014; Tuladhar et al. 2014). As a result, although the analysis presented in this report suggests a significant possible role for solar energy in delivering environmental and health benefits, achieving those benefits in the most cost-effective way might be best supported by a policy framework that directly addresses key market failures and unpriced externalities.

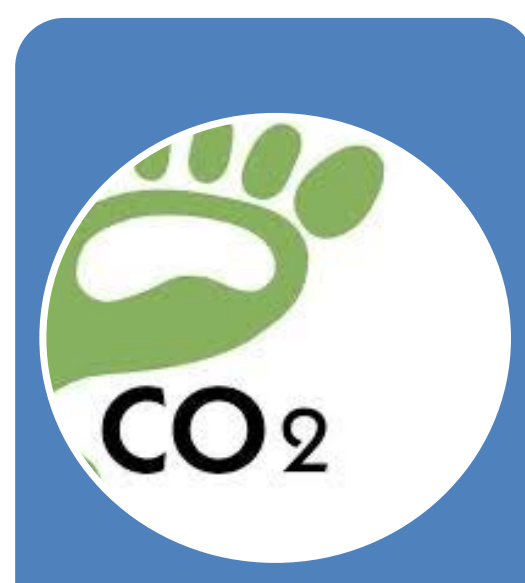

$10 \%$ reduction in powersector life-cycle greenhouse gas emissions: 2015-2050

\section{$\$ 259$ billion}

in present-value benefits of avoided global damages range: \$56-\$789 billion

\section{$\$ 238$ billion}

in present-value benefits of compliance cost offsets range: $\$ 60-\$ 347$ billion

Equivalent to: 2c/kWh-solar for central estimates

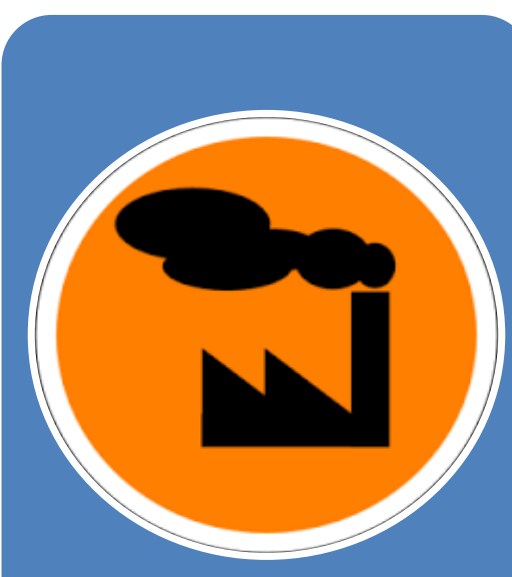

$9 \%\left(\mathrm{SO}_{2}\right), 11 \%\left(\mathrm{NO}_{\mathrm{x}}\right)$, and $8 \%$ $\left(\mathrm{PM}_{2.5}\right)$ reduction in powersector emissions: 2015-2050

\section{\$167 billion}

in present-value health and environmental benefits range: \$77-\$298 billion

\section{Equivalent to:}

1.4c/kWh-solar for central estimates

\section{5,000-59,000}

avoided premature mortalities: 2015-2050

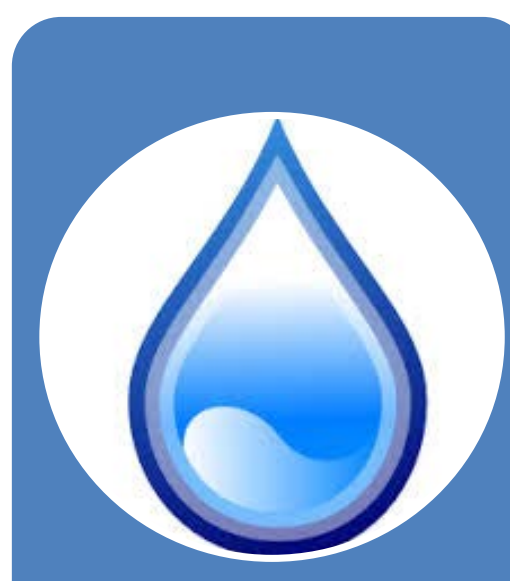

$4 \%$ reduction in powersector water withdrawals and $9 \%$ reduction in water consumption: 2015-2050

\section{Withdrawals fall in 35}

states in 2050; consumption falls in 36 states; notably including many droughtprone and arid states

Consumption savings in 2050 = water demands of:

\section{3 million} households

Figure 21. Environmental and health benefits of achieving the SunShot Vision Scenario ( $14 \%$ of U.S. electricity demand by 2030 and $27 \%$ by 2050 ) 


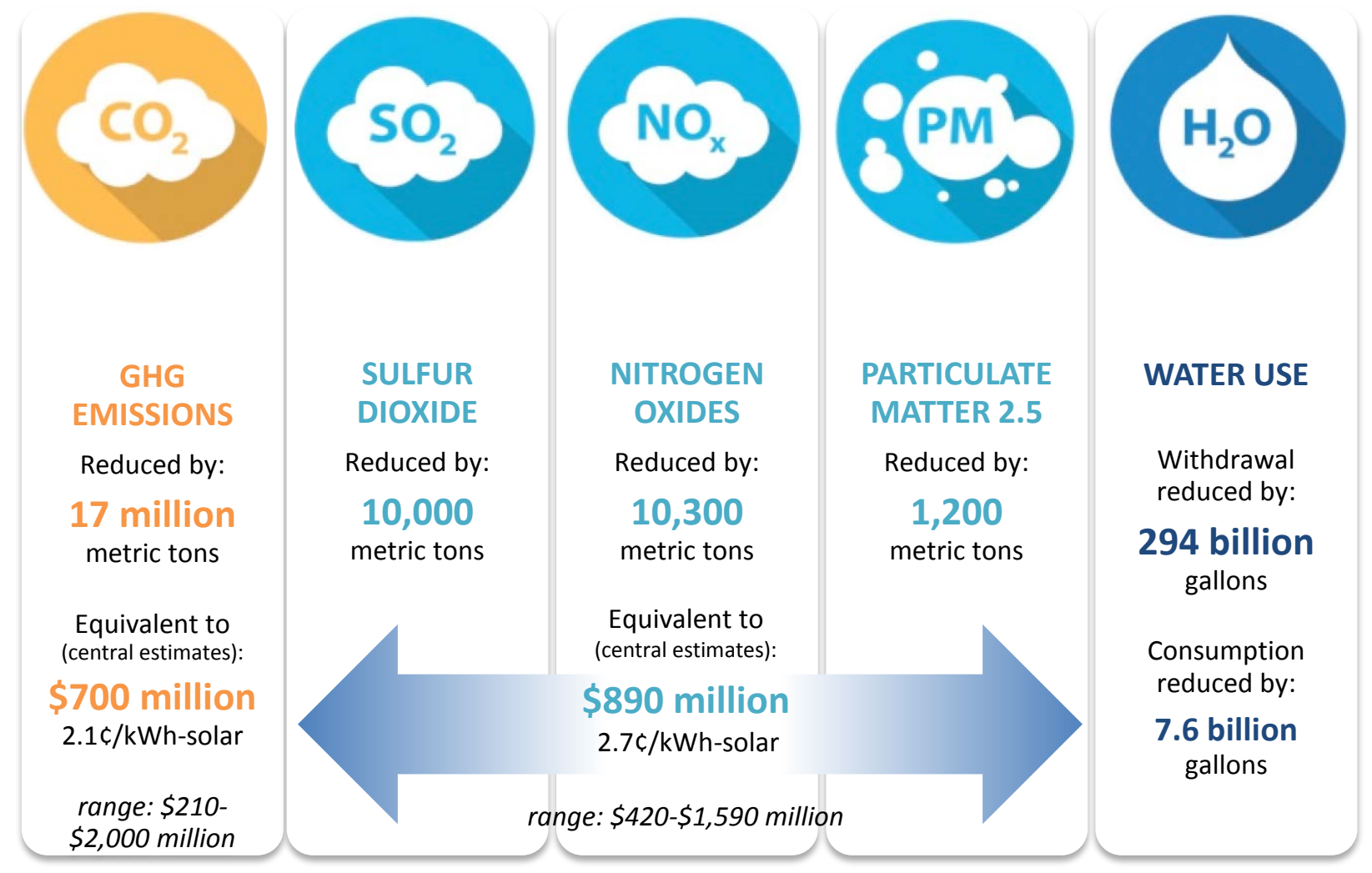

Figure 22. Annual environmental and health benefits of the $20 \mathrm{GW}$ of solar power installed by the end of 2014 


\section{References}

Ackerman, F., and E. Stanton. 2012. "Climate Risks and Carbon Prices: Revising the Social Cost of Carbon.” Economics: The Open-Access, Open-Assessment E-Journal 6: 1-25.

Arent, D., J. Pless, T. Mai, R. Wiser, M. Hand, S. Baldwin, G. Heath, J. Macknick, M. Bazilian, A. Schlosser, and P. Denholm. 2014. "Implications of High Renewable Electricity Penetration in the US for Water Use, Greenhouse Gas Emissions, Land-Use, and Materials Supply." Applied Energy 123: 368-77.

Arrow, K., M. Cropper, C. Gollier, B. Groom, G. Heal, R. Newell, W. Nordhaus, R. Pindyck, W. Pizer, P. Portney, T. Sterner, R.S.J. Tol, and M. Weitzman. 2013. "Determining Benefits and Costs for Future Generations." Science 341(6144): 349-50.

Averyt, K., J. Fisher, A. Huber-Lee, A. Lewis, J. Macknick, N. Madden, J. Rogers, and S. Tellinghuisen. 2011. Freshwater Use by U.S. Power Plants: Electricity's Thirst for a Precious Resource. Cambridge, MA: Union of Concerned Scientists.

Averyt, K., J. Macknick, J. Rogers, N. Madden, J. Fisher, J. Meldrum, and R. Newmark. 2013. "Water Use for Electricity in the United States: An Analysis of Reported and Calculated Water Use Information for 2008." Environmental Research Letters 8 (015001).

Barbose, G., J. Miller, B. Sigrin, E. Reiter, K. Cory, J. McLaren, J. Seel, A. Mills, N. Darghouth, and A. Satchwell. 2016. On the Path to SunShot: Utility Regulatory and Business Model Reforms for Addressing the Financial Impacts of Distributed Solar on Utilities. Golden, CO: National Renewable Energy Laboratory. NREL/TP-6A20-65670. http://www.nrel.gov/docs/fy16osti/ 65670.pdf.

Barbose, G., N. Darghouth, D. Millstein, M. Spears, R.H. Wiser, M. Buckley, R. Widiss, and N. Grue. 2015. Tracking the Sun VIII: An Historical Summary of the Installed Price of Photovoltaics in the United States from 1998-2014. Berkeley, CA: Lawrence Berkeley National Laboratory.

Barbose, G., R. Wiser, A. Phadke, and C. Goldman. 2008. "Managing Carbon Regulatory Risk in Utility Resource Planning: Current Practices in the Western United States." Energy Policy 36(9): 3300-11.

Bell M.L., A. McDermott, S.L. Zeger, J.M. Samet, and F. Dominici. 2004. "Ozone and ShortTerm Mortality in 95 US Urban Communities, 1987-2000." Journal of the American Medical Association 292(19): 2372-78.

Bird, L., C. Chapman, J. Logan, J. Sumner, and W. Short. 2011. "Evaluating Renewable Portfolio Standards and Carbon Cap Scenarios in the U.S. Electric Sector." Energy Policy 39(5): 2573-85.

Bokenkamp, K., H. LaFlash, V. Singh, and D. Bachrach Wang. 2005. "Hedging Carbon Risk: Protecting Customers and Shareholders from the Financial Risk Associated with Carbon Dioxide Emissions." The Electricity Journal 18(6): 11-24. 
Bolinger, M., and J. Seel. 2015. Utility-Scale Solar 2014: An Empirical Analysis of Project Cost, Performance, and Pricing Trends in the United States. Berkeley, CA: Lawrence Berkeley

National Laboratory.

Borenstein, S. 2012. "The Private and Public Economics of Renewable Electricity Generation." Journal of Economic Perspectives 26(1): 67-92.

Buonocore, J., P. Luckow, G. Norris, J. Spengler, B. Biewald, J. Fisher, and J. Levy. 2015. "Health and Climate Benefits of Different Energy-Efficiency and Renewable Energy Choices." Nature Climate Change (August): advance online publication.

Cai, H., M. Wang, A. Elgowainy, and J. Han. 2012. Updated Greenhouse Gas and Criteria Air Pollutant Emission Factors and Their Probability Distribution Functions for Electric Generating Units. ANL/ESD/12-2. Lemont, IL: Argonne National Laboratory.

Cai, H., M. Wang, A. Elgowainy, and J. Han. 2013. Updated Greenhouse Gas and Criteria Air Pollutant Emission Factors of the U.S. Electric Generating Units in 2010. Lemont, IL: Argonne National Laboratory.

Callaway, D., M. Fowlie, and G. McCormick. 2015. Location, location, location: The variable value of renewable energy and demand-side efficiency resources. Berkeley, CA: Energy Institute at Haas.

Chandel, M.K., L.F. Pratson, and R.B. Jackson. 2011. "The Potential Impacts of Climate-Change Policy on Freshwater Use in Thermoelectric Power Generation." Energy Policy 39: 6234-42.

Chung, D., K. Horowitz, and P. Kurup. 2016. On the Path to SunShot: Emerging Opportunities and Challenges in U.S. Solar Manufacturing. Golden, CO: National Renewable Energy Laboratory. NREL/TP-7A40-65788. http://www.nrel.gov/docs/fy16osti/65788.pdf.

Clemmer, S., J. Rogers, S. Sattler, J. Macknick, and T. Mai. 2013. "Modeling Low-Carbon US Electricity Futures to Explore Impacts on National and Regional Water Use." Environmental Research Letters 8 (015004).

Cohen, S., K. Averyt, J. Macknick, and J. Meldrum. 2014. "Modeling Climate-Water Impacts on Electricity Sector Capacity Expansion." Proceedings of the ASME 2014 Power Conference. POWER2014-32188. July 28-31, 2014, Baltimore, MD.

Cole, W., T. Mai, K. Eurek, D. Steinberg, and R. Margolis. 2015. "Considering the Role of Solar Generation under Rate-Based Targets in the EPA's Proposed Clean Power Plan.” The Electricity Journal 28(8):20-28.

Cullen, J. 2013. "Measuring the Environmental Benefits of Wind-Generated Electricity." American Economic Journal: Economic Policy 5(4): 107-33.

Denholm, P., E. Drury, and R. Margolis. 2009. The Solar Deployment System (SolarDS) Model: Documentation and Sample Results. NREL/TP-6A2-45832. Golden, CO: National Renewable Energy Laboratory. 
Denholm, P., M.M. Hand, T. Mai, R. Margolis, G. Brinkman, E. Drury, M. Mowers, and C. Turchi. 2012. Potential Role of Concentrating Solar Power in Enabling High Renewables Scenarios in the United States. NREL/TP-6A20-56294. Golden, CO: National Renewable Energy Laboratory.

Denholm, P., K. Clark, and M. O'Connell. 2016. On the Path to SunShot: Emerging Issues and Challenges in Integrating High Levels of Solar into the Electrical Generation and Transmission System. Golden, CO: National Renewable Energy Laboratory. NREL/TP-6A20-65800. http://www.nrel.gov/docs/fy16osti/65800.pdf.

Dockery, D.W., C.A. Pope, X. Xu, J.D. Spengler, J.H. Ware, M.E. Fay, B.G. Ferris, and F.E. Speizer. 1993. "An Association between Air Pollution and Mortality in Six U.S. Cities." New England Journal of Medicine 329: 1753-59.

DOE (U.S. Department of Energy). 2008. 20\% Wind Energy by 2030: Increasing Wind Energy's Contribution to U.S. Electricity Supply. DOE/GO-102008-2567. Washington, DC: U.S.

Department of Energy.

DOE. 2012. "SunShot Vision Study." Washington, DC: U.S. Department of Energy. DOE/GO102012-3037. http://www.nrel.gov/docs/fy12osti/47927.pdf.

DOE. 2013. U.S. Energy Sector Vulnerabilities to Climate Change and Extreme Weather. DOE/PI-0013. Washington, DC: U.S. Department of Energy.

DOE. 2015. Wind Vision: A New Era for Wind Power in the United States. DOE/GO-1020154557. Washington, DC: U.S. Department of Energy.

Driscoll, C.T., J.J. Buonocore, J.I. Levy, K.F. Lambert, D. Burtraw, S.B. Reid, H. Fakhraei, and J. Schwartz. 2015. "US Power Plant Carbon Standards and Clean Air and Health Co-Benefits." Nature Climate Change 5: 535-40.

Drury, E., P. Denholm, and R. Margolis. 2013. Sensitivity of Rooftop PV Projections in the SunShot Vision Study to Market Assumptions. NREL/TP-6A20-54620. Golden, CO: National Renewable Energy Laboratory.

Edenhofer, O., L. Hirth, B. Knopf, M. Pahle, S. Schlömer, E. Schmid, and F. Ueckerdt. 2013. "On the Economics of Renewable Energy Sources." Energy Economics 40, Supplement 1 (December): S12-S23.

EIA (U.S. Energy Information Administration). 2014. Annual Energy Outlook 2014 with Projections to 2040. DOE/EIA-0383(2014). Washington, DC: U.S. Department of Energy.

EIA (U.S. Energy Information Administration). 2015a. Annual Energy Outlook 2015 with Projections to 2040. DOE/EIA-0383(2015). Washington, DC: U.S. Department of Energy.

EIA (U.S. Energy Information Administration). 2015b. Electric Power Annual 2013. Washington, DC: U.S. Department of Energy. 
EPA (U.S. Environmental Protection Agency). 2009. Cooling Water Intake Structures-CWA 316(b), Phase II-Large Existing Electric Generating Plants. Washington, DC: U.S.

Environmental Protection Agency.

EPA (U.S. Environmental Protection Agency). 2011. Environmental and Economic Benefits Analysis for Proposed Section 316(b) Existing Facilities Rule. EPA 821-R-11-002. Washington, DC: U.S. Environmental Protection Agency.

EPA (U.S. Environmental Protection Agency). 2013. Progress Report: SO2 and NOX Emissions, Compliance, and Market Analyses. Washington, DC: U.S. Environmental Protection Agency.

EPA (Environmental Protection Agency). 2014a. AVoided Emissions and geneRation Tool (AVERT) User Manual, Version 1.2. Washington, DC: U.S. Environmental Protection Agency.

EPA (Environmental Protection Agency). 2014b. User's Manual for the Co-Benefits Risk Assessment (COBRA) Screening Model Version: 2.61. Washington, DC: U.S. Environmental Protection Agency.

EPA (U.S. Environmental Protection Agency). 2015a. Climate Change in the United States: Benefits of Global Action. Washington, DC: U.S. Environmental Protection Agency.

EPA (U.S. Environmental Protection Agency). 2015b. Carbon Pollution Emission Guidelines for Existing Stationary Sources: Electric Utility Generating Units. Washington, DC: U.S.

Environmental Protection Agency.

EPA (U.S. Environmental Protection Agency). 2015c. Standards of Performance for Greenhouse Gas Emissions from New, Modified, and Reconstructed Stationary Sources: Electric Utility Generating Units. Washington, DC: U.S. Environmental Protection Agency.

EPA (U.S. Environmental Protection Agency). 2015d. Regulatory Impact Analysis for the Clean Power Plan Final Rule. Docket ID EPA-452/R-15-003. Research Triangle Park, NC: U.S. Environmental Protection Agency.

EPIA (European Photovoltaic Industry Association). 2014. Global Market Outlook for Photovoltaics: 2014-2018. Brussels, Belgium: European Photovoltaic Industry Association.

Eurek, K., P. Denholm, R. Margolis, and M. Mowers. 2013. Sensitivity of Utility-Scale Solar Deployment Projections in the SunShot Vision Study to Market and Performance Assumptions. NREL/TP-6A20-55836. Golden, CO: National Renewable Energy Laboratory.

Fann, N., K.R Baker, and C.M. Fulcher. 2012. "Characterizing the PM2.5-Related Health Benefits of Emission Reductions for 17 Industrial, Area and Mobile Emission Sectors Across the U.S.” Environment International 49: 141-51.

Feldman, D., and M. Bolinger. 2016. On the Path to SunShot: Emerging Opportunities and Challenges in Financing Solar. Golden, CO: National Renewable Energy Laboratory.

NREL/TP-6A20-65638. http://www.nrel.gov/docs/fy16osti/65638.pdf. 
Fell, H. and J. Linn. 2013. "Renewable Electricity Policies, Heterogeneity, and Cost Effectiveness." Journal of Environmental Economics and Management 66(3): 688-707.

Fischer, C. and R.G. Newell. 2008. "Environmental and Technology Policies for Climate Mitigation." Journal of Environmental Economics and Management 55(2): 142-62.

Fripp, M. 2011. "Greenhouse Gas Emissions from Operating Reserves Used to Backup LargeScale Wind Power.” Environmental Science \& Technology 45(21): 9405-12.

GAO (U.S. Government Accountability Office). 2014. Regulatory Impact Analysis:

Development of Social Cost of Carbon Estimates. GAO-14-663. Washington, DC: U.S. Government Accountability Office.

GE Energy Consulting. 2014. PJM Renewable Integration Study. Schenectady, NY: General Electric Energy Consulting Group. Report for PJM Interconnection.

Göransson, L., and F. Johnsson. 2009. "Dispatch Modeling of a Regional Power Generation System - Integrating Wind Power.” Renewable Energy 34(4): 1040-49.

Graff Zivin, J.S., M.J. Kotchen, and E. Mansur. 2014. "Spatial and Temporal Heterogeneity of Marginal Emissions: Implications for Electric Cars and Other Electricity-Shifting Policies." Journal of Economic Behavior \& Organization 107: 248-68.

Gross, R., P. Heptonstall, D. Anderson, T. Green, M. Leach, and J. Skea. 2006. The Costs and Impacts of Intermittency: An Assessment of the Evidence on the Costs and Impacts of Intermittent Generation on the British Electricity Network. Imperial College London: UK Energy Research Centre (UKERC).

GTM/SEIA. 2015. U.S. Solar Market Insight Report: 2014 Year in Review. Washington, DC: GTM Research and Solar Energy Industries Association.

Hartmann, H. M., M.A. Grippo, G.A. Heath, J. Macknick, K.P. Smith, R. Sullivan, L.J. Walston, and K.L. Wescott. Forthcoming. On the Path to SunShot: Understanding Emerging Impacts and Long-Term Requirements Related to Utility-Scale Solar Development. ANL /EVS-15/8. NREL/TP-6A20-65801. Argonne, IL: Argonne National Laboratory.

IPCC (Intergovernmental Panel on Climate Change). 2011. Special Report on Renewable Energy Sources and Climate Change Mitigation (SRREN). Cambridge, UK: Cambridge University Press.

IPCC (Intergovernmental Panel on Climate Change). 2013. Climate Change 2013: The Physical Science Basis: Working Group I Contribution to the Fifth Assessment Report of the IPCC. Cambridge, UK: Cambridge University Press.

IPCC (Intergovernmental Panel on Climate Change). 2014a. Climate Change 2014: Impacts, Adaptation, and Vulnerability: Working Group II Contribution to the Fifth Assessment Report of the IPCC. Cambridge, UK: Cambridge University Press. 
IPCC (Intergovernmental Panel on Climate Change). 2014b. Climate Change 2014: Mitigation of Climate Change: Working Group III Contribution to the Fifth Assessment Report of the IPCC. Cambridge, UK: Cambridge University Press.

IWG (U.S. Interagency Working Group on the Social Cost of Carbon). 2010. Technical Support Document: Social Cost of Carbon for Regulatory Impact Analysis under Executive Order 12866. Washington, DC: U.S. Interagency Working Group on the Social Cost of Carbon.

IWG (U.S. Interagency Working Group on the Social Cost of Carbon). 2015. Technical Support Document: Technical Update of the Social Cost of Carbon for Regulatory Impact Analysis under Executive Order 12866. July 2015 Revision. Washington, DC: U.S. Interagency Working Group on the Social Cost of Carbon.

Johnson, L.T., and C. Hope. 2012. "The Social Cost of Carbon in U.S. Regulatory Impact Analyses: An Introduction and Critique.” Journal of Environmental Studies and Sciences 2(3): 205-21.

Johnson, L., S. Yeh, and C. Hope. 2013. "The Social Cost of Carbon: Implications for Modernizing Our Electricity System.” Journal of Environmental Studies and Sciences 3(4): 36975.

Jorgenson, J., P. Denholm, and M. Mehos. 2014. Estimating the Value of Utility-Scale Solar Technologies in California under a 40\% Renewable Portfolio Standard. NREL/TP-6A20-61685. Golden, CO: National Renewable Energy Laboratory.

Kaffine, D., B. McBee, and J. Lieskovsky. 2013. "Emissions Savings from Wind Power Generation in Texas." The Energy Journal 34(1): 155-75.

Kalkuhl, M., O. Edenhofer, and K. Lessman. 2013. "Renewable Energy Subsidies: Second-Best Policy or Fatal Aberration for Mitigation?” Resource and Energy Economics 35(3): 217-34.

Kenny, J.F., N.L. Barber, S.S. Hutson, K.S. Linsey, J.K. Lovelace, and M.A. Maupin. 2009. Estimated Use of Water in the United States in 2005. No. CIR - 1344. Reston, VA: U.S. Geological Survey.

Kopp, R.E., A. Golub, N.O. Keohane, and C. Onda. 2012. "The Influence of the Specification of Climate Change Damages on the Social Cost of Carbon." Economics: The Open-Access, OpenAssessment E-Journal 6(2012-13): 1-40.

Kopp, R.E., and B.K. Mignone. 2012. "The U.S. Government's Social Cost of Carbon Estimates after Their First Two Years: Pathways for Improvement." Economics: The Open-Access, OpenAssessment E-Journal 6(2012-15): 1-41.

Krewski, D., M. Jerrett, R.T. Burnett, R. Ma, E. Hughes, Y. Shi, M.C. Turner, C.A. Pope, G. Thurston, E.E. Calle, M.J. Thun, B. Beckerman, P. DeLuca, N. Finkelstein, K. Ito, D.K. Moore, K.B. Newbold, T. Ramsay, Z. Ross, H. Shin, and B. Tempalski. 2009. Extended Follow-Up and Spatial Analysis of the American Cancer Society Study Linking Particulate Air Pollution and Mortality. Research Report (Health Effects Institute) 140: 5-114. 
Lantz, E., D. Steinberg, M. Mendelsohn, O. Zinaman, T. James, G. Porro, M. Hand, T. Mai, J. Logan, J. Heeter, and L. Bird. 2014. Implications of a PTC Extension on U.S. Wind Deployment. NREL/TP-6A20-61663. Golden, CO: National Renewable Energy Laboratory.

Lepeule, J., F. Laden, D. Dockery, and J. Schwartz. 2012. "Chronic Exposure to Fine Particles and Mortality: An Extended Follow-Up of the Harvard Six Cities Study from 1974 to 2009." Environmental Health Perspectives 120: 965-70.

Levy, J.I., S.M. Chemerynski, and J.A. Sarnat. 2005. "Ozone Exposure and Mortality: An Empiric Bayes Metaregression Analysis.” Epidemiology 16(4): 458-68.

Lew, D., G. Brinkman, E. Ibanez, A. Florita, M. Heaney, B.-M. Hodge, M. Hummon, G. Stark, J. King, and S.A. Lefton. 2013. The Western Wind and Solar Integration Study Phase 2.

NREL/TP-5500-55588. Golden, CO: National Renewable Energy Laboratory.

Lim, S. et al. 2012. "A Comparative Risk Assessment of Burden of Disease and Injury Attributable to 67 Risk Factors and Risk Factor Clusters in 21 Regions, 1990-2010: A Systematic Analysis for the Global Burden of Disease Study." Lancet 380: 2224-60.

Logan, J., A. Lopez, T. Mai, C. Davidson, M. Bazilian, and D. Arent. 2013. "Natural Gas Scenarios in the U.S. Power Sector.” Energy Economics 40: 183-95.

Luckow, P., E. Stanton, S. Fields, B. Biewald, S. Jackson, J. Fisher, and R. Wilson. 2015. 2015 Carbon Dioxide Price Forecast. Cambridge, MA: Synapse Energy Economics, Inc.

Luderer, G., R.C. Pietzcker, C. Bertram, E. Kriegler, M. Meinshausen, and O. Edenhofer. 2013. "Economic Mitigation Challenges: How Further Delay Closes the Door for Achieving Climate Targets." Environmental Research Letters 8(3): 034033.

Macknick, J., S. Cohen, V. Tidwell, R. Newmark, A. Martinez, and P. Sullivan. 2015. Water Constraints in an Electric Sector Capacity Expansion Model. NREL/TP-6A20-64270. Golden, CO: National Renewable Energy Laboratory.

Macknick, J., R. Newmark, G. Heath, and K.C. Hallett. 2012a. “Operational Water Consumption and Withdrawal Factors for Electricity Generating Technologies: A Review of Existing Literature." Environmental Research Letters 7(4): 045802.

Macknick, J., S. Sattler, K. Averyt, S. Clemmer, and J. Rogers. 2012b. “The Water Implications of Generating Electricity: Water Use across the United States Based on Different Electricity Pathways through 2050." Environmental Research Letters 7(4): 045803.

Mai, T., D. Mulcahy, M.M. Hand, and S. Baldwin. 2014. "Envisioning a Renewable Electricity Future for the United States." Energy 65: 374-86.

Maulbetsch, J.S., and M.N. DiFilippo. 2006. Cost and Value of Water Use at Combined-Cycle Power Plants. CEC-500-2006-034. Sacramento, CA: California Energy Commission. 
Maupin, M.A., J.F. Kenny, S.S. Hutson, J.K. Lovelace, N.L. Barber, and K.S. Linsey. 2014. Estimated Use of Water in the United States in 2010. U.S. Geological Survey Circular 1405. Washington, DC: U.S. Geological Survey.

McKibbin, W.J., A.C. Morris, and P.J. Wilcoxen. 2014. "Pricing Carbon in the U.S.: A ModelBased Analysis of Power-Sector-Only Approaches." Resource and Energy Economics 36(1): $130-50$.

McCubbin, D., and B.K. Sovacool. 2013. "Quantifying the Health and Environmental Benefits of Wind Power to Natural Gas.” Energy Policy 53(February): 429-41.

Mehos, M., C. Turchi, J. Jorgenson, P. Denholm, C. Ho, and K. Armijo. 2016. On the Path to SunShot: Advancing Concentrating Solar Power Technology, Performance, and Dispatchability. Golden, CO: National Renewable Energy Laboratory. NREL/TP-5500-65668.

http://www.nrel.gov/docs/fy16osti/65668.pdf.

Meldrum, J., S. Nettles-Anderson, G. Heath, and J. Macknick. 2013. "Life Cycle Water Use for Electricity Generation: A Review and Harmonization of Literature Estimates." Environmental Research Letters 8: 015031.

Melillo, J.M., T.C. Richmond, and G.W. Yohe. 2014. Climate Change Impacts in the United States: The Third National Climate Assessment. Washington, DC: U.S. Global Change Research Program.

Mignone, B.K., T. Alfstad, A. Bergman, K. Dubin, R. Duke, P. Friley, A. Martinez, M. Mowers, K. Palmer, A. Paul, S. Showalter, S. Steinberg, M. Woerman, and F. Wood. 2012. "CostEffectiveness and Economic Incidence of a Clean Energy Standard." Economics of Energy \& Environmental Policy 1(3): 59-86.

Muller, N.Z., R. Mendelsohn, and W. Nordhaus. 2011. "Environmental Accounting for Pollution in the United States Economy." American Economic Review 101(5): 1649-75.

Nordhaus, W.D. 2013. The Climate Casino: Risk, Uncertainty, and Economics for a Warming World. New Haven, CT: Yale University Press.

Novan, K. 2014. Valuing the Wind: Renewable Energy Policies and Air Pollution Avoided. Working paper. Davis, CA: University of California, Davis.

NRC (National Research Council). 2010. Hidden Costs of Energy: Unpriced Consequences of Energy Production and Use. National Research Council of the National Academies. Washington, DC: National Academies Press.

NREL (National Renewable Energy Laboratory). 2012. Renewable Electricity Futures Study. M.M. Hand, S. Baldwin, E. DeMeo, J.M. Reilly, T. Mai, D. Arent, G. Porro, M. Meshek, and D. Sandor, editors. 4 vols. NREL/TP-6A20-52409. Golden, CO: National Renewable Energy Laboratory. 
Oates, D.L., and P. Jaramillo. 2013. "Production Cost and Air Emissions Impacts of Coal Cycling in Power Systems with Large-Scale Wind Penetration." Environmental Research Letters 8(2): 024022.

Palmintier, B., R. Broderick, B. Mather, M. Coddington, K. Baker, F. Ding, M. Reno, M. Lave, and A. Bharatkumar. 2016. On the Path to SunShot: Emerging Issues and Challenges in Integrating Solar with the Distribution System. Golden, CO: National Renewable Energy Laboratory. NREL/TP-5D00-65331. http://www.nrel.gov/docs/fy16osti/65331.pdf.

Pehnt, M., M. Oeser, and D.J. Swider. 2008. "Consequential Environmental System Analysis of Expected Offshore Wind Electricity Production in Germany.” Energy 33(5): 747-59.

Perez-Arriaga, I.J., and C. Batlle. 2012. "Impacts of Intermittent Renewables on Electricity Generation System Operation.” Economics of Energy \& Environmental Policy 1(2).

Peters, A., D.W. Dockery, J.E. Muller, and M.A. Mittleman. 2001. "Increased Particulate Air Pollution and the Triggering of Myocardial Infraction." Circulation 103: 2810-2815.

Pindyck, R.S. 2013. “Climate Change Policy: What Do the Models Tell Us?” Journal of Economic Literature 51(3): 860-72.

Pizer, W., M. Adler, J. Aldy, D. Anthoff, M. Cropper, K. Gillingham, M. Greenstone, B. Murray, R. Newell, R. Richels, A. Rowell, S. Waldhoff, and J. Wiener. 2014. "Using and Improving the Social Cost of Carbon." Science 346(6214): 1189-90.

Rausch, S., and V. Karplus. 2014. "Markets versus Regulation: The Efficiency and Distributional Impacts of U.S. Climate Policy Proposals.” The Energy Journal 35(SI1):199-227.

Ricci, A. 2010. Policy Use of the NEEDS Results. Deliverable 5.3-RS. Rome: New Energy Externalities Developments for Sustainability (NEEDS).

Rogers, J., K. Averyt, S. Clemmer, M. Davis, F. Flores-Lopez, D. Kenney, J. Macknick, N. Madden, J. Meldrum, S. Sattler, E. Spanger-Siegfried, and D. Yates. 2013. Water-Smart Power: Strengthening the U.S. Electricity System in a Warming World. Cambridge, MA: Union of Concerned Scientists.

Roy, S.B., L. Chen, E.H. Girvetz, E.P. Maurer, W.B. Mills, and T.M. Grieb. 2012. "Projecting Water Withdrawal and Supply for Future Decades in the U.S. under Climate Change Scenarios." Environmental Science and Technology 46: 2545-56.

Sarzynski, A., J. Larrieu, and G. Shrimali. 2012. "The Impact of State Financial Incentives on Market Deployment of Solar Technology." Energy Policy 46(0): 550-57.

Schmalensee, R., and R.N. Stavins. 2013. "The SO2 Allowance Trading System: The Ironic History of a Grand Policy Experiment.” Journal of Economic Perspectives 27(1): 103-22.

Sherwood, L. 2014. U.S. Solar Market Trends 2013. Latham, NY: Interstate Renewable Energy Council. 
Shindell, D. 2015. "The Social Cost of Atmospheric Release.” Climatic Change 130(2): 313-26.

Short, W., P. Sullivan, T. Mai, M. Mowers, C. Uriarte, N. Blair, D. Heimiller, and A. Martinez. 2011. Regional Energy Deployment System (ReEDS). NREL/TP-6A20-46534. Golden, CO:

National Renewable Energy Laboratory.

Shrimali, G., and S. Jenner. 2013. "The Impact of State Policies on Deployment and Cost of Solar PV in the US: A Sector Specific Empirical Analysis.” Renewable Energy 60: 679-90.

Sigrin, B., P. Sullivan, E. Ibanez, and R. Margolis. 2014. Representation of Solar Capacity Value in the ReEDS Capacity Expansion Model. NREL/TP-6A20-61182. Golden, CO: National Renewable Energy Laboratory.

Siler-Evans, K., I.M. Azevedo, M.G. Morgan, and J. Apt. 2013. "Regional Variations in the Health, Environmental, and Climate Benefits of Wind and Solar Generation." Proceedings of the National Academy of Sciences 110(29): 11768-73.

Sinha, P., M. de Wild-Scholten, A. Wade, and C. Breyer. 2013. "Total Cost Electricity Pricing of Photovoltaics." $28^{\text {th }}$ European Photovoltaic Solar Energy Conference, Paris, France.

Solley, W.B., R.R. Pierce, and H.A. Perlman. 1998. Estimated Use of Water in the United States in 1995. U.S. Geological Survey Circular 1200. Reston, VA: U.S. Geological Survey.

Sullivan, P., W. Cole, N. Blair, E. Lantz, V. Krishnan, T. Mai, D. Mulcahy, and G. Porro. 2015. 2015 Standard Scenarios Annual Report: U.S. Electric Sector Scenario Exploration. NREL/TP6A20-64072. Golden, CO: National Renewable Energy Laboratory.

Sullivan, P., C. Uriarte, and W. Short. 2014. "Greenhouse Gas Mitigation Options in the U.S. Electric Sector: A ReEDS Analysis.” Energy Journal 35(SI1): 101-14.

Tidwell, V.C., J. Macknick, K. Zemlick, J. Sanchez, and T. Woldeyesus. 2014. "Transitioning to Zero Freshwater Withdrawal in the U.S. for Thermoelectric Generation." Applied Energy 131: 508-16.

Tidwell, V.C., L.A. Malczynski, P.H. Kobos, G.T. Klise, and E. Shuster. 2013. "Potential Impacts of Electric Power Production Utilizing Natural Gas, Renewables and Carbon Capture and Sequestration on U.S. Freshwater Resources." Environmental Science and Technology 47: 8940-47.

Tol, R. 2011. "The Social Cost of Carbon.” Annual Review of Resource Economics 3(1): 419-43.

Tuladhar, S., S. Mankowski, and P. Bernstein. 2014. "Interaction Effects of Market-Based and Command-and-Control Policies." The Energy Journal 35(SI1):61-88.

Turchi, C.S., M.J. Wagner, and C.F. Kutscher. 2010. Water Use in Parabolic Trough Power Plants: Summary Results from WorleyParsons' Analyses. NREL/TP-5500-49468. Golden, CO: National Renewable Energy laboratory. 
Turconi, R., A. Boldrin, and T. Astrup. 2013. "Life Cycle Assessment (LCA) of Electricity Generation Technologies: Overview, Comparability and Limitations." Renewable and Sustainable Energy Reviews 28: 555-65.

UCS (Union of Concerned Scientists). 2012. UCS EW3 Energy-Water Database. V.1.3. Cambridge, MA: Union of Concerned Scientists.

U.S. Census Bureau. 2012. 2012 National Population Projections Summary Tables, Table 1. Projections of the Population and Components of Change for the United States: 2015 to 2060. Washington, DC: U.S. Census Bureau Population Division.

Valentino, L., V. Valenzuela, A. Botterud, Z. Zhou, and G. Conzelmann. 2012. "System-Wide Emissions Implications of Increased Wind Power Penetration." Environmental Science \& Technology 46(7): 4200-206.

van Vliet, M.T.H., J.R. Yearsley, F. Ludwig, S. Vogele, D.P. Lettenmaier, and P. Kabat. 2012. "Vulnerability of US and European Electricity Supply to Climate Change." Nature Climate Change 2: 676-81.

Ventyx. (2013). Ventyx Energy Velocity Suite.

Weitzman, M.L. 2012. "GHG Targets as Insurance against Catastrophic Climate Damages." Journal of Public Economic Theory 14(2): 221-44.

Weyant, J. 2014. "Integrated Assessment of Climate Change: State of the Literature." Journal of Benefit-Cost Analysis 5(3): 377-409.

Wiser, R., T. Mai, D. Millstein, J. Macknick, A. Carpenter, S. Cohen, W. Cole, B. Frew, and G. Heath. 2016. On the Path to SunShot: The Environmental and Public Health Benefits of Achieving High Penetrations of Solar Energy in the United States. Golden, CO: National Renewable Energy Laboratory. NREL/TP-6A20-65628. http://www.nrel.gov/docs/ fy16osti/65628.pdf.

Woodhouse, M., R. Jones-Albertus, D. Feldman, R. Fu, K. Horowitz, D. Chung, D. Jordan, and S. Kurtz. 2016. On the Path to SunShot: The Role of Advancements in Solar Photovoltaic Efficiency, Reliability, and Costs. Golden, CO: National Renewable Energy Laboratory. NREL/TP-6A20-65464. http://www.nrel.gov/docs/fy16osti/65464.pdf.

Zhai, H., and E.S. Rubin. 2010. "Performance and Cost of Wet and Dry Cooling Systems for Pulverized Coal Power Plants with and Without Carbon Capture and Storage." Energy Policy 38(10): 5653-60. 


\section{Endnotes}

${ }^{\mathrm{i}}$ Cumulative reductions are lower-in percentage terms - than reductions in 2030 and 2050 because solar deployment is assumed to increase over time, with lower penetration levels from 2015 to 2030 . Additionally, 2050 emissions reductions (18\%) are lower than the $27 \%$ solar penetration level in that year because solar displaces a relatively high amount of both natural gas and wind generation and a relatively lower amount of coal.

${ }^{\text {ii }}$ Across a range of social cost of carbon estimates, total benefits span $\$ 56$ billion $(0.5 \not / \mathrm{kWh}$-solar $)$ to $\$ 789$ billion $(6.8 \notin / \mathrm{kWh}$-solar). Benefits are estimated in real $2015 \$$, on a discounted basis.

iii The benefits of achieving the SunShot Vision scenario range from $\$ 60$ billion to $\$ 92$ billion ( $0.5-0.8 \notin / \mathrm{kWh}$-solar) when only considering the U.S. Environmental Protection Agency's Clean Power Plan estimates and from \$142 billion to $\$ 347$ billion (1.2-3.0 $\mathrm{k} / \mathrm{kWh}$-solar) when considering longer-term carbon-reduction policy possibilities. iv Across the full set of methods considered, total monetary health and environmental benefits from air-pollution reductions range from $\$ 77$ billion $(0.7 \notin / \mathrm{kWh}$-solar) to $\$ 298$ billion $(2.6 \notin / \mathrm{kWh}$-solar) .

${ }^{\mathrm{v}}$ Withdrawals are defined as the amount of water removed or diverted from a water source for use, while consumption refers to the amount of water that is evaporated, transpired, incorporated into products or crops, or is otherwise removed from the immediate water environment.

${ }^{\text {vi }}$ For more about the SunShot Initiative, see energy.gov/eere/sunshot/sunshot-initiative.

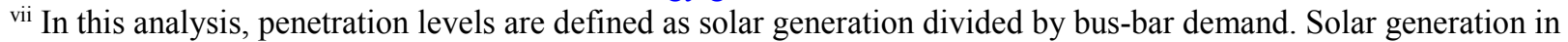
the numerator is estimated after any required curtailment. Bus-bar demand is greater than end-use demand in that it reflects the amount of electricity needed to cover losses in distribution networks.

viii The SunShot Vision report also includes a limited number of sensitivity scenarios resulting in different solar penetration estimates. Follow-on reports include more complete sensitivity analyses with respect to rooftop PV adoption (Drury et al. 2013) and utility-scale solar deployment (Eurek et al. 2013).

ix The 2012 reference scenario assumes more-limited price reductions for solar energy systems compared to the SunShot scenario.

${ }^{x}$ The target solar penetration levels were applied as a lower-bound constraint and therefore can be exceeded. As described in the text, only slight exceedance occurs.

xi With few exceptions, we make no attempt to replicate the non-solar results from the SunShot Vision Study

(DOE 2012). This enables a more accurate assessment of the dispatch and capacity-expansion impacts of high solar penetrations based on current market conditions.

xii The SunShot Vision Study (DOE 2012) did not include a no-new-solar scenario.

xiii Year-end 2014 solar capacity is based on data from Ventyx (now ABB) Velocity Suite and GTM/SEIA (2015).

xiv The Solar Deployment System (SolarDS) rooftop PV consumer-adoption model (Denholm et al. 2009) was used to generate the DGPV trajectory in the SunShot Vision Study (DOE 2012), which is applied for the present analysis. ${ }^{x v}$ We use ReEDS model version 2015.2, which is most closely linked to the versions used in the Wind Vision study (DOE 2015) and in the NREL Standard Scenarios Annual Report (Sullivan et al. 2015).

${ }^{\text {xvi }}$ ReEDS includes regional supply curves to treat the elastic interactions between electric-sector natural gas demand and price. The AEO 2015 Reference scenario is used to inform these supply curves.

xvii Specifically, cost and performance assumptions for CSP are identical to those developed for the SunShot Vision Study and reflect dry-cooled systems. As previously described, we do not develop new DGPV scenarios for the present analysis; therefore, technology assumptions are not needed for rooftop PV. We apply minor updates for UPV, including updating the 2020 SunShot price target of $\$ 1 / \mathrm{W}_{\mathrm{DC}}$ to be in 2015 dollars (as opposed to 2010 dollars in the SunShot Vision Study), adjusting current capital costs to align better with other market estimates, and updating capacity factors and output profiles. We use $\$ 2.07 / \mathrm{W}_{\mathrm{DC}}$ (in $2015 \$$ ) for overnight installed costs in 2014 and linearly ramp these costs down to the SunShot $\$ 1 / \mathrm{W}_{\mathrm{DC}}$ target level. As consistent with the SunShot Vision Study (DOE 2012), we keep UPV prices at $\$ 1 / \mathrm{W}_{\mathrm{DC}}$ for all years beyond 2020. PVWatts 5 and its default parameters are used to estimate regional PV performance.

xviii This assumption is consistent with the SunShot Initiative goal of cost-competitive solar without subsidies.

xix 28 GW CSP, 121 GW DGPV, and 171 GW UPV.

xx 80 GW CSP, $240 \mathrm{GW}$ DGPV, and $388 \mathrm{GW}$ UPV.

${ }^{x x i}$ ReEDS builds CSP systems with thermal energy storage.

${ }^{x x i i}$ CSP technologies require direct normal irradiance, whereas PV can rely on more diffuse solar radiation.

xxiii Differences between CSP and PV arise from technological differences (which influence water demands), geographic differences in resources (where CSP is primarily constrained to the southwestern states and PV deployment can be more broadly distributed), and output-profile differences (particularly when thermal energy 
storage is used with CSP). These technical, spatial, and temporal differences would lead to differences in avoided generation and capacity as well as associated emissions and water benefits (Jorgenson et al. 2014). For example, avoided generation from CSP may - to a greater extent than PV-derive from lower-emission technologies in the West (compared with PV, which may also offset higher-emission generation in the East). At the same time, PV may displace higher-cost, but lower-emitting natural gas-fired generation during the afternoon compared with potentially greater avoided coal generation from CSP production in the evenings and overnight. In addition, CSP - especially with wet cooling - has significantly greater water requirements than PV and generally will be deployed in waterstressed regions; however, relative net water impacts will ultimately depend on the displaced generation as well as water requirements for solar technologies. These complex interactions and how they might change under different solar penetration levels have not been studied comprehensively. Further research is needed to assess the direction and magnitude of changes to estimated environmental and health benefits under different CSP and PV market shares compared to those evaluated herein. However, we expect that estimated benefits of different solar portfolios will likely be similar — or at least within the same order of magnitude - as those reported in the current report.

xxiv Combustion-related emissions estimates consider $\mathrm{CO}_{2}$ from combustion of fuels during plant operations. They do not consider two other important sets of emissions attributable to electricity generation: GHG emissions from other life-cycle stages and GHG emissions from non- $\mathrm{CO}_{2}$ gases. These omissions that may be particularly important for methane released in coal mining, oil production, and natural gas production and transport. A focus on combustion-only emissions also ignores GHG emissions from upstream materials supply, equipment manufacturing and construction, operations and maintenance, and plant decommissioning. Our adjustments account for all of these various additional life-cycle impacts.

${ }^{\mathrm{xxv}}$ An extensive review and analysis of previously published LCAs on electricity-generation technologies was conducted through NREL's LCA Harmonization project (see http://www.nrel.gov/harmonization). Based on that literature, we developed median life-cycle, non-combustion GHG emission values for each generation technology and for the fuel cycle, construction, and decommissioning phases. To estimate non-combustion GHG emissions from the fuel cycle, we use the electricity-production estimates (in MWh) provided by ReEDS for all generation technologies and apply the median, literature-derived estimates of technology-specific, non-combustion fuel-cycle GHG emissions. We assume that biomass combustion emissions are entirely offset by carbon absorption to produce the biomass feedstocks. This is a potentially aggressive assumption given the wide range in estimates of indirect, land-use-related biomass emissions (IPCC 2011), but it has little effect on our results because biomass deployment is not sizable in either scenario evaluated here. To estimate GHG emissions from construction, we use the capacity estimates (in MW) provided by ReEDS over the 2015 to 2050 timeframe and apply the median, literature-derived estimates of technology-specific, construction-related GHG emissions. Finally, to estimate GHG emissions from decommissioning, we use decommissioning capacity estimates (in MW) provided by ReEDS over the 2015 to 2050 timeframe and apply the median, literature-derived estimates of technology-specific, decommissioning-related GHG emissions. This approach was used in DOE (2015), where the methods are described in greater detail.

${ }_{\text {xxvi }}$ Research has sought to estimate the magnitude and timing of climate-change impacts, damages, and associated costs (IPCC 2014a; IPCC 2014b; IWG 2010; IWG 2015; Melillo et al. 2014; Weitzman 2012). Because of the uncertainties involved, estimates of the SCC span a wide range (IPCC 2014b; Tol 2011; Weyant 2014), leading some to suggest possible improvements to SCC estimates and procedures (Ackerman and Stanton 2012; Arrow et al. 2013; Johnson and Hope 2012; Kopp et al. 2012; Pizer et al. 2014; Weyant 2014) or even to question the use of these estimates (Pindyck 2013).

xxvii As a result, many utilities already regularly consider the possibility of future policies to reduce GHGs in resource planning and thereby treat renewable energy sources as options for reducing the possible future costs of climate mitigation (Barbose et al. 2008; Bokenkamp et al. 2005; Luckow et al. 2015).

xxviii This is because, under strictly binding caps, renewable energy does not reduce emissions per se, but instead alleviates the need to reduce emissions elsewhere in order to achieve the cap.

xxix In addition to national average cost estimates, EPA has also estimated state-level marginal carbon-abatement costs. We prefer to use national average estimates for two reasons. First, states have considerable flexibility in achieving the CPP, so any state-level estimate is inherently more uncertain than a national estimate. Second, the level of carbon reductions envisioned in the SunShot Vision scenario represent a sizable contribution to CPP compliance, in which case marginal cost estimates may not be as appropriate as average ones.

${ }^{\mathrm{xxx}}$ Studies have found that the GHG benefits of variable renewables are diminished by, at most, less than $10 \%$ (Göransson and Johnsson 2009; Gross et al. 2006; Pehnt et al. 2008; Perez-Arriaga and Batlle 2012), with far lower levels anticipated at smaller penetrations of renewable energy in large electric systems (Fripp 2011; Valentino et al. 2012). In the most sophisticated of the studies, Lew et al. (2013) find the impact to be negligible (less than 1\%). 
xxxi The application of IWG's SCC estimates to life-cycle $\mathrm{CO}_{2}$ e creates some inaccuracy in that the IWG is clear that its values may not be appropriate for pollutants other than $\mathrm{CO}_{2}$, even when translated into $\mathrm{CO}_{2} \mathrm{e}$ based on global warming potential (IWG 2010). The level of inaccuracy is unclear, but given the scale of non- $\mathrm{CO}_{2}$ gases in total lifecycle emissions, this inaccuracy is likely considerably smaller than the range in SCC estimates applied in the present analysis. IWG intends, in the future, to develop methods to value non- $\mathrm{CO}_{2}$ greenhouse gases. EPA's CPP, meanwhile, covers the U.S. power sector, so combustion-related power-sector emissions are more relevant than lifecycle emissions (because some of the life-cycle emissions occur outside of the power sector and, to a degree, outside of the United States).

xxxii We estimate that cumulative (2015-2050) emissions in four states-Delaware, Maine, Washington, and West Virginia - are higher under the SunShot Vision scenario compared with the NNS baseline scenario. Among these states, Maine experiences the largest relative increase $(10 \%)$, while emissions increases for the other three states total only $1 \%$.

xxxiii $\mathrm{PM}_{2.5}$ emission estimates are developed for both scenarios as the product of ReEDS generation outputs (MWh, by generation type and vintage) and average emission rates (grams/MWh, by generation type). Average $\mathrm{PM}_{2.5}$ emissions rates (reported by Argonne National Laboratory: Cai et al. 2012; Cai et al. 2013) are differentiated by generation type (coal, gas, or oil) and U.S. state. Additionally, $\mathrm{PM}_{2.5}$ emission factors are adjusted over time to comply with scheduled $\mathrm{PM}_{2.5}$ MATS limits for existing plants (for more details see Appendix L of the Wind Vision report, DOE 2015).

xxxiv Although CSAPR is represented in ReEDS, it is essentially non-binding owing to the $\mathrm{SO}_{2}$ reductions required for MATS and the long-term substitution of natural gas and other generation sources for coal power generation. Although MATS and CSAPR are both under some legal uncertainty, we assume that MATS or something like MATS will remain as an active regulation. Supporting this assumption to a significant degree, the effect of MATS has already been seen through actual and announced coal plant retirements. Absent one or both of these regulations, future absolute air pollution emissions would likely be higher than those estimated by ReEDS; however, it is uncertain how the absence of one or both of these regulations might impact estimated avoided emissions. For example, without both MATS and CSAPR, solar might displace higher-polluting generation, thereby increasing the estimated benefits of the SunShot Vision scenario. However, absent only MATS, the CSAPR pollution caps would likely be binding, and solar might therefore have little physical benefit in avoiding $\mathrm{SO}_{2}$ or $\mathrm{NO}_{\mathrm{x}}$ emissions (but would have benefits in reducing compliance costs). Despite the uncertainties associated with these two particular air quality regulations, it is reasonable to expect that over multiple decades similar or even more-stringent regulations are likely to be in place. Historical trends support a general move towards increasingly stringent air quality and environmental regulations over time.

xxxv Benefits calculated by AP2 and EPA CPP differ in a number of respects. For example, the AP2 model accounts for not only mortality and morbidity, but also air pollution-induced reductions in timber and agriculture yields, visibility reductions, accelerated materials degradation, and reductions in recreation services; the benefits calculated with the EPA CPP benefit-per-ton approach only include mortality and morbidity. Both the EPA CPP benefit-perton approach and the AP2 model include the benefits from primary and secondary particulate reductions and from ozone reductions; however, the exact pollutants considered in terms of primary particulate exposure varies.

xxxvi EPA Low is based on research summarized in Krewski et al. (2009) and Bell et al. (2004), whereas EPA High is based on research presented in Lepeule et al. (2012) and Levy et al. (2005). Both sets of epidemiology research have different strengths and weakness, and EPA does not favor one result over the other.

xxxvii The AP2 model contains monetized benefit-per-ton estimates based on emissions in the year 2008, so damages from AP2 are scaled over time based on Census population projections (U.S. Census Bureau 2012) and per capita income growth projections used by EIA (2014), using an elasticity of the VSL to income growth consistent with NRC (2010). EPA benefit-per-ton values are developed for each year within each of three large regions by linearly extrapolating EPA's provided benefit-per-ton values. In this manner, there is implicit representation of the population and income growth assumptions incorporated in EPA's analysis. The 2015-2025 benefit-per-ton values are based on the linear trend established by EPA's 2020 and 2025 values. The 2026-2050 benefit-per-ton values are based on the linear trend established by EPA's 2025 and 2030 values. The same process is used for EPA's health incidence-per-ton (mortality and morbidity outcomes) estimates.

xxxviii Though our analysis does not capture these effects, results from recent research suggest that emissions are reduced by variable renewables, even after accounting for any emissions penalties (Oates and Jaramillo 2013; Valentino et al. 2012). Lew et al. (2013) find that accounting for impacts related to increased coal-plant cycling slightly improves (by $1 \%-2 \%$ ) the avoided $\mathrm{NO}_{\mathrm{x}}$ emissions of wind and solar relative to the avoided emissions based on an assumption of a fully loaded plant, but that accounting for cycling impacts reduces the avoided $\mathrm{SO}_{2}$ emissions 
of wind and solar by $3 \%-6 \%$. A similarly detailed analysis in the mid-Atlantic region reports more substantial emissions penalties (GE Energy Consulting 2014). In both cases, however, the impacts are not large enough to alter dramatically the basic results reported here.

xxxix This is because, under strictly binding caps, renewable energy does not reduce emissions per se, but instead alleviates the need to reduce emissions elsewhere in order to achieve the cap. In this instance, the benefits of solar energy derive not from reduced health and environmental damages but instead from reducing the cost of complying with the air-pollution regulations. As mentioned above, ReEDS simulations indicate CSAPR $\mathrm{SO}_{2}$ and $\mathrm{NO}_{\mathrm{x}}$ caps are largely non-binding over time owing to the presumed existence of MATS. This also follows recent historical experience, because the largest regional $\mathrm{SO}_{2}$ and $\mathrm{NO}_{\mathrm{x}}$ cap-and-trade program (CAIR) was non-binding in 2013 (EPA 2013; Schmalensee and Stavins 2013). We therefore do not estimate the benefits of the SunShot Vision scenario from the perspective of reducing pollution-regulation compliance costs. Nonetheless, we mention this alternative valuation approach because it is possible that future cap-and-trade regulations applied either nationally or regionally could impact the size and nature of the benefits from the SunShot Vision scenario. It is also possible that our emissions treatment may not incorporate some more-localized existing binding cap-and-trade programs; however, the geographic extent of these programs is limited, so they will not substantially bias our results. ${ }^{\mathrm{xl}}$ An estimate of ozone benefits, separate from the total benefits, corresponding to the AP2 valuation was not available within the model.

${ }^{x l i}$ Cooling systems for the existing fleet are assigned to ReEDS balancing-area generating capacity based on an analysis of individual electric-generating units aggregated at the ReEDS balancing-authority level, as described elsewhere (Averyt et al. 2013; UCS 2012).

xlii CSP performance inputs used in ReEDS relied on dry-cooling assumptions. Similarly, we used capital and O\&M costs for CSP from the SunShot Vision Study (DOE 2012), which also reflects dry-cooled technologies.

xliii Some states see slight increases in water withdrawals and/or consumption in the SunShot Vision scenario relative to the NNS baseline scenario. These are a result of ReEDS' electric-sector capacity additions and operations simulations. Regions where these increases are modeled to occur are historically not as drought prone as the states that are estimated to have decreases in withdrawals and/or consumption. In addition, these slight increases are likely to be within the range of uncertainties associated with future electric sector water use.

xliv Ocean water resource impacts are not modeled in this analysis.

xlv The actual benefits, in terms of cost savings, would be lower than these figures for a few reasons. First, many regions of the country are not facing water scarcity, so the economic benefits of reduced water use are geographically limited. Second, to the extent that solar offsets more electricity supply (kilowatt-hours) than electricity capacity (kilowatts), it may not be able to offset the full capital and operating cost of less water-intensive cooling technologies. Third, to date few plants have been required or chosen to implement dry cooling; alternative, lower-cost means of obtaining and/or reducing water have predominated, including simply locating plants where water is available. Alternative water resources, such as municipal wastewater or shallow brackish groundwater, could also be more cost effective than dry cooling in some regions (Tidwell et al. 2014). These lower-cost methods of reducing water use are likely to dominate for the foreseeable future. Because of these complicating factors, a separable monetary benefit of the SunShot Vision scenario in terms of reduced water use is not estimated.

xlvi Distributed PV includes the sum of commercial and residential PV.

xlvii EPA's Avoided Emissions and geneRation Tool (AVERT) was used to estimate the characteristics and location of fossil generation sources displaced by end-of-2014 solar capacity. As described in EPA (2014a), this model uses historical data to estimate changes in generation and emissions within each of 10 AVERT regions resulting from an increase in renewable electricity (or energy efficiency). As with any model, AVERT has its limitations, as described in the user guide (EPA 2014a). In our analysis, we used AVERT regional data files for the year 2014-implying that the results shown in the text box are tuned to the recent impacts of end-of-2014 solar capacity. Note that we modeled all solar capacity installed by the end of 2014; this somewhat overestimates the impact of solar in 2014 as incremental solar capacity became operational throughout the year. Because the statistical relationships in the AVERT files already reflect the effects of solar plants operating in 2014, we modeled the impact of those resources by "removing" them (i.e., treating them as negative generation sources) rather than by adding them in as additional renewable resources, beyond what was already in operation in 2014. Furthermore, solar generation quantities were input into AVERT as hourly profiles. This required translating the end-of-2014 installed capacity into aggregate hourly generation profiles for each region, using default solar rooftop and utility scale PV profiles built into AVERT. Hourly profiles for CSP were developed differently than profiles for PV. Capacity factors from the Bolinger and Seel (2015) dataset for all U.S. CSP plants were applied to find the annual total energy generated by each plant. Hourly profiles were then created for all the plants without storage based on the utility PV profiles built 
into AVERT. A custom hourly profile was used to model CSP plants with storage. CSP capacity represented roughly $10 \%$ of total solar capacity at the end of 2014 , so the national results have little sensitivity to the CSP representation. Using the database from Bolinger and Seel (2015), we identified solar plants that transferred electricity to a neighboring AVERT region (e.g., plants operating in Nevada that transferred their output to California), and we accounted for these transfers within AVERT by transferring the energy profile of each plant to the region in which the electricity is delivered. Distributed (residential and commercial) PV capacity totals were available by state, however, a number of states contain multiple AVERT regions. Utilities, on the other hand, are wholly contained within individual AVERT regions, and we used total customers by utility (EIA 2015b) as a proxy to assign state-wide PV installations to AVERT regions within states represented by multiple AVERT regions. Installed distributed PV capacity in a number of states were grouped into an "other" category in GTM/SEIA (2015); we used state-level capacity data from 2013 (Sherwood 2014) to weight capacity in the 'other' category to the remainder of the states. To assign utility PV state total capacity to AVERT regions, we first assigned each plant in the dataset that underlies Bolinger and Seel (2015) to an AVERT region; for any utility-scale capacity not included in this dataset, we used the relative weightings from the Bolinger and Seel (2015) dataset allocate capacity to AVERT regions.

xlviii The health and monetary impacts of $\mathrm{SO}_{2}, \mathrm{NO}_{\mathrm{x}}$, and $\mathrm{PM}_{2.5}$ emission reductions were calculated using the AP2 and the EPA CPP approaches described in Section 5, and also with an additional method suitable for present day analysis: EPA 's COBRA model (EPA 2014b). Following the EPA CPP approach, COBRA reports two sets of health impacts, 'high' and 'low', based on the same underlying epidemiology relationships used in the CPP approach. COBRA uses a different air quality modeling approach than is employed in the CPP approach, however, and also covers different impact pathways (e.g., COBRA only considered particular matter exposure, and not ozone). COBRA was not used earlier because it is not suitable for analyzing impacts in the distant future; it's advantages are in analyzing the present day and in being able to assign health burdens and benefits to the specific regions where those benefits are felt by human populations (the other tools used here identify the locations from which the benefits are derived by virtue of emissions reductions).

${ }^{x l i x} \mathrm{CO}_{2}$ reductions were calculated using AVERT, as described above. Note that unlike in Section 4, the GHG reductions reported here are combustion-only $\mathrm{CO}_{2}$, and do not account for lifecycle impacts. We apply the IWG SCC values for the year 2015 to best approximate the recent impacts of end-of-2014 solar capacity.

${ }^{1} \mathrm{CO}_{2}$ emission reduction benefits shown by region and state are based on the location of the emission reductions: for the AVERT regions, emission reductions and solar generation/delivery are aligned, but at the state level, solar generation can offset fossil generation within a neighboring state within the same AVERT region. The benefits of reducing $\mathrm{CO}_{2}$ emissions are based on the global $\mathrm{SCC}$, and so are not contained within the state or region in which the emission reduction occurred.

${ }^{1 i} \mathrm{SO}_{2}$ and $\mathrm{NO}_{\mathrm{x}}$ reductions were calculated using AVERT, as described above. $\mathrm{PM}_{2.5}$ was calculated as a function of generation reduction (MWh) by plant type and state (as calculated by AVERT) and state-level $\mathrm{PM}_{2.5}$ emission factors $(\mathrm{g} / \mathrm{MWh})$ described in Section 5.

lii In this case, total air quality benefits are based on the average of COBRA high and low and are presented based on where the air quality and health benefits occur, not based on where the emissions are reduced.

liii The normalized air quality benefits are the average of COBRA high and low. COBRA was run separately for each AVERT region based on the emissions reductions in those regions, so benefits are able to be attributed to the region in which the solar energy was generated or delivered even though some of the air quality benefits will be gained outside the region of origin.

liv The impacts to water withdrawal and water consumption were calculated based on the displaced generation of each power plant (as found from AVERT), as well as any operational water demands from the solar generators. AVERT data, however, do not define the cooling system of each unit. To match AVERT generators with cooling system characteristics, we make an initial assignment based on the Office of Regulatory Information Systems Plant Location (ORISPL) Plant ID number, which is provided by AVERT, as well as the UCS EW3 Energy-Water Database (UCS 2012), along with updates from Ventyx (2013). From this preliminary matching of power plants, we assign prime mover technology, cooling system technology, and water type (freshwater or saline water) to individual AVERT generators at the power plant based on matches of nameplate capacity. Additional details can be found in Averyt et al. (2013). For cases in which there is no obvious match, prime mover types and cooling systems are assigned based on similar generators within the same power plant or via internet research. 